Review

\title{
Waste materials in highway applications: An overview on generation and utilization implications on sustainability
}

\author{
Gideon O. Bamigboye ${ }^{a}$ * , Daniel E. Bassey ${ }^{a}$, David O. Olukanni ${ }^{a}$, Ben U. Ngene ${ }^{a}$, \\ Dunmininu Adegoke a, Abimbola O. Odetoyan a, Mutiu A. Kareem ${ }^{\text {b }}$, David O. Enabulele a, \\ Austin T. Nworgu a \\ a Department of Civil Engineering, Covenant University, Ota, Ogun State, Nigeria \\ ${ }^{\mathrm{b}}$ Department of Civil Engineering, Osun State University, Osogbo, Nigeria
}

\section{A R T I C L E I N F O}

\section{Article history:}

Received 14 May 2020

Received in revised form

29 August 2020

Accepted 5 October 2020

Available online 8 October 2020

Handling Editor: Prof. Jiri Jaromir Klemeš

\section{Keywords:}

Construction materials

Sustainable materials

Pavement performance

Compressive strength

Economic impact analysis

Recycled waste materials

\begin{abstract}
A B S T R A C T
The rate at which the construction industry explores and consumes non-renewable natural aggregates and other industrial products such as bitumen, lime, and cement during construction and rehabilitation of road pavements has over time proven to be environmentally degrading and non-sustainable. This, alongside the issues of high solid waste generation and inadequate disposal, has led to series of studies by various researchers to find methods to integrate these solid wastes as alternative materials in road construction and maintenance. This paper provides a simple yet detailed review of recent relevant studies conducted to understand the alarming rate of generation and the effects of reusing these waste materials in both flexible and rigid pavements. The review further outlines the advantages and disadvantages of the selected waste materials and compare the results with that of conventional materials in accordance with relevant standards while highlighting the performance, and life cycle environmental and economic sustainability implications. The study shows that the adoption of these materials offers efficiency in waste disposal while reducing the demand for natural aggregates and consequently, significantly reducing life cycle impacts and costs. The challenges limiting the effective practical implementation of these waste recycling techniques in the construction industry were discussed and possible solutions were suggested to encourage and ensure its utilization in road construction.
\end{abstract}

๑) 2020 Elsevier Ltd. All rights reserved.

\section{Contents}

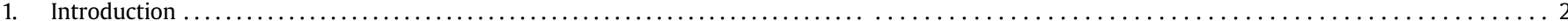

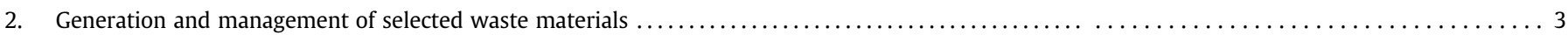

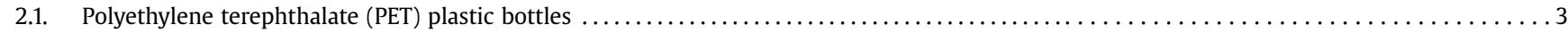

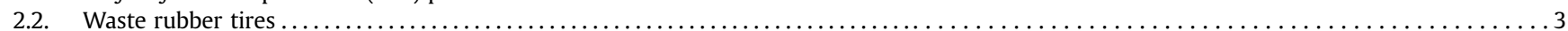

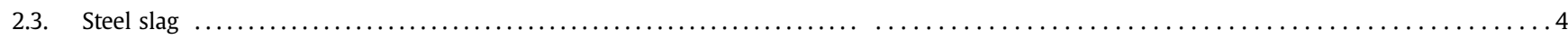

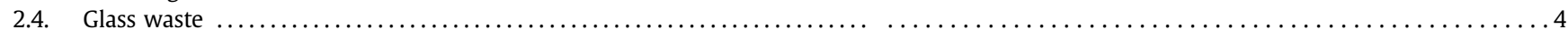

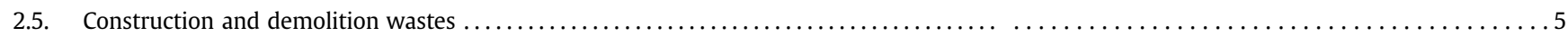

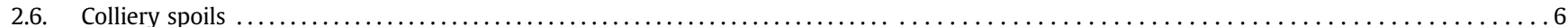

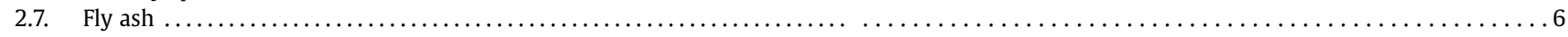

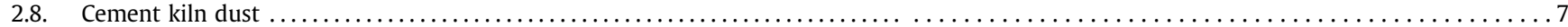

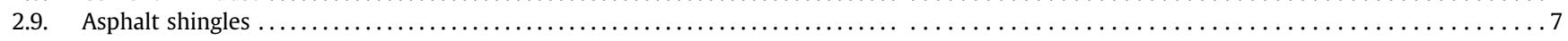

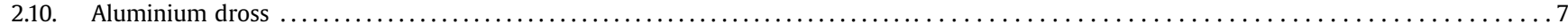

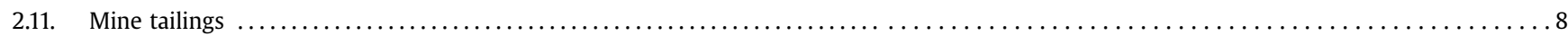

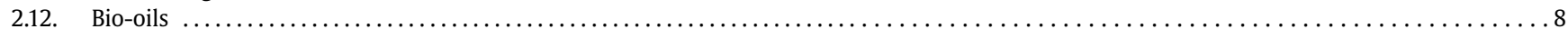

\footnotetext{
* Corresponding author.

E-mail address: gideon.bamigboye@covenantuniversity.edu.ng

(G.O. Bamigboye).
} 


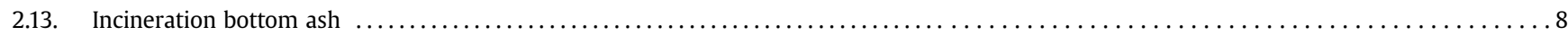

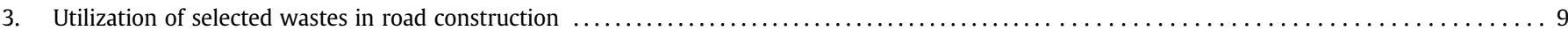

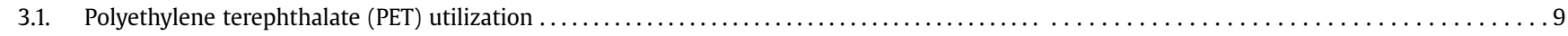

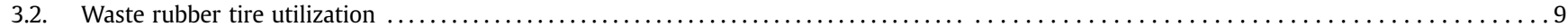

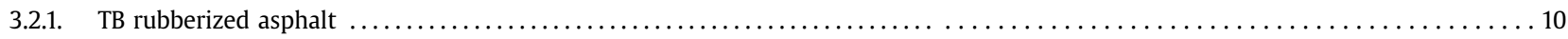

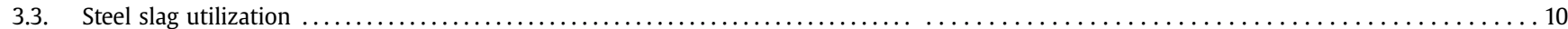

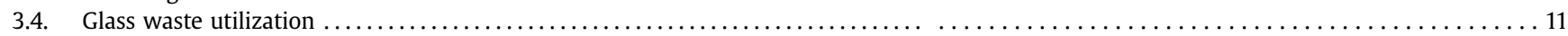

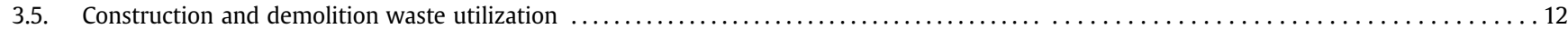

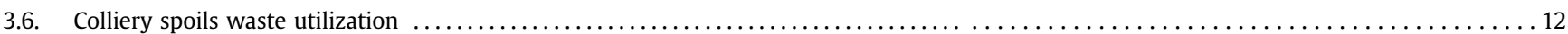

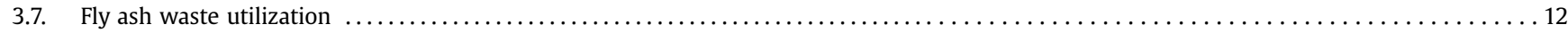

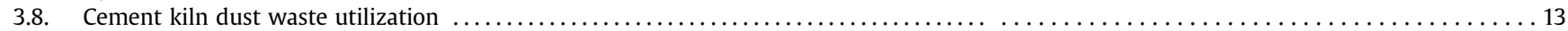

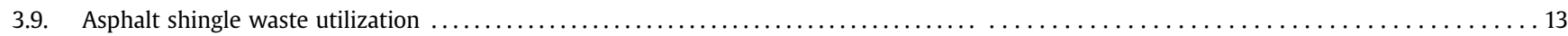

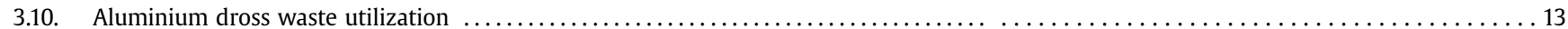

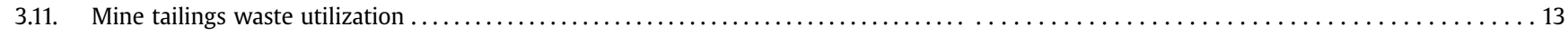

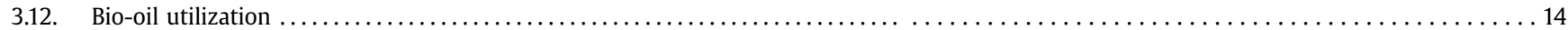

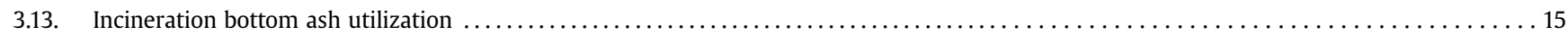

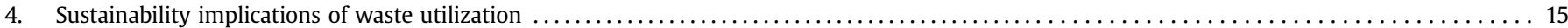

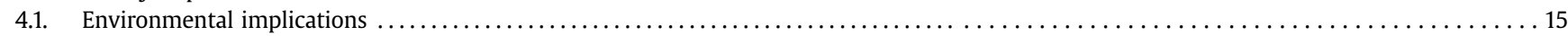

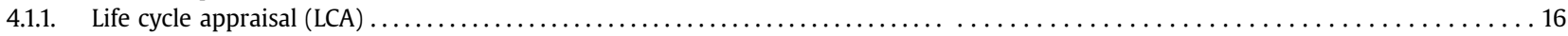

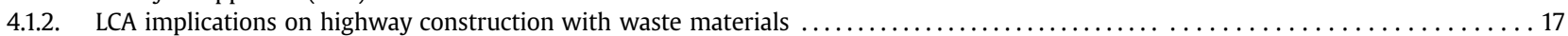

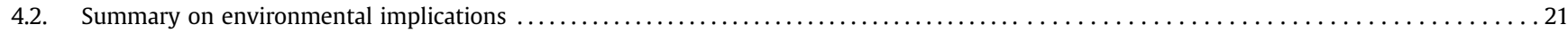

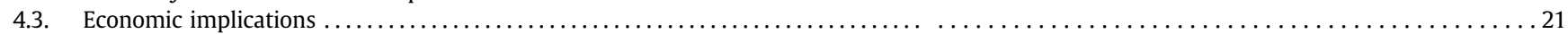

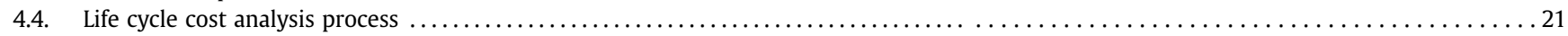

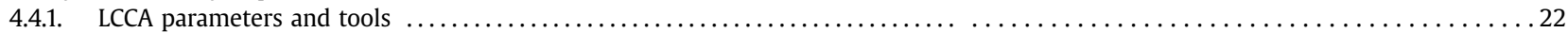

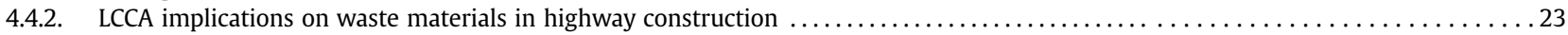

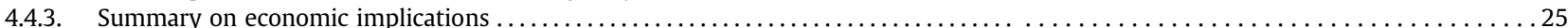

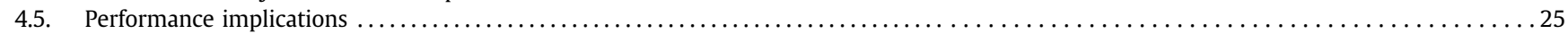

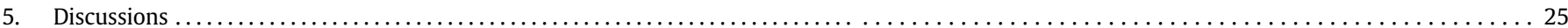

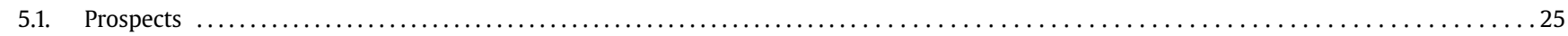

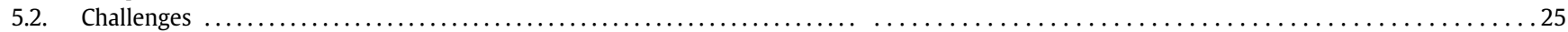

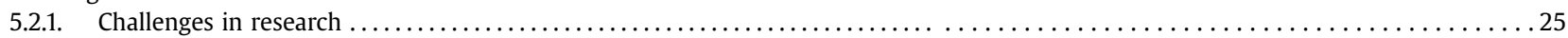

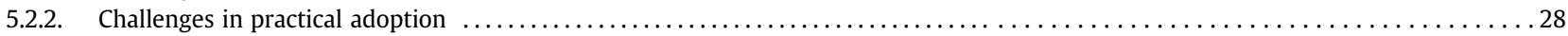

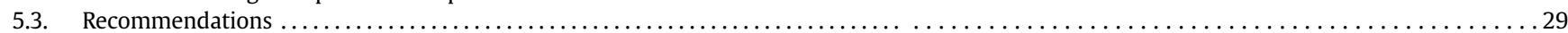

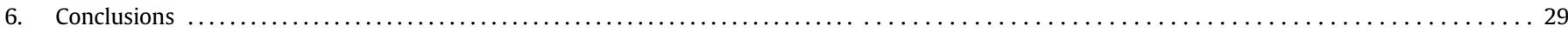

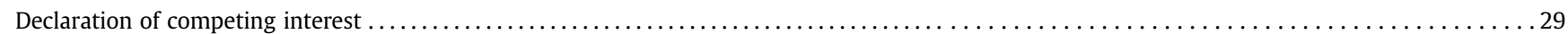

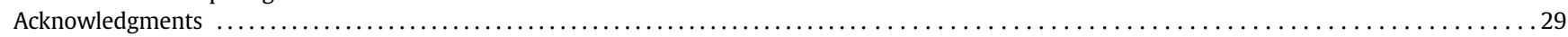

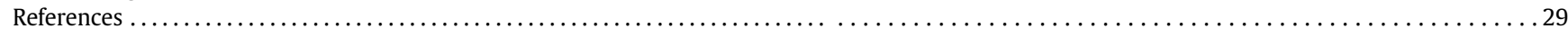

\section{Introduction}

While the need for construction and maintenance of roads and other highway facilities remains a key factor in the socio-economic development of a society, it has over time began to pose negative externalities on the environment. Road pavement construction often involves the exploration of high volumes of materials (mostly aggregates) and mass haulage which result in increased emissions of greenhouse gases (Majer and Budziński, 2018). According to Garside (2019), over 257 million metric tons of sand and gravel was produced in the year 2017 by the leading countries in sand and gravel exploration. The USA accounts for about 102 million tons out of that. Yet in the year 2018, another 277 million metric tons of aggregate was produced for industrial purposes. The current exploration rate does not seem to be in line with the United Nations Development Program's (UNDP) sustainable development goals that drive sustainable construction alongside environmental protection by minimizing the utilization of natural resources (Huang et al., 2007). The continuous rise in global economy and standard of living will surely result in an increased rate of raw material consumption worldwide. A report by the Organisation for Economic Co-operation and Development (OECD) projects that by 2060, the use of natural raw materials (especially metals and non-metallic minerals) will rise to about 167 gigatons from 90 gigatons today, while world population is also expected to rise to about 10 billion people (Weber and Kroll, 2019).

To tackle this, various researchers have in the last two decades studied means of incorporating sustainable materials in road construction to support conservation. Some of these methods include the reuse of selected waste materials such as construction and demolition wastes (Stehlik et al., 2015; Zhang et al., 2019), glass waste (Kadhim et al., 2019), Waste tire rubber (Bonicelli et al., 2017), fly ash and granulated blast furnace slag (GBFS) (Bakare et al., 2019), colliery spoils (Suescum-Morales et al., 2019), polyethylene terephthalate (PET) (Sojobi et al., 2016), mine tailings, shingles (Haas et al., 2019), aluminium dross (López-Alonso et al., 2019), and bio oils (Kousis et al., 2020) to list a few, in the construction and rehabilitation of roadways. These materials have been evaluated separately or alongside other waste materials as a full or partial replacement for certain traditional construction materials.

The need for material diversification can also be ascribed to the rising need for durability, increased performance, and reduced maintenance and construction costs in road pavements, especially in developing countries (Sojobi et al., 2016). The rapid rise in population brings about an increase in vehicular traffic and axle loads resulting in road section failures (Ede, 2014). These failures mostly occur either at the bottom of the surfacing layer (fatigue and cracking due to tensile stresses between layers) or at the subgrade layer (rutting due to compressive forces from wheel load) (Indian Road Congress (IRC), 2012). Fig. 1 illustrates the basic layers in road pavements and indicates failure points.

This paper reviews recent relevant literature to compare various sustainable materials and methods that have been adopted in the 


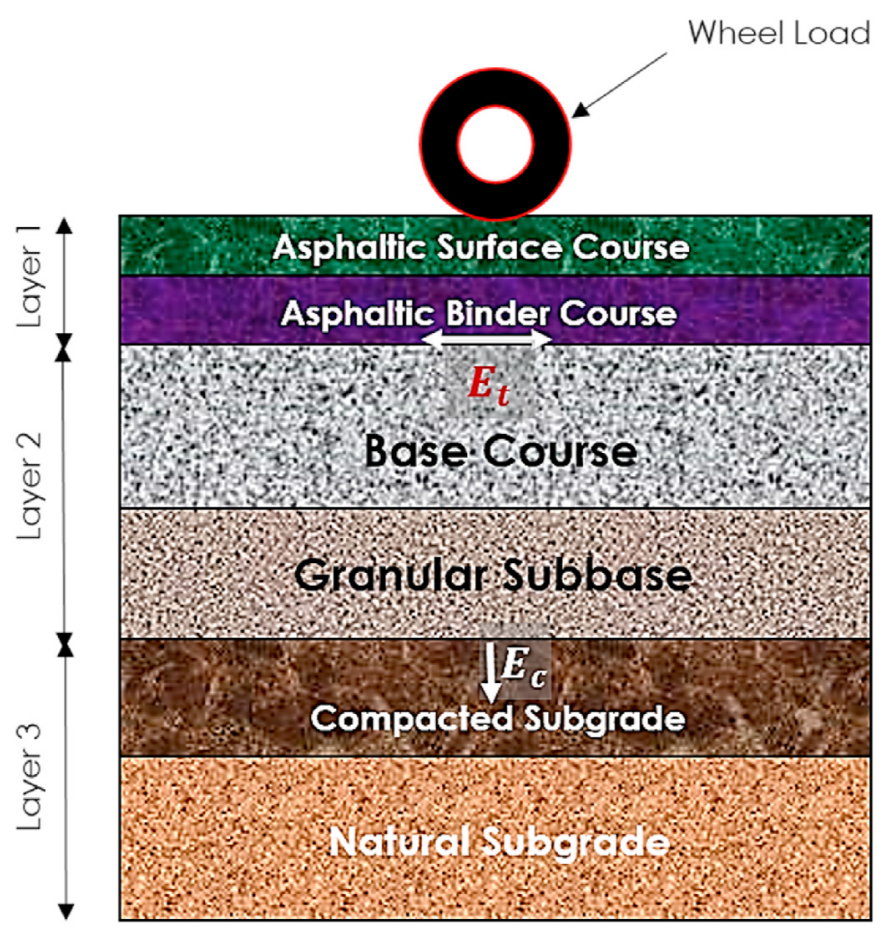

Fig. 1. Layers and stress positions in flexible pavement (Source: Indian Road Congress, 2012).

modification of conventional road pavement materials. The generation rate and application of the selected waste materials, and their effects on the physical and mechanical performance of road pavement was reviewed. The environmental and economic implications resulting from the utilization of these waste material on sustainability were also discussed.

\section{Generation and management of selected waste materials}

The rising complexity and volume of solid waste generated continue to pose grave threats to the ecosystem and public health. According to the UNEP (2019) survey, about 11.2 billion tons of solid waste is collected worldwide annually, the decay of the organic fraction accounts for about 5 percent of emissions of greenhouse gas globally. Poor management of these wastes (from collection to disposal) causes reductions in air, water, and soil quality. Some of the highly generated wastes that have the potential to be used in the road construction industry are discussed in the following subsections.

\subsection{Polyethylene terephthalate (PET) plastic bottles}

The usage of plastics has rapidly become a common practice in many aspects of human activities daily. Plastic may exist in two forms (Claisse, 2016): thermoplastic which soften when heated and hardened when cooled and thermosetting plastic which polymerized and set when mixed with hardener and will not soften when heated. Thermoplastics constitute the larger proportion of plastic waste stream and also easily recyclable. Thermoplastics types that are widely used include high density polyethylene (HDPE), Polyvinyl chloride (PVC) and polyethylene terephthalate (PET) (Hassan et al., 2004). Among the single-use plastics, PET packaging waste has been identified as one of the most common plastic waste pollutants. According to UN Environment (2018), about 1 million plastic bottles are purchased every minute and about 5 trillion plastic bags are used globally every year. This is due to its undeniable user-friendly, light- weight and durability advantages (Perera et al., 2019). Production of plastic containers from pellets is a quicker and much cheaper process compared to the recycling and reuse processes this brings about a continuous increase in the generation of PET (Hopewell et al., 2009; Thompson et al., 2009). The rising-rate at which these plastic wastes are disposed cause negative impacts such as visual pollution, flooding, endangerment of sea animals, and wildlife (Maharaj et al., 2019; Bamigboye et al., 2019) PET has also made grave economic impacts. A report by Weber and Kroll (2019) states that plastic waste results in damages to the marine ecosystem worth US\$13 billion annually. They are specifically produced for a first-use cycle and amount in a 95\% loss to the economy thereafter. This indicates the need for proper management (Wong et al., 2015).

As of 1976, only about 50 million metric tons of plastic was produced (Sojobi et al., 2016). In the early 2000s, PET waste output up surged more in a decade than it had in the previous four decades. By the year 2013, Sojobi et al. (2016) reported that PET output had exceeded 200 million metric tons. Globally today, over 250 million metric tons of PET waste are generated annually as illustrated in Fig. 2. A Study by UN Environment (2018) indicate that over 8.3 billion tons of plastic has been produced since the 1950's and over 60 percent of these wastes end up as landfill thus polluting our natural environment.

In recent times, we have seen a digression from the manufacture of durable plastics and towards light-weight disposable single-use plastics. About $99 \%$ of plastics are made from chemicals derived from non-renewable natural gas, coal, and oils. With the current trend, it is projected that by 2050 , the PET industry could be responsible for $20 \%$ of global oil consumption. Presently, only $9 \%$ of all PET waste ever generated have been recycled, about 12 percent have been incinerated, leaving about 79 percent to accrue in refuse dumps and landfills thereby polluting surrounding environments (UN Environment, 2018). Some of the areas where plastic waste has shown the potential of usage in highway construction are in geogrid or separation membranes, soil stabilization and paving systems, road aggregates, lightweight aggregate, lightweight aggregate, polymer concrete, sheet piling, asphalt binder (Hassan et al., 2004).

\subsection{Waste rubber tires}

Waste rubber tires also known as end-of-life tires (ELT) or styrenebutadiene-styrene (SBS) are classified as non-biodegradable materials as they were designed for durability under critical weathering conditions (Sugiyanto, 2017). They possess outstanding acid and water resistance, plastic energy absorption, high impact resistance, and sound/thermal insulation properties (Saberian et al., 2019). Over the years, ELT became a major issue in many countries. The USA currently produces the largest volume of scrap tires, recording over 4 million tons yearly. Japan records about 1 million tons of ELT stockpiled yearly (Sugiyanto, 2017), Australia, England, Germany and Thailand produce 0.5 million (Saberian, Li, and Cameron, 2019), 0.4 million (Huang et al., 2007), 0.6 million (Sugiyanto, 2017) and 0.4 million tons (Duangburong et al., 2015), respectively of scrapped tires. This high rate of ELT generation led to illegal dumping in lakes, roadsides, abandoned lands, and public landfills.

Disposal of ELT by stockpiling and landfilling is no longer permitted as it poses risks to the environment and human health (Arulrajah et al., 2019). Most countries have enacted laws to ensure the reuse of ELT's. Weber and Kroll (2019) reported that in 2017, about 300 million tires were scraped in the USA generating about 4 million tons of scrap tires of which about 3.4 million tons went back into the market giving a reutilization rate of over $81 \%$, quantity landfilled was around $16.15 \%$. From the reutilized fraction, nearly $45 \%$ was used as rubber-derived fuel in pulp and paper producing facilities, cement kilns and industrial boilers, $25 \%$ was shredded for 


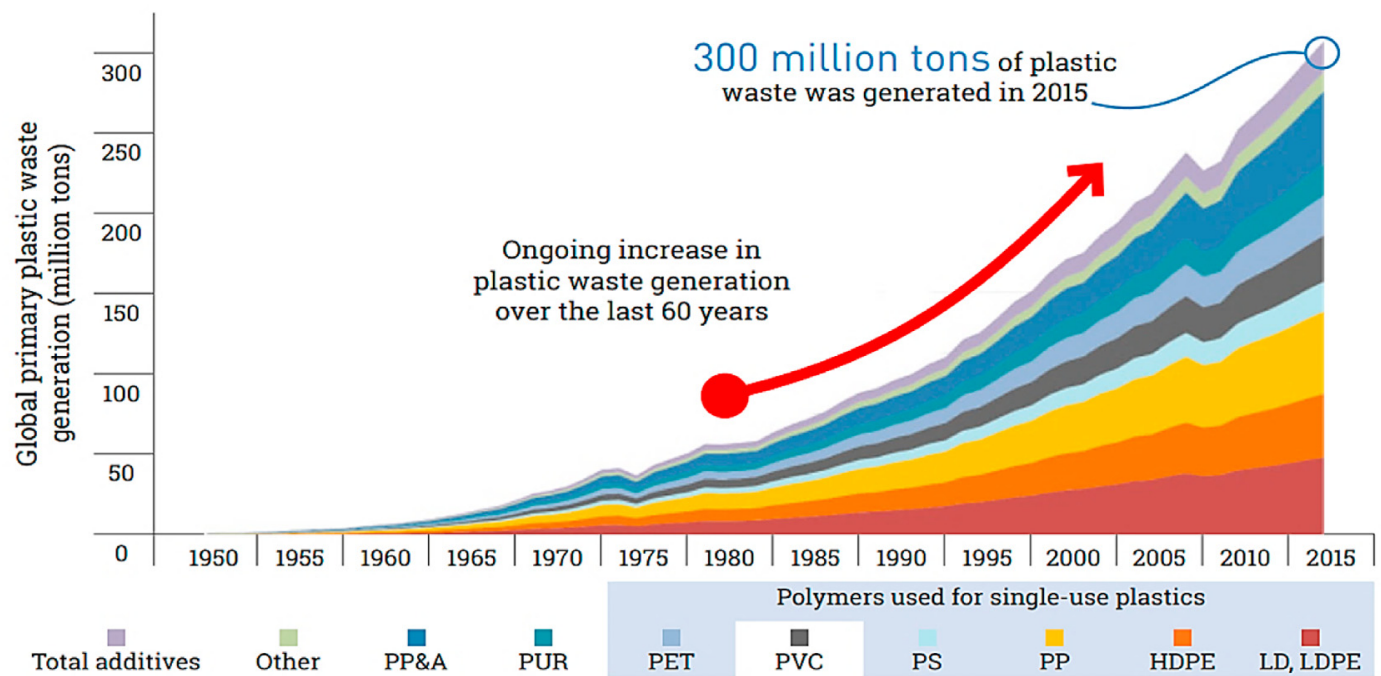

Fig. 2. Worldwide plastic waste generation, including PET (1950-2015) (Source: UNEP, 2018).

ground rubber solutions, 8\% was utilized for civil engineering infrastructure works and 3\% exported. SBS is now one of the most commonly used polymer for bitumen modification (Fernande et al., 2019). In 2016, the EU28 vol situation showed that 117,000 tons were used in the construction industry (Weber and Kroll, 2019). Fig. 3 shows a typical BOMATIC GmbH® automatic vertical tire shredder. Utilization of waste rubber as material for use in construction industries is considered as a suitable alternative way of disposal of waste rubber. Thus, waste rubber had been previously evaluated for use in road surface dressing, sport or safety surfacing. Other areas of its application include embankment construction, aggregate substitute, asphalt modifier, retaining walls, drainage, backfills and thermal insulation (Hassan et al., 2004).

\subsection{Steel slag}

Steel has always been one of the most important natural resource in modernization. It has been used in innumerous applications. During steel production, all unwanted elements and

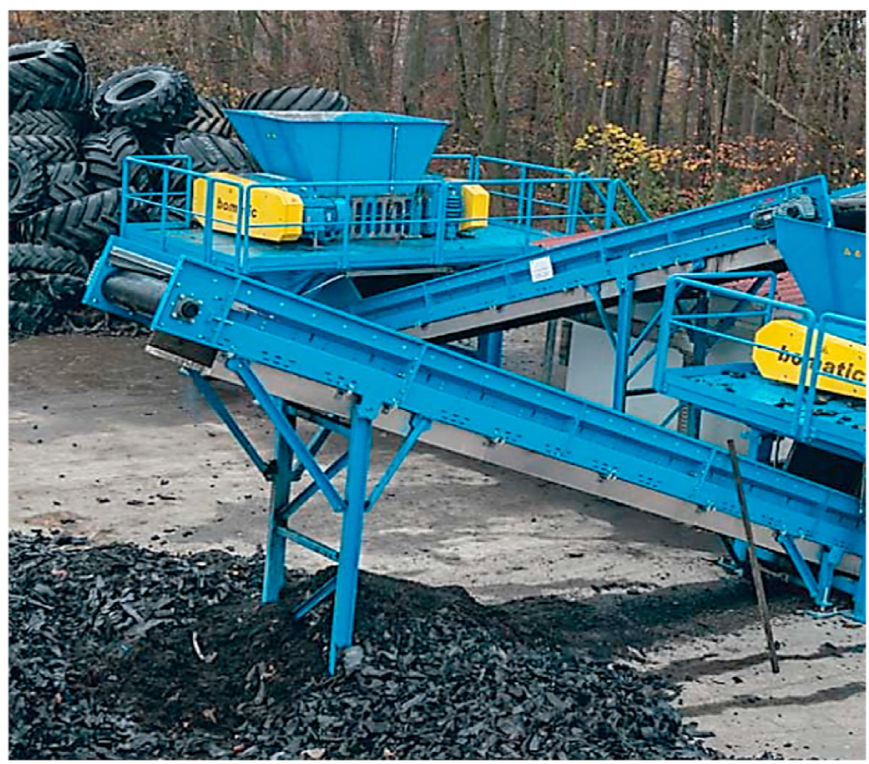

Fig. 3. Rubber tire shredder (source: Weber and Kroll, 2019). impurities are expelled as "slag" to guarantee maximum iron recovery (Government of India-Ministry of Steel, 2019). Steel slag waste has for many years been deposited in slag storage yards, farmlands, and surface water streams (Günay et al., 2004).

Steel slag can either be classified based on steel type as carbon steel slag or stainless steel slag or based on the production process as basic oxygen furnace slag (BOFS), pretreatment slag, electrical and furnace slag (EAFS), castle residue and ladle refining slag (Yi et al., 2012).

A Report by Worldsteel Association (2018) shows that over 400 million tons of slag is produced worldwide annually. Averagely, for every ton of steel produced, a minimum of $200 \mathrm{~kg}$ or $400 \mathrm{~kg}$ of slag is produced (by EAF or BOF) respectively (Malhotra, 2019). As of 2010, China alone was reported to produce 90 million tons (Yi et al., 2012), and India, the third-largest producer of steel generated nearly 40 million tons of slag between 2017 and 2018 (Government of IndiaMinistry of Steel, 2019). Fig. 4 indicates the quantity of steel slag generated from steel production in India between 2017 and 2018.

The reuse and recovery of these solid waste material has contributed to a material efficiency of just over $97 \%$ worldwide and reductions in environmental pollution thereby driving sustainability (Worldsteel Association, 2018). The goal for many countries is to achieve $100 \%$ material efficiency. In the UK, steel slag has been used as aggregates in the production of cement and asphaltic concrete in the construction industry (Huang et al., 2007).

\subsection{Glass waste}

Glass is in many ways a major part of the daily lives of most persons. It is found easily as Municipal Solid Waste (MSW). Glass is produced either from the processing of sand, soda, and limestone or from waste glass feedstock. Tentatively, all fragments of highquality new glass materials can be manufactured from $100 \%$ of old glass, this process requires lower energy consumption and zero natural materials (Ozer et al., 2015). Over 80\% of the total mass of glass produced worldwide is either in the form of canisters for food packaging and pharmaceutical products or plane glass for automobile and building construction (Butler and Hooper, 2019). The potential source of glass waste includes cullet, bottle bank glass, kerbside, collection glass, pubs and clubs, and other waste flat glass from demolition and replacement window industries (Hassan et al., 2004). The US Environmental Protection Agency (EPA)., 2017 reported the quantity of glass generation in the US at 11.4 million tons 


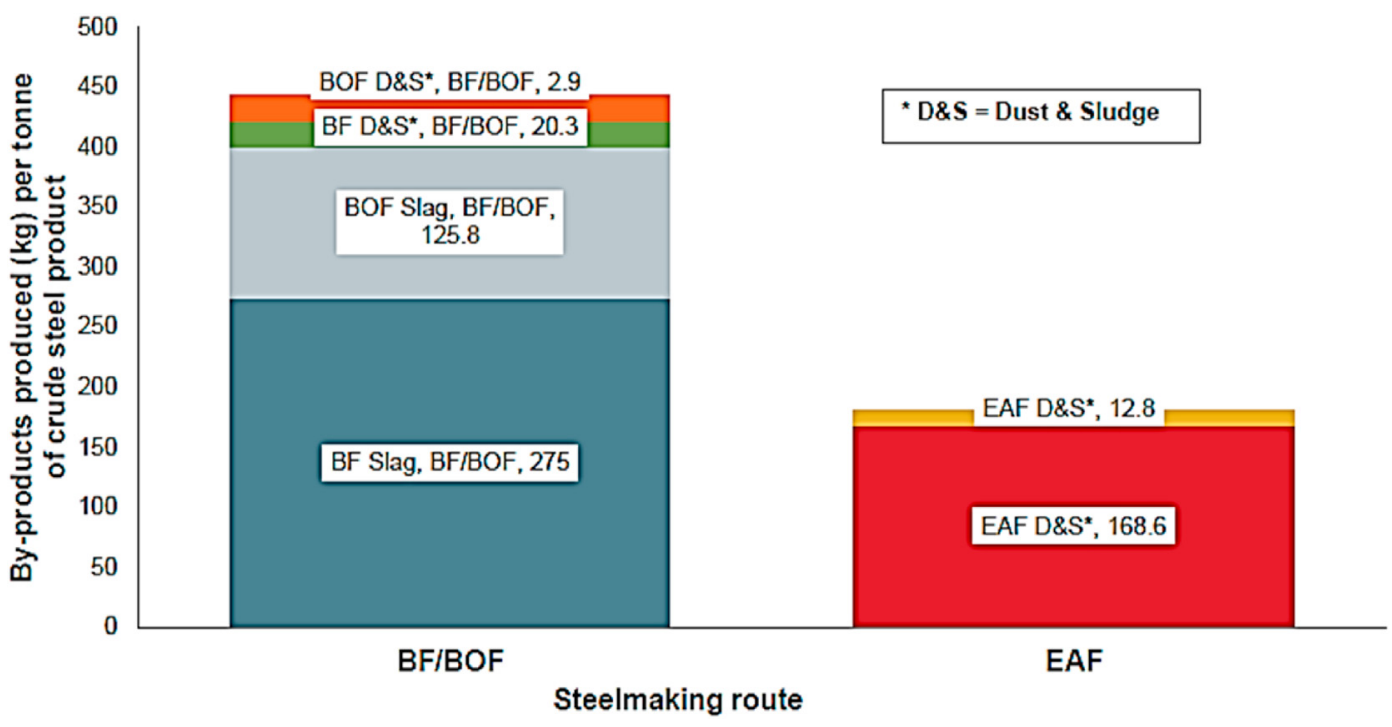

Fig. 4. By-products from steel production (Source: India-Ministry of Steel, 2019).

with the amount of recycled glass as 3 million tons, combusted glass was 1.5 million tons and 7 million tons disposed in landfills (US EPA, 2019). Fig. 5 illustrates the glass waste management practice adopted in the US between 1960 and 2017.

A survey carried out by World Bank as reported by Kurpinska et al. (2019) showed that annual global waste generation is up to 2 billion tons of which glass waste accounts for about $10 \%-15 \%$. In Europe, the average glass waste generated per capita is about 11-40 kg. The quantity of glass waste stockpiled annually in Europe, US, and Australia is approximated at 15, 10, and 1 million tons respectively (Saberian et al., 2019; Saberian, 2019).

Quite several methods have been adopted to manage the impacts of these wastes on the environment. Some of these methods include recycling, utilization of crushed glass in road works, and civil engineering projects and as aggregates in asphaltic concrete
(Harder, 2018). Glassphalt is the term used to describe glass waste composed asphaltic concrete. About 225,000 tons of the glassphalt composite was used in New York in the 1990s for resurfacing (Kadhim et al., 2019). Other applications of glass waste in highway construction include sand for bedding paving block.

\subsection{Construction and demolition wastes}

Debris from Construction and Demolition (C and D) are usually not included in MSW. C and D wastes are often composed of heavy materials such as concrete, bricks, wood, Asphalt, ceramics, metals, and gypsum (Zhang et al., 2019). Generation data show that C and D debris results from construction, rehabilitation, and demolition of physical infrastructures (Balaguera et al., 2018; Pranav et al., 2020; Presti et al., 2017).

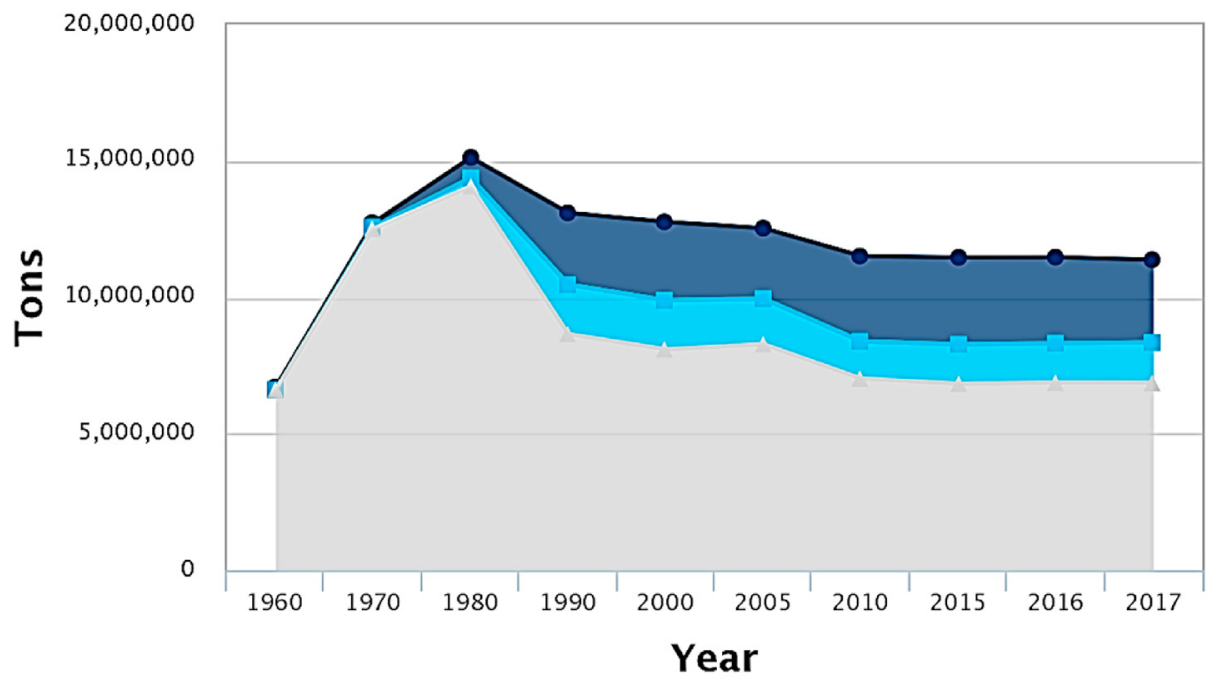

Recycled $\square$ Composted $\square$ Combustion with Energy Recovery $\square$ Landfilled

Fig. 5. Glass waste management in the US (1960-2017) (Source: US EPA, 2019). 
A report by the US Environmental Protection Agency (EPA) (2019a) showed that about 569 million tons of C and D waste was generated in the USA in 2017 with C and D cement concrete accounting for $69.7 \%$ and asphaltic concrete constituting $15 \%$. Other $C$ and D debris accounted for $15.2 \%$ combined. Construction and rehabilitation activities only represented under $10 \%$ while demolition activities represented over $90 \%$ of the entire C and D waste generated. In China, approximately 2 billion tons of $C$ and $D$ waste is produced annually, this accounts for about $40 \%$ of the total MSW generated. However, only less than $5 \%$ of these wastes are presently being recycled (Zhang et al., 2019). Fig. 6 shows the distribution by material type of C and D waste generated in the USA in the year 2017. C and D had shown the potential for use in highway construction as bulk fill, capping and sub-base application (Hassan et al., 2004).

Data from the Colombian Ministry of Environment as reported by Martinez-Arguelles, Acosta, Dugarte, and Fuentes (2019) show that over 22 million tons of $C$ and $D$ waste is produced annually in Colombia. This accounts for $60 \%$ in natural material exploitation, $40 \%$ total energy consumption and $30 \%$ of $\mathrm{CO}_{2}$ emissions.

The total consumption of Natural Aggregates (NA) globally is over 15 billion tons annually. Aggregates accounts for $70 \%-80 \%$ of Portland cement concrete (PCC) and $75 \%-85 \%$ of asphaltic concrete by volume (Martinez-Arguelles et al., 2019). The integration of $C$ and D waste as a substitute for NA would offer substantial reductions in the exploitation of natural resources and adverse environmental effects (Arulrajah et al., 2019a; Balaguera et al., 2018; Stehlik et al., 2015). Reclaimed asphalt aggregates are also considered as $C$ and $D$ and are being produced in the range of 4-5 $\mathrm{Mt} / \mathrm{a}$ with high-value application in the manufacture of new asphalt (Hassan et al., 2004). The inclusion of Reclaimed asphalt debris in asphalt production for road surfacing has become a common practice (Jin Li et al., 2019; Majer and Budziński, 2018; Venturini et al., 2017). Recycled asphalt aggregates had been evaluated for use in highway construction as unbound granular material with additional benefit of some binding properties.

\subsection{Colliery spoils}

The process of extraction of coal from the earth is termed coal mining. A colliery (or coal mine) is a coal exploration structure (a pit head and the superstructure). Coal is the second most used source of energy worldwide, in 2015 , about $70 \%$ of extracted coal was used in electricity generation (Suescum-Morales et al., 2019). It is approximated that about 38\% of the total electricity generated in 2018 was from coal fuels (BP Statistical Review of World Energy, 2019). Fig. 7 indicates the global coal production and consumption quantities across regions.

Colliery spoils (CS) are generated on the surface outside of coal mines during coal extraction, they are composed of erratic portions of coal, rocks, minerals, and other debris from mining operations (Kokh et al., 2015). CS can be heaped in very large volumes, According to Donnelly and Bell (2011), the total volume of CS on the Yorkshire coalfield in Northern England is about 4 million cubic meters. CS heaps are highly susceptible to burning and this causes atmospheric pollution and other environmental hazards which have over time threatened the health of populace around collieries (Silva and Oliveira, 2014). Over time, traces of acid run-off are noticed on evacuated CS fields due to the presence of pyrite and as such the European Waste Catalogue (EWC) classified CS as being hazardous and potentially dangerous and recommended continuous monitoring and remediation of CS (Ghataora et al., 2015).

The use of CS has been adopted in the construction industry in the production of cement concrete as an alternative material (Suescum-Morales et al., 2019). Another study by (Modarres and Ayar, 2014) used CS in the construction of sub-layers for road pavement structures.

\subsection{Fly ash}

Fly Ash (FA) (also known as pulverized fuel ash) is a by-product from coal combustion (Heidrich et al., 2013). In 2012, Coal-fueled electricity power plants in the UK produced about 6 million metric tons of $\mathrm{FA}$, around $50 \%$ of these wastes were used in the construction sector while the other half was disposed of in landfills (American Coal Ash Association, 2018). In India, it was reported by

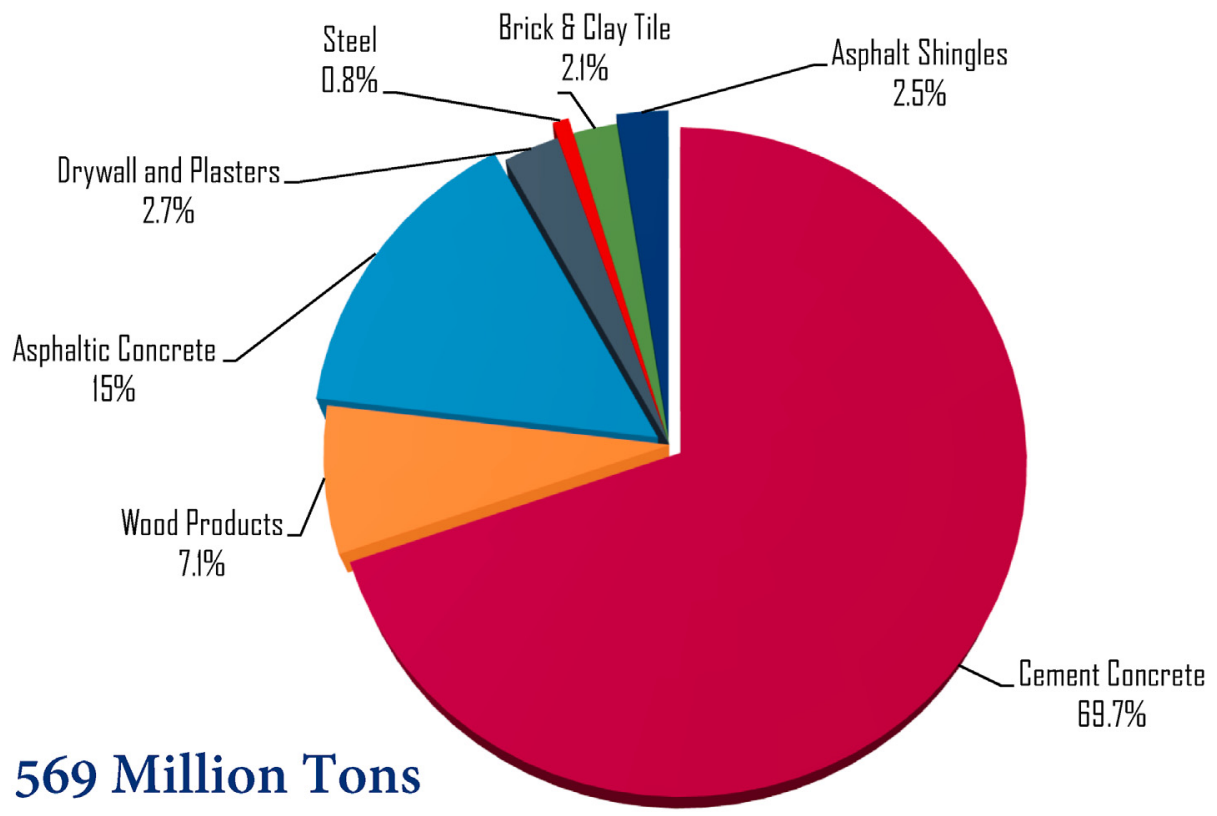

Fig. 6. 2017 C and D waste generation by material in USA (source: US EPA, 2019a). 


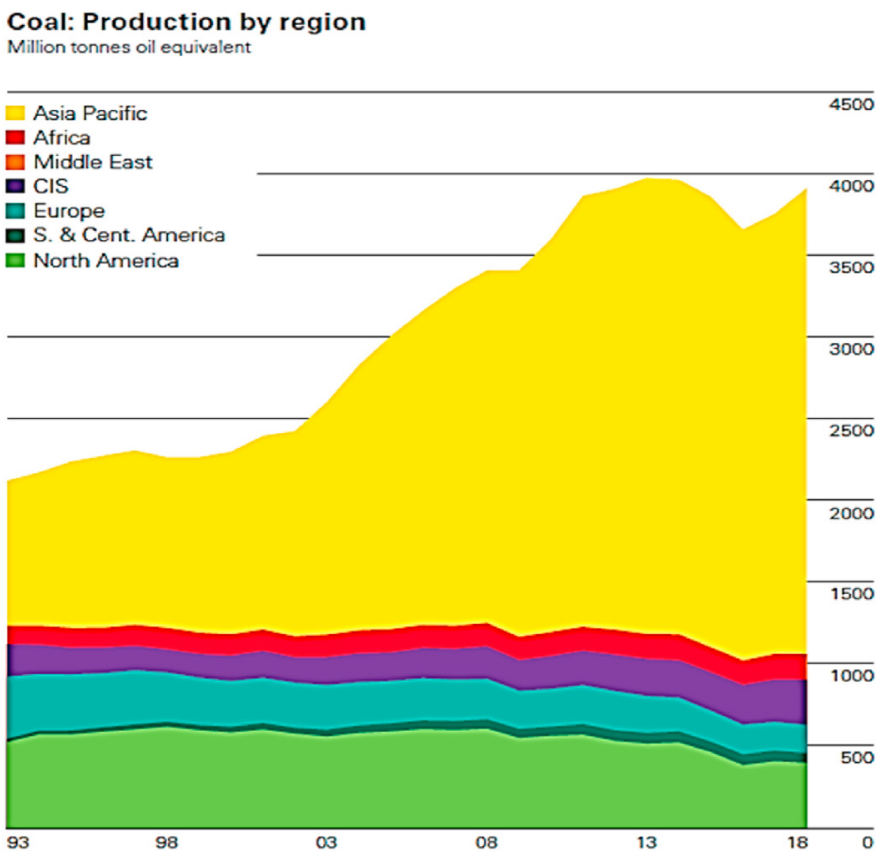

Coal: Consumption by region

Million tonnes oil equivalent

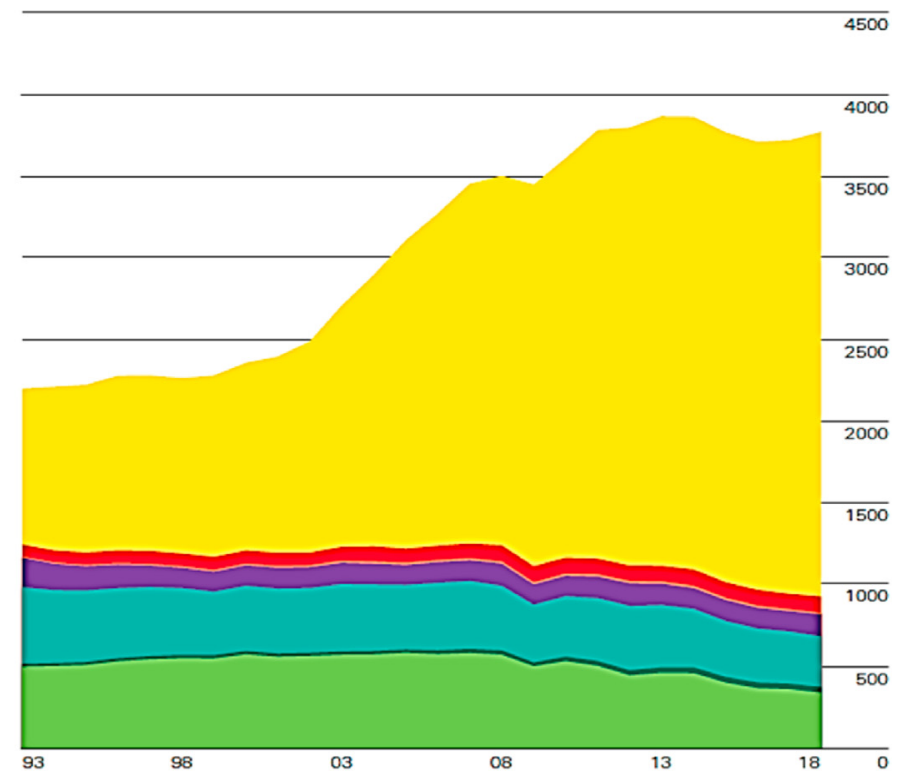

Fig. 7. Coal production and consumption by regions (Source: BP Statistical Review of World Energy, 2019).

Bakare et al. (2019) that about 196 million tons of FA has been produced yearly since 2017 with almost 70\% rate of utilization.

In order to reduce the deposition of FA in landfills, reuse measures have been widely encouraged especially in the road construction industry (Kumar and Panwar, 2019). Hoy et al. (2016) studied the application of FA in the production of road pavement base layer geopolymers. Li et al. (2019) and several other researches have used FA as an alternative material in the modification of conventional aggregates. The UK reduced the use of coal fuels for energy production. Only 1.6 million metric tons of FA was generated in the UK in 2016, that's a 70\% decline from what was generated in 2012. As at 2017, only $2 \%$ of the total energy consumed was from coal. Despite the efforts, $30 \%-50 \%$ of FA was still deposited in landfills. It is projected that by 2025, coal usage in the UK would have ceased (American Coal Ash Association, 2018). However, only 55\% power station FA which is estimated as $5.5 \mathrm{Mt} / \mathrm{a}$ are found applicable in various applications as general fill, grout, concrete additive, blocks and hydraulic binder while the remaining $45 \%$ is sent to landfill. In order to increase the trend of applications of FA for construction purposes, high quality FA with low loss on ignition with the advantage of generating low carbon footprint with the use of carbon reduction technology (Hassan et al., 2004).

\subsection{Cement kiln dust}

Cement kiln dust (CKD) is collected as a waste product of cement manufacturing operations (Seo et al., 2019). It is generally classified as special industrial waste (Center for Health Environment and Justice, 2011). CKD is composed of high-alkaline fine-particulate solids with a similar appearance as Portland cement (UNEP, 2011). In 2017, global cement production rate was recorded at about 5 billion metric tons per year. CKD generation rate ranged between 54 and $200 \mathrm{~kg}$ per ton of cement (Seo et al., 2019). In the last two decades, CKD generation reached 2.7 million tons in Egypt (AbdelGhani et al., 2018).

Several studies have gone into integrating CKD as an alternative material in the production of cement concrete for buildings and road pavement structures (Vijayakumar et al., 2019) and in the modification of the engineering properties of high plasticity soils for road construction (Jala and Sharma, 2019). These studies have in recent times aided in the relief of landfills from CKD.

\subsection{Asphalt shingles}

Shingle is a material whose name was cropped from a German name Schindle which means a roofing slate (Bach, and Siegert, 2016). Asphalt shingles which are petroleum-based (and hence a non-renewable resource) is very effective as a roofing material due to its water resistance and durability. However, these same material properties make it a highly-severe concern on environmental sustainability (Johnson, 2017). Asphalt shingles are derived from coating either organic matter or fibreglass sheets with an asphalt mix of glass, sand, or ceramic. They are therefore classified into two groups, which are fibreglass, and organic shingles (Johnson, 2017). These shingles comprise various rates of mineral fibres, mineral fillers, and hard rock granules in addition to asphalt cement (Abukhettala, 2016). Waste asphalt shingles of about 11 million tons is generated yearly in the US (Sengoz and Topal, 2005), requiring about 1.16 billion square meter for dumping. In the past, disposal of these waste has been done by hauling and depositing in landfills. As such, the American association of state highway transport officials (AASHTO) have developed a tentative standard specification indicating certain specific criteria for integrating waste asphalt shingled in hot mix asphalt (HMA) (McGraw et al., 2007). In countries like Canada and China, organic shingles recently have become one of the most used waste in HMA works having properly coated aggregates of high quality (Hasan et al., 2017). Fibreglass shingles are about 15\% lesser in volume than organic shingles in asphalt cement, this makes it cheaper and more preferable over organic ones (Ding et al., 2019).

\subsection{Aluminium dross}

Aluminium dross is a waste from aluminium production. It is formed during the refining and oxidation of the liquid metal under various operations. It consists of a complex conglomerate of metallic 
oxides, nitrides, chlorides, fluorides, carbides, sulphides, phosphides, and other impurities from metallic aluminium (between a range of 20 and 80\%) (Mahinroosta and Allahverdi, 2018). During the metallurgical process, toxic chemicals are added to aluminium ore, which remains in dross after the extraction process. As a result of this, the dross becomes hazardous, exhibiting possible leaching effects due to the heavy metals present. China was recorded to be the world's largest aluminium producing country as at 2017, with an estimated aggregate production to reach 38.4 million metric tonnes in 2020, accounting for over half of the global output (Hao et al., 2016). This volume is alarming for a country alone, even without considering other developed countries. Therefore, there is a great need for utilization to preserve the environment owing to several prospective properties of this waste despite its toxicity.

\subsection{Mine tailings}

Tailings are waste materials that remain after the processing and separation of the valuable fractions of an ore. It has been evaluated that since the stone age, 1150 million tons of heavy metals have been mined, thereby generating tailings in a range of 5-7 billion tonnes per year throughout the world (Ojuri et al., 2017). Mine tailings are normally obtained from the mill in slurry form, containing fine mineral particles and water mixture. In attempt dispose tailings from the mining sites, several methods have been used in the past such as tailing dams and ponds, paste tailings, dry stacking, storage in underground workings, riverine tailings, submarine tailings, and Phyto stabilization. None of these methods have been effective enough for tailing disposal due to the leaching effect resulting from the presence of heavy metals (Ye et al., 2017). However, quite recently, positive efforts have been made by researchers in the utilization of this waste in surface courses and other pavement interlayers during road construction.

\subsection{Bio-oils}

The growing demand for petroleum-based products alongside the rapidly depleting reserves for crude oil has significantly resulted in a steady rise in the cost of asphalt (Tayh et al., 2014). The adoption of alternative binder materials offers sustainability in terms of the material's life cycle environmental impact. Bio-oils are renewable energy sources obtained from the conversion of biomasses (agricultural and other organic wastes), that can be incorporated into bituminous blends as a modifier in producing bioasphalt (Raman et al., 2015).

Bio-oil is a brownish dark fluid, extracted from rapid pyrolysis of biomass. It has different components in comparism to petroleum derived additives. The arrangement of these components differ, subject to the kind of biomass as well as the degree of the heat involved process. Biomass serve as the main source of power in various countries across the globe, aiding about $78 \%$ of the countries basic power supply (Situmorang et al., 2020). The sources of biomass include; wood wastes, bagasse, agriculture and industrial residues, paper wastes, municipal solid waste, sawdust, bio solids, grass, waste from processed food, animal wastes, aquatic plants and algae (Okolie et al., 2020). The main constituent of bio-oil is water. Its additional components include hydroxyl aldehydes, hydroxyl ketones, sugars, carboxylic acids and phenols (Chen et al., 2019). Fini et al. (2017), were successful in converting pig compost into oil at a pressure of $40 \mathrm{MPa}$ and temperature of $380^{\circ} \mathrm{C}$. According to Nie et al. (2020), bio-oil exhibit comparable constituents just like asphalt binder obtained from crude oil which could be categorized as asphaltenes, polars, aromatics and saturates. However, due to the high content of oxygen presence in bio-oil, its primary elements also vary notably from well-known asphalt (Lozano et al., 2020).
The advantages of bio-asphalts over traditional asphalts are quite numerous as they proven to be renewable, eco-friendly, offer energy savings, and provide several economic opportunities globally (Tayh et al., 2014). A summary of these benefits include 1) Reductions in carbon footprint, 2) Potency to act as a modifier or extender and directly replace petroleum-based liquefied asphalts, 3 ) Reduced temperature requirement during production and subsequent cost decrease of up to $20 \%$, 4) Lessened rate of emission of greenhouse gases (up to $30 \%$ ) due to lower energy use, 5) Potential increase in pavement serviceability resulting from the anti-oxidant effect, 6) Potential to extend the range of asphalt grades, 7) reduces demand for petroleum importation (Vignesh et al., 2013).

Any living thing with a capacity to store solar energy can be a biomass. Plants continuously produce biomass via the photosynthesis process. Goyal et al. (2006) broadly categorized biomasses into two: derived and natural materials, comprising of resources such as agricultural crops and corresponding by-products, MSW, animal wastes, food processing wastes, algae and other aquatic plants, timber and waste timbers, amongst others. Biomasses are further classified into wastes, forest products and energy crops as illustrated in Fig. 8.

Biomass materials may be transformed into several energy forms through different techniques, depending on the composition of the raw feedstock and the energy output required (Bao et al., 2019). Among the numerous techniques, pyrolysis remains the most adopted, due to its operational simplicity. Pyrolysis, conducted in the absence of oxygen, converts biomass into three distinct products: a condensable liquid (bio-oil), charcoal, and a gaseous blend (syngas) (Raman et al., 2015). Bio-oils, with densities around $1200 \mathrm{~g}$ per litre at $15^{\circ} \mathrm{C}$ and energy content of up to $18 \mathrm{MJ}$ per kilogram are normally the target product of the pyrolysis process. In the fast pyrolysis process, the biomass feedstock is heated rapidly under two seconds to get the constituent parts to temperatures ranging between 400 and $550{ }^{\circ} \mathrm{C}$ (Raman et al., 2015). However, the thinner the dimensions of the particles, the faster the heat transfer process, which is consequential in improved quality and yield of the bio-oil (Tayh et al., 2014).

It should be noted that the increase in demand of crude oil leads to change in price per barrel and increase the cost of asphalt binder and energy cost of asphalt pavement. Therefore, application of biooil was suggested as an alternative which could improve asphalt binder properties while reducing asphalt paving construction cost (Abdel Raouf and Williams, 2010; Abdul Raman et al. 2016). The benefit of applying bio-oil in asphalt binder are the ease of production from domestic non-food waste, reduction of temperature of hot mix asphalt with the advantage of decreasing the paving costs, provision of anti-oxidant effect which could increase the service life of pavements (Vignesh et al., 2013).

\subsection{Incineration bottom ash}

Incineration of solid wastes at high temperature results in the production of stable gases or ashes (Luo et al., 2017). The treatment of waste using incineration method has proven to be effective for the reduction of municipal solid waste up to $90 \%$ in volume and energy production (Toraldo et al., 2013). The presence of noncombustible or unburnt materials from the incineration of solid wastes and the qualities of the ash depend on the incineration technology (Astrup et al., 2016). The two categories of the constituents of bottom ash are the melting products (glasses, silicate minerals and oxide minerals) and non-combustible materials (waste glass, soil minerals, metals and alloy). The concerns for the use of bottom ash emanated from the attempt to find alternative way of disposal of bottom ash due to the shortage of landfills (Alhassan et al., 2012; Luo et al., 2017). Thus, finding alternative use 


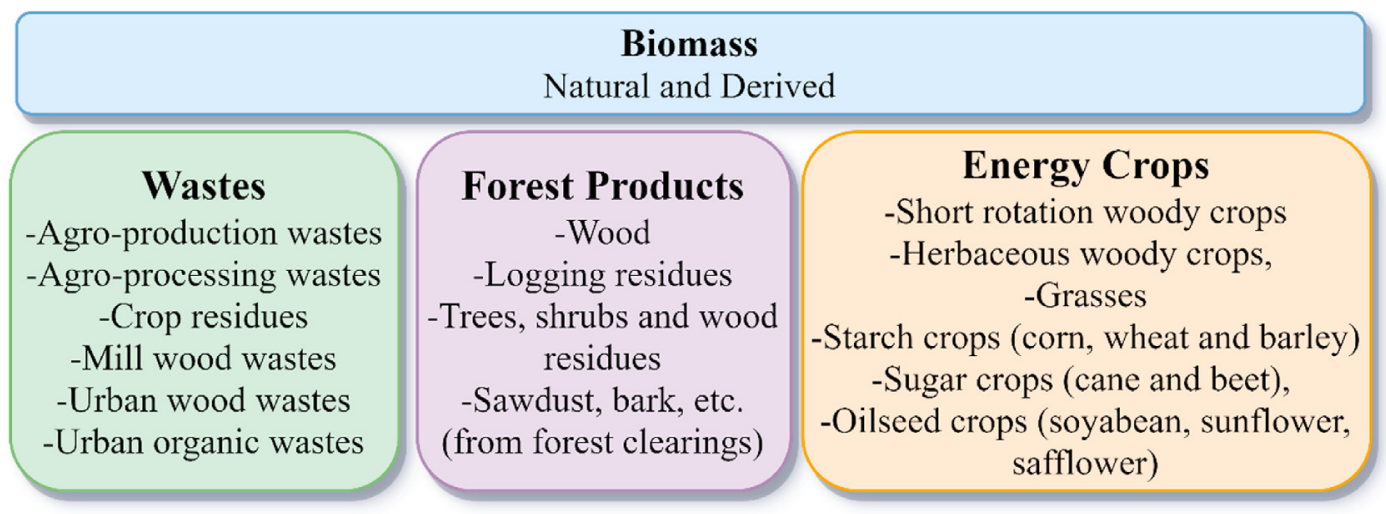

Fig. 8. Source categorization of biomass (Adapted from Goyal et al., 2008).

for bottom ash is imperative as a solution to environmental pollution resulting from solid waste disposal with the additional benefit of reduction of the amount of ash designated for landfill to increase the lifespan of landfill (Patra et al., 2017; Luo et al., 2017). The available options for the application of incineration bottom ash in construction industries include aggregate in concrete, aggregate in asphalt mixture and pozzolanic admixture (Astrup et al., 2016).

\section{Utilization of selected wastes in road construction}

\subsection{Polyethylene terephthalate (PET) utilization}

Sojobi et al. (2016) studied the use of PET coated aggregates (PCA) and PET modified bitumen (PMB) in the production of bituminous asphaltic concrete and compared both results to that of conventional bituminous asphalt. Laboratory tests showed that penetration values of PMB decreased as PET increased indicating increases in stiffness and softening point while ductility values, on the other hand, increased with increasing PET content indicating a more stable asphalt. For both PCA and PMB, Marshall stability values increased with rising PET content. Air voids increased with rising PET content in PCA but was seen to decrease in the case of PMB. PMB-enhanced asphalt utilizes more PET (with optimum required bitumen content of $9 \%$ ) compared to PCA-enhanced asphalt (with optimum required bitumen content of $16.7 \%$ ).

Perera et al. (2019) studied the application of PET blends alongside recycled crushed aggregate (RCA) and crushed brick (CB) as road base course material, results were compared with applicable standards. Addition of PET had no significant effect on the grain size distribution. CBR results was found to be over $80 \%$ while LA abrasion values obtained was below stated limits. Repeated load triaxial (RLT) test results indicated that RCA/PET blends had better performance than $\mathrm{CB} / \mathrm{PET}$ blends, both blends exceeded the minimum RLT requirement for road base/subbase materials of $125 \mathrm{MPa}$ indicating their capacity to tolerate repeated pavement loads. The Modulus of Resilience $\left(\mathrm{M}_{\mathrm{R}}\right)$ decreased with increasing PET content due to the reduction of internal friction between particles.

Maharaj et al. (2019) reported on the durability and performance of road pavement surfacing with PET and Crumb rubber (CR). Marshal mix results showed that the optimum content of PET and CR polymer is $1 \%$ and $5 \%$ respectively. The $5 \%$ PET enhanced samples gave a Marshall stability value of $10.2 \mathrm{kN}$ with a $3.2 \mathrm{~mm}$ flow value which was similar to the values from unmodified samples. A gradual increase in voids was noticed with increasing percentages of PET; nevertheless, all modified samples apart from the $5 \%$ PET exhibited an acceptable range of voids between $14 \%$ and $20 \%$. A higher compressive strength and resistance to weathering was noticed from the compressive strength and AW tests in both the $1 \%$ and $5 \%$ PET samples when compared to unmodified mixes indicating higher durability and providing a sustainable reuse method for the PET polymer.

According to Action Program (WRAP), PET is the most recycled plastic waste from a household waste stream when compared to other plastic wastes. It is also the most used due to its high gasbarrier resistance, higher wearing resistance, low friction coefficient making it applicable in various ways which other plastics are not. It is as well the most effective as an additive due to its rheological nature and low glass transition temperature (Ahmad et al., 2017).

\subsection{Waste rubber tire utilization}

Bonicelli et al. (2017) performed laboratory analysis using natural fine aggregates and recycled waste tire rubber on pervious concrete for rigid pavement application. Batches of control mix and modified mixes with Styrene butadiene styrene (SBS) and natural aggregates were produced with varying $\mathrm{w} / \mathrm{c}$ ratios. The density values of the sample's natural aggregates (sand) fell within acceptable limits while that of the SBS mix fell below the allowable range. SBS addition as fine aggregate in pervious rigid pavement offers varying effects depending on crumb sizes. Smaller Particles ranging between $0.08 \mathrm{~mm}$ and $1 \mathrm{~mm}$ in size increased the overall density while decreasing indirect tensile strength of the material. However, larger crumbs with sizes ranging between $0.6 \mathrm{~mm}$ and $2.5 \mathrm{~mm}$ gave slight growth in strength. Bonicelli et al. (2017) noted that the mechanical properties of pervious concrete can only be enhanced using SBS if crumb quantity and size is correctly proportioned.

Sugiyanto (2017) investigated the integration of scrapped rubber tires as fine aggregate in asphalt production. Three sets of asphalt mixtures were produced with $0 \%, 50 \%$ and $100 \%$ of SBS waste. Laboratory tests showed that the 50\% SBS mix had the highest optimum asphalt content (7.1\%), compared to the control mix (6.78\%) and the 100\% SBS mix (6.22\%). Marshall immersion test result revealed that 50\% SBS mix yielded $96.55 \%$ resilience, while the $100 \%$ SBS mix yielded $92.83 \%$ and the control mix gave only $89.04 \%$. Based on these results, SBS can be used to improve pavement resistance to rutting under high temperature and loading conditions.

Qadir et al. (2018) did a study on the rutting potential and life cycle of SBS and PP modified flexible pavements and compared the results to that obtained from conventional mixes. Average rut depth was determined for all samples at 10,000-wheel passes using a total compressive energy of $240 \mathrm{~kJ}$, SBS modified asphalt recorded lower rutting depths when compared to the two PP modified and 
unmodified mixes. Statistical analysis performed reaffirmed the above result with varying temperature levels. Life cycle cost evaluated using Net Present Value (NPV) for SBS modified, PP modified, and conventional asphalt was found to be US\$160,000, $\$ 220,000$ and $\$ 270,000$ respectively, indicating that the use of SBS modification, even with an increased initial investment, eventually offers saving in costs at the end of the pavement design life.

Saberian and Li (2019) investigated the long-term permanent deformation behavior of SBS and RCA in road pavement base and subbase layers. Seven sets of samples were created with varying percentage of SBS. (i.e. RCA only, RCA $+1 \%$ fine SBS, RCA $+0.5 \%$ coarse SBS, RCA $+2 \%$ coarse SBS, RCA $+0.5 \%$ fine, RCA $+2 \%$ fine $S B S$, and $\mathrm{RCA}+1 \%$ coarse SBS). The Repeated load triaxial strength test shows that plastic shakedown (primary stage) was experienced in the control RCA and 0.5\% SBS samples only, these samples endured large initial permanent strain accompanied by a declining rate of permanent strain. The RCA $+1 \%$ fine SBS, and $\mathrm{RCA}+2 \%$ fine SBS, experienced plastic creep (secondary stage) in which the samples endured large initial permanent deformations and then a decrease to a low constant strain rate. Samples with $1 \%$ and $2 \%$ coarse SBS experienced incremental collapse (tertiary stage) in which the permanent strain progressively increased with each load cycle causing early collapse. The results indicate that only the RCA only, and RCA $+0.5 \%$ SBS fine and coarse samples can be adopted as road base and subbase material based on the Werkmeister's shakedown criteria.

Leng et al. (2018), investigated the viability of employing depolymerised waste PET additives, obtained via an aminolysis method, to enhance the storage stability and rheological performance of crumb rubber modified asphalt. At the study, $10 \%$ of the powdery tyre crumbs and laboratory developed PET additives named BHETA (3-7\%) were mixed with heated bitumen of grade $60 / 70$ at $180{ }^{\circ} \mathrm{C}$. Result showed that with the introduction of PET additives to the rubber crumbs modified asphalt, enhancement was noticed in the storage stability, fatigue resistance, rutting as well as the rotational viscosity (RV) of the improved binders.

Ziari et al. (2019), investigated the effect of amorphous carbon powder as to moisture sensitivity, fatigue performance and rutting resistance of crumb rubber asphaltic concrete mix. The grounded tire was used as a modifier while the amorphous carbon was introduced as fillers. The outcome revealed that the resilient modulus and indirect tensile strength of the mix increased likewise the fatigue resistance of asphalt mixture. The addition of $8 \%-16 \%$ grounded tyre powder into clean bitumen increased the high performance temperature of bitumen $6.2^{\circ} \mathrm{C}$ to $15.6{ }^{\circ} \mathrm{C}$ and lower performance temperature up till $4.5^{\circ} \mathrm{C}$. This variation in performance with respect to temperature showed enhanced asphalt mixture resistance to rutting and low-temperature cracks. Also, when the amorphous carbon powder was increased from $25 \%$ to $50 \%$ in the asphaltic mix which contain 8,12 and $16 \%$ of rubber increased the resilient modulus by $21.8 \%, 19.5 \%$, and $22.9 \%$, accordingly.

Waste rubber has also been reutilized as additives in asphalt mixtures in the past few decades. From the environmental stand point, this alternative has been seen to be attractive, yet, it has not been extensively adopted because its implications on road life cycle cost and performance have not been conclusively established (Ganiron, 2014). The two different techniques adopted in incorporating these wastes are: 1 ) the wet process and 2) the dry process (Rodríguez-Fernández et al., 2020; Tahami et al., 2019). In the wet process, CR play the role of a binder modifier, whereas in the dry process, $C R$ and/or granulated rubber is utilized in the replacement of the fines (Sun et al., 2020). In both scenarios, CR is widely referred to as CR modifiers (CRM) due to the fact that its incorporation modifies the characteristics of the produced HMA.

Terminal and field blends of asphalt are some of the techniques developed via the wet process to integrate CR into asphalt binders. As such, warm mix asphalt techniques were established to limit the challenges met during processing of these CRM binders. The terminal blend (TB) technique is further discussed as has been seen to substantially enhance the engineering properties of CR-based asphalts compared to other conventional CRM processing techniques.

\subsubsection{TB rubberized asphalt}

The rubber asphalt TB technology has been utilized in the USA since the 1980s. TB is proven to offer high stability in storage life as a result of the blended process which is similar to that of polymermodified asphalts. It is a product of the wet process. However, based on the California Department of Transportation (CALTRANS) specifications, TB holds a reduced rotational viscosity at $177^{\circ} \mathrm{C}$, typically $<1500 \mathrm{cP}$ compared to traditional wet process rubber asphalts (Davide Lo Presti, 2013; Davide Lo Presti et al., 2012). Additionally, TB offers improved aesthetics in its finished products with homogenous and smoother surfaces with less protruding particles compared to the wet process as illustrated in Fig. 9. Fundamentally, crumb rubber from 100 percent rubber tyre is digested and integrated into the asphalt binder at a stationary asphalt terminal, the constituent materials are heated extensively over a period of time before being transported to the hot mix asphalt plant as produced TB binder (Picado-Santos et al., 2020). Subsequent agitations are not necessary for TB binders to produce an evenly dispersed rubber tyre particle-matrix binder. Previously, TB combined finely ground CRM at a maximum of $10 \%$ by mass and some polymers to avoid the need for mechanical agitation. However, current studies report TB binders containing up to 15\% CRM by base binder weight (Davide Lo Presti, 2013; Davide Lo Presti et al., 2012). TB processing typically involves the use of 30-mesh maximum-sized CRM in modifying the base binder to ensure a rapid breakdown and stable dispersal of the crumb rubber by a normalized flow within the storage tank, rather than by auger or paddle agitation (Han et al., 2016).

The TB production process utilizes a non-stop blend-reaction system requiring no additional alterations or adjustments to the asphalt plants. In producing TB binders, special considerations are giving to the blend technique, mixing temperature, reaction period, and pressure. The typical process for producing TB binders is shown in Fig. 10. Firstly, the base asphalt is heated up to about $200^{\circ} \mathrm{C}$ then fed into the mixer alongside specified quantities of 30-mesh max CRM powder under a high shearing condition. The rate of shearing is usually about $3000-8000 \mathrm{RPM}$ for $40-60 \mathrm{~min}$, at a pressure higher than $1 \mathrm{~atm}$ (Davide Lo Presti, 2013). The characteristic swelling procedure of rubber asphalt is replaced by the devulcanization and depolymerisation of the rubber into the asphalt matrix, under a relatively high curing state, resulting in a smooth final binder product.

\subsection{Steel slag utilization}

Ebrahim and Behiry (2013) investigated the use of steel slag and aggregates of limestone to increase the strength and density of pavement subbase material while resisting stress, strain and deflection. Laboratory tests showed that increasing the percentage of steel slag in the blended mix increases the CBR, MDD and $M_{R}$. Optimal density and strength for subbase layer was obtained at 70\% slag mix blend. Resistance to vertical strain, radial stress and deflection was observed to increase with the addition of steel slag. A reduction in rutting and reduced rate of deformation of about $600 \mathrm{~mm}$ from the point of load impact with the addition of steel slag.

Chen et al. (2017) studied the application of reclaimed asphalt BOF slag as road base or subbase aggregate. CBR figures decreased with increasing percentage of RAP BOF aggregate. The CBR values 

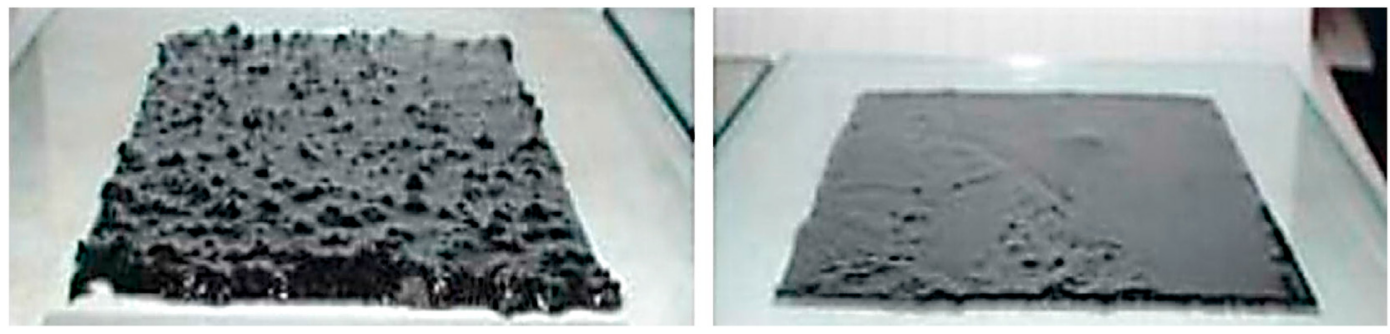

Fig. 9. Final surface of rubber asphalt wet process (left) and TB binder (right) (Source: Shatnawi, 2010).

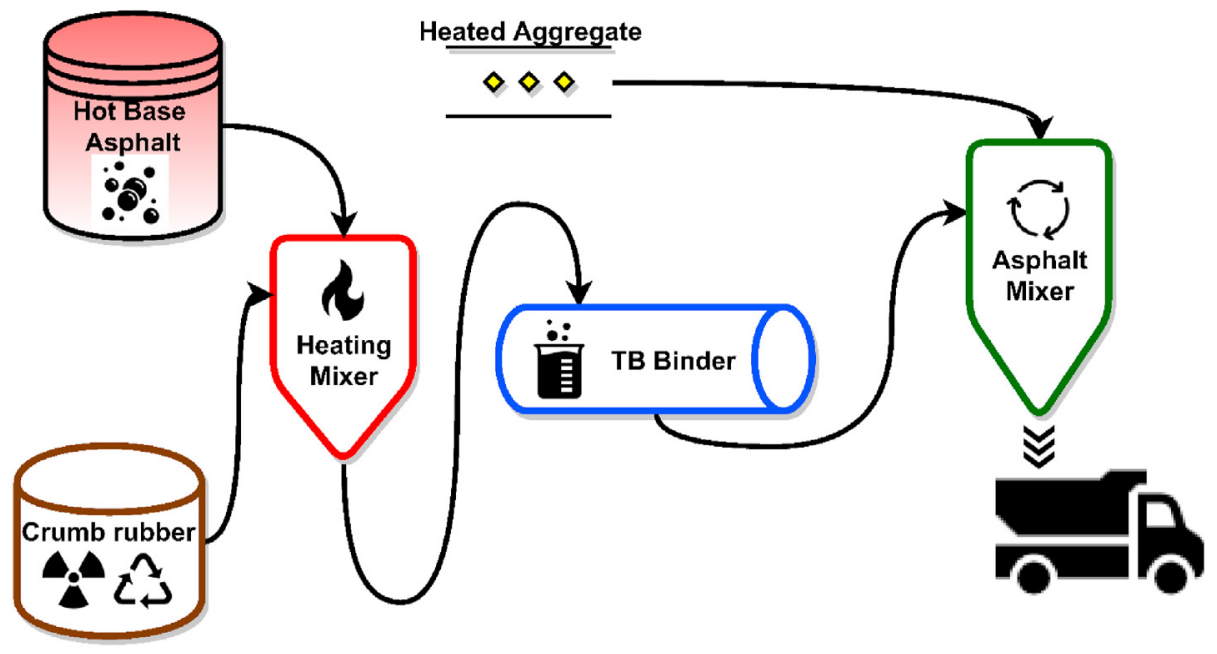

Fig. 10. Schematics for TB bound rubber asphalt production (Source: Wen et al., 2018).

obtained for samples with $0 \%, 20 \%$ and $40 \%$ RAP BOF met standard requirements for subbase and base course, while the $60 \%$ RAP BOF sample only met the required standard for subbase. Samples with $60 \%$ RAP BOF did not meet the expansion ratio standards of CNS15311for road subbase and base courses. When 95\% of the MDD was reached by the compaction, the CBR values got somewhat higher than the OMC. Higher values of internal friction of the samples was achieved as RAP BOF percentage increased. Optimal RAP BOF replacement value was seen to be $20 \%$ from laboratory tests.

Gao et al. (2017) studied the utilization of steel slag as aggregate in asphalt mixtures for microwave de-icing of pavement against freezing adhesion action between ice layers and pavement surfacing. Steel slag was seen to possess greater MH capacity when compared to limestone and conventional aggregate as a result of the high-level active $\left(\mathrm{Fe}_{2} \mathrm{O}_{3}\right.$ and $\left.\mathrm{FeS}\right)$ and hyperactive $\left(\mathrm{Fe}_{3} \mathrm{O}_{4}\right)$ components. Steel slag with particle size over $0.6 \mathrm{~mm}$ maintained a high level of surface temperature indicating particle size variation affects microwave heating capacity. The most effective sizes were determined to be $9.5 \mathrm{~mm}, 2.36 \mathrm{~mm}$, and $0.6 \mathrm{~mm}$. As a result of the porousness of steel slag, an increase in the content of steel slag significantly decreases the thermal conductivity of asphalt mixtures. Steel slag was seen to be advantageous in the microwave deicing of asphaltic pavement as it presents an environmentally friendly cost-effective approach compared to methods using carbon fiber, steel fiber and carbonyl iron powder.

Gökalp et al. (2018) examined the mechanical and physical characteristics of steel slag for use in pavement layers. The mechanical and physical properties of steel slag presented both superior and poorer features compared to natural aggregates (NA). Higher absorption of water and dry density was seen in slag and was considered as a poor characteristic. While the high resistance to fragmentation, abrasion, weathering and polishing were considered as superior qualities of slag. Images from SEM showed that slag has higher surface roughness compared to NA. The aggregate rupture potential was revealed from the affinity and adhesion tests. Hence to prevent chips loss, modification of bitumen with adjuvant is necessary. Gökalp et al. (2018) finally stated that the utilization of steel slag in surface courses provides a durable surface with high skid resistance leading to lower maintenance costs.

\subsection{Glass waste utilization}

A study by Kadhim et al. (2019) evaluated the effect of crushed fine glass aggregate (FGA) waste on the quality of cold bituminous mixtures (CBEM). The Retained Marshal Stability, Dynamic Stability and Wheel Track Tests, showed that FGA-CBEM samples had higher resistance than Hot Mix Asphalt (HMA) samples. On the other hand, results from the Indirect Tensile Strength (ITS), Marshall flow and stability test yielded relatively comparable values. All FGA-CBEM achieved ITS values of over $1 \mathrm{MPa}$, which is similar to nominal HMA. FGA-CBEM75\% samples yielded the closest ITS value to that of HMA. All FGA-CBEM samples had higher rutting resistance than HMA and met standard requirements. Lower density values were observed with increasing percentages of FGA in CBEM as a result of higher air voids.

A study by Saberian et al. (2019) was aimed at understanding the effect of crushed glass (CG) on the behavior of recycled pavement materials. Tests revealed that CG addition to the aggregates brought about a decrease in the workability of the mix. Dry CBR tests indicated that the increase in CG content led to increasing CBR values, with all CG samples meeting the least allowable CBR value for road base of $80 \%$. Increasing percentages of CG also resulted in 
increasing UCS values because of the reduced porosity level in the mix as well as the structure of the CG particles. The increase in the CG percentage increased the resilience modulus $\left(M_{R}\right)$. In the same vein, the addition of CG to other recycled crushed aggregates resulted in higher increases in $\mathrm{M}_{R}$.

Kurpinska et al. (2019) researched on the use of granulated expanded glass aggregate (GEGA) with cement grout in road construction. Volume density tests were performed on samples made with GEGA and samples made of natural fine aggregates (NATU) at 7 and 28 days, results showed that at 7 and 28 days, NATU had $1834 \mathrm{~kg} / \mathrm{m}^{3}$ and $1787 \mathrm{~kg} / \mathrm{m}^{3}$ respectively while GEGA recorded lower values of $832 \mathrm{~kg} / \mathrm{m}^{3}$ and $785 \mathrm{~kg} / \mathrm{m}^{3}$ respectively. Compressive strength test was also conducted, results showed that at 7,28 and 56 days, NATU gave $1.3 \mathrm{MPa}, 3.2 \mathrm{MPa}$ and $3.8 \mathrm{MPa}$ respectively while GEGA gave higher values of $1.9 \mathrm{MPa}$, 3.7 $\mathrm{MPa}$ and 4.9 MPa respectively. From the frost resistance (FR) tests, both groups of samples met the Polish Technical Requirement standards WT-5 2010 minimum value of 0.7. The NATU samples gave an FR index of 0.74 while the GEGA samples gave FR index of 0.94 . Results confirmed that GEGA material can be suitable as a frost protection layer for pavement sub-base and subgrade stabilization.

\subsection{Construction and demolition waste utilization}

Roque et al. (2016) assessed the leaching possibility of construction and demolition wastes in road pavements. Leachability batch-test performed on $C$ and $D$ and natural aggregate specimens showed that no component in $\mathrm{C}$ and $\mathrm{D}$ waste possess leaching values higher than the standard leaching limit of the Portuguese Decree-law 183/2009 for acceptable landfill and inert wastes. These results indicate that $C$ and $D$ waste materials are eco-friendly and can be adopted in the construction of pavement layers.

A study by Leite et al. (2011) as reported by Gautam et al. (2018) showed that the $C$ and $D$ materials exhibit a rougher surface texture, higher water absorption and lower specific gravity compared to natural aggregates of the same size, improving the aggregate-mortar adhesion in concrete. CBR tests gave average CBR of $73 \%$ and $117 \%$ for intermediate and modified effort respectively. The CBR of C and D aggregate increases as the compressive effort increases while the resilience displacement reduces by $10 \%-20 \%$. The results encouraged the use of $C$ and $D$ aggregates as an alternative for pavement construction.

Delongui et al. (2018) investigated the use of C and D waste parameters in pavement design. Tests showed that $C$ and $D$ waste presents good elastic strain and resilience modulus behavior compared to densely graded crushed basalt (DGCB). Material was seen to maintain moduli values between 200 and $300 \mathrm{MPa}$ for thin asphalt surface which is recommended for pavement design purposes. Shear strength tests revealed that $C$ and $D$ waste has internal friction angle of $41^{\circ}$ which is lower than that of DGCB $\left(58^{\circ}\right)$ and cohesion value of $136 \mathrm{kPa}$ similar to DGCB's value of $142 \mathrm{kPa}$. C and $\mathrm{D}$ wastes road bases will be safe against shear failure if used in road pavements for low to medium traffic volume.

Zhang et al. (2019) studied the use of C and D waste in highway embankments. The modulus of resilience and permanent deformation tests on $\mathrm{C}$ and $\mathrm{D}$ wastes proved its stress-dependent property. $C$ and D wastes yielded higher resilient moduli and permanent deformation values when compared embankment clayey soil. C and D wastes were used on the G95 Beijing expressway project as the only embankment fill material, this application was found to utilize a whole lot more of $C$ and $D$ wastes than any other. Hence, USCS and AASHTO soil classification rates recycled C and D wastes as excellent materials for embankment fill.

\subsection{Colliery spoils waste utilization}

Jung and Santagata (2014) studied the behavior of colliery spoils treated with calcium-based stabilizers. Expansion was noticed in all spoil-calcium mixtures. The final values of swelling strain (ranging between 5.2 and $12.1 \%$ ) exceeded values obtained from the untreated spoils. The swelling was attributed to the formation of new phases due to multiple reactions between chemicals. Existence of ettringite (expansion prone mineral formed in the presence of calcium, sulfate ions and alumina) was confirmed from XRD and TGA analysis. The highest swelling was seen in spoils sample treated with $3 \%$ hydrated lime. It appears that strain occurs as a result of the combination of the restraint induced by soil treatment and swelling pressures due to ettringite formation. Results showed that surface-induced swelling is likely to occur in subgrade materials made of colliery spoils of the study location.

Suescum-Morales et al. (2019) studied the use of colliery spoils as a subbase material for low traffic pavements. The spoils were composed mainly of quartz, silicates and coal. Based on the 2003/ $33 / \mathrm{EC}$, the spoils are classified as inert. Hence, no risk of environmental degradation by leaching of heavy metals. Colliery spoils was seen to possess plastic properties and is not suitable as unbound materials in road base course but can be used in road sub-base in both bound and unbound form. Combining spoils with cement as a bound material gives higher bearing capacity, whereas, the combination with lime is not recommended as it yields no increase in mechanical strength and bearing capacity.

\subsection{Fly ash waste utilization}

Rad and Modarres (2017) studied the durability of non-air entrained compacted rigid pavements made of fly ash in the presence of de-icing salts. Addition of FA up to 3\% partial cement replacement reduced the permeable void content. However, FA increase beyond 3\% had an opposite effect on the voids. Finer grades o FA and the chemical reaction between pozzolanic particles and $\mathrm{Ca}(\mathrm{OH})_{2}$ increased the transition zone resistance, reduced microcracks and reduced concrete permeability. Besides the control mix that showed resistance to intermediate surface scaling, the resistance of FA mixes was in accordance with the $\mathrm{W} / \mathrm{C}$ ratio. Mixes with $2 \%$ and $3 \%$ FA achieved more resistance to surface scaling than the control samples. In freeze-thaw conditions with the presence of de-icing salts, surface scaling decreased with water-binder ratio reductions. The optimum FA content was determined to be $3 \%$ by dry aggregate mass. Hence, recommended mix design is the mix composed of $11 \%$ cement and 3\% FA with W/C ratio of 0.41 .

Opiso et al. (2019) investigated the effect of fly ash and sawdust (SD) on the performance of pervious concrete. Results showed that mixes with FA and SD with a mix ratio of $1: 3: 5$ and $W / C$ ratio of 0.35 met the specified requirements for compressive, flexural and permeability as per National Ready-Mix Concrete Association (NRMCA). Laboratory tests revealed that cement usage could be minimized by up to $10 \%$ in FA-SD blended mixes without adversely affecting the strength and permeability of the composite. In-situ compressive strength tests on core samples gave acceptable values. Hence, the application of FA and SD as additives is proven to be a feasible and sustainable option and is encouraged in the performance improvement of pervious rigid pavement concrete.

Wang et al. (2019) studied the mixture of FA and coal wash (CW) in road pavement. Laboratory tests (including compaction, UCS, CBR and collapse potential) evaluated the reuse potential of CW and FA blends with $0 \%, 7 \%, 10 \%$ and $13 \%$ FA content as road base and subbase materials. FA was used as the void filler. Modified proctor compaction indicated that $7 \%$ addition of FA sufficiently increased the amount of fines, yielding a minimum void ratio in the blend. 
Further increase in FA content reduced compaction efficiency. The 7\% FA blend also yielded the highest UCS and lowest axial deformation at OMC compaction. CBR value greater than 100 was only achieved with the 7\% FA mix. The potential for collapse of all FA-CW mixes was within the acceptable range. Hence, no sudden and significant settlement is expected. All FA-CW mixes are found to be resistant to moisture infiltration with $5 \times 10^{-7} \mathrm{~m} / \mathrm{s}$ permeability value.

\subsection{Cement kiln dust waste utilization}

Arulrajah et al. (2017) studied the use of CKD and FA mixtures as binder in the stabilization of construction and demolition waste aggregates for construction. The $C$ and $D$ aggregate was classified as well-graded gravels. The MDD and OMC of all stabilized mixes were determined independently due to the high quantity of additive binders. Dry density values of all CKD-FA stabilized samples reduced significantly compared to unbound aggregates. Scanning electron microscope (SEM) images of CKD powder clumps showed that higher specific area of CKD results in increased water absorption during hydration causing reductions in OMC. Results show that CKD-FA binders performs better than individual CKD or FA binders. Elastic modulus and UCS test results had a high correlation in the CKD-FA while the dynamic modulus was increased with increasing CKD content.

Al-Homidy et al. (2017) assessed the use of CKD in the improvement of sabkha soil. The soil was classified as SM and A-3 based on USCS and AASHTO, respectively. Three batches of samples were created with soil $+2 \%$ cement mixed with CKD of $10 \%, 20 \%$, and $30 \%$ by dry soil weight. Soaked CBR tests showed that increasing the CKD content increases the CBR. CBR value of $11 \%$ was increased to $55 \%, 95 \%$, and $129 \%$ with CKD addition of $10 \%, 20 \%$, and $30 \%$, respectively. Durability tests per ASTM D559/D559M-15 showed that the $30 \% \mathrm{CKD}+2 \%$ cement samples meet the requirement for use as sub-base material in rigid pavement construction which lead to a $5 \%$ reduction in cement quantity thereby reducing costs. CKD samples without cement did not meet the Portland cement Association (PCA) and USA corps of Engineers (USACE) strength requirements and as such is not recommended.

Eberemu et al. (2019) used CKD and locust bean waste ash (LBWA) in the stabilizing black clay for pavement application. Laboratory results classified the soil as A-7-6 (13) and $\mathrm{CH}$ based on AASHTO and USCS, respectively. All Atterberg limits and indices (LL, PL and PI) improved with increased percentages of CKD and LBWA, all samples exceeded the $30 \%$ minimum value recommended for subgrade materials. The UCS and CBR increased with increasing CKD-LBWA content, the highest UCS value $\left(1621 \mathrm{kN} / \mathrm{m}^{2}\right)$ was achieved with $6 \%$ CKD+6\%LBWA but failed to meet the recommended value $\left(1720 \mathrm{kN} / \mathrm{m}^{2}\right)$ for cement stabilization. The highest CBR value was achieved with 6\% CKD and 6\%LBWA samples. The optimal blend recommended for treatment of black clay is the $6 \% \mathrm{CKD}+6 \%$ LBWA blend based on strength requirements for sub-base materials.

\subsection{Asphalt shingle waste utilization}

The essence of utilizing shingles in road construction is to minimize the quantity of asphaltic binder required for asphaltic concrete production. Researchers in the past have utilized these shingles with great success. Haas et al. (2019), in their study, evaluated the effect of Recycled Asphalt Shingles (RAS) on the asphalt binder mixture performance. They came up with a design method which took the stiffness of the RAS asphalt binder into consideration to help reduce the possibility of fatigue cracking. $13-18 \%$ replacement of the total asphaltic binder was done for performance grades (PG) of PG64-22 and PG76-22. The result obtained showed increased stiffness and resultant PG at high and intermediate temperatures.

Ding et al. (2019) also carried out a study on the utilization of recycled asphalt shingles in pavement by extraction method. During the evaluation, a broad span of asphaltic blends was prepared with three methods which include the extraction process, mixing of RAS binder with soft asphalt, and a mix of rejuvenator with RAS binder. An unmodified binder, known as PG 52-28 based on Superpave specifications, was chosen as the soft binder. Similarly, PG 64-22 unmodified asphalt was used for comparison with the RAS binder that was extracted while an abietic-acid-derived oil called Hydrogreen was used as a rejuvenator. Heptanol and Trichloroethylene were also mixed with the reclaimed asphalt shingles to dissolve it for easy extraction. According to the laboratory outcome, the introduction of this extract improved the antiageing properties of binder at the temperature range of $28-75.2^{\circ} \mathrm{C}$.

In another research carried out by Zhu et al. (2017), evaluation of fatigue performance was carried out on fine aggregate mix having recycled asphalt shingles. $15 \%$ of the reclaimed asphalt shingle mix was evaluated with the addition of rejuvenator and it was discovered that the fatigue performance improved appreciably.

\subsection{Aluminium dross waste utilization}

López-Alonso et al. (2019) did a laboratory study on the feasible use of recycled aluminium waste combined with recycled aggregates in road construction. Materials used for the study were concrete, mortar, unbound natural aggregates, and ceramics. Result showed that $\mathrm{Ca}^{-}$and $\mathrm{Al}^{-}$containing silicates were present in the aluminium waste-containing mixtures which accounts for improvement in the mechanical properties of the aggregates mixed with aluminium waste.

Similarly, Busari et al. (2018) investigated the Stabilizing effect of aluminium dross on tropical lateritic soil for pavement construction. Stabilization was achieved by adding the aluminium dross at $2 \%$ intervals starting from $2 \%$ to $16 \%$. From the analysis of the result, the addition of aluminium dross as a stabilizing agent helped in modifying the engineering properties of the soil sample. Also, the Atterberg's limits; the liquid limit, and the plastic limit increased from $43 \%$ to $54.61 \%$, and $28.02 \%-40.8 \%$, respectively, while the plasticity index reduced from $15.1 \%$ to $13.8 \%$ indicating improvement in the soil. The load-bearing capacity of the soil sample was also noticed to increase from $51.22 \%$ to $62.41 \%$.

In another work, Javali et al. (2017) utilized aluminium dross and iron slag as partial replacement materials for cement and sand in concrete. Samples were produced in various proportions containing cement, aluminium dross, and iron slag. Partial replacement of aluminium dross was done with $5-20 \%$ of the cement weight while the granular iron slag substitution was from 10 to $40 \%$. This mix was employed for analysing the strength and durability properties of M40 concrete. It was discovered that aluminium dross $-5 \%$ and iron slag $-20 \%$ gave close result to that of conventional concrete.

\subsection{Mine tailings waste utilization}

Ojuri et al. (2017), used mine tailings alongside lime-cement as stabilizing binder for weak lateritic soil. The binder was used in the ratio 1:2 and the Strength characteristics, as well as environmental impact, was assessed for the Lateritic Soil-Mine Tailings Binder Mix. From the results, it showed that with the addition of mine tailings, there was improvement in the geotechnical properties of the soil. It was also reported that the maximum dry density increased with a decrease in the optimum moisture content. The California bearing ratio and the unconfined compressive strength readings indicated 
an increase in strength of the weak soil.

Oluwasola et al. (2016) worked on the comparative evaluation of dense-graded and gap-graded asphalt mix incorporating copper mine tailings with electric arc furnace steel slag. In their study, an investigation was carried out to check how suitable electric arc furnace (EAF) steel slag and copper mine tailings (CMT) are, as alternative materials for asphaltic concrete. During the laboratory tests, sixteen mix designs were evaluated. Different mix ranging from $100 \%$ granite- $0 \%$ mine tailings, to $40 \%$ granite and $20 \%$ CMT. The test results showed that there was an improvement in rutting control and reduced susceptibility to permanent deformation.

Etim et al. (2017) worked on Stabilization of black cotton soil with lime and iron ore tailings (IOT) at $8 \%$ lime mixed with $10 \%$ IOT by dry weight of soil. They carried out tests on the index, compaction, strength and durability properties of the soil. It was discovered that the optimum percentage of $8 \%$ lime/8\%IOT gave improvement, meeting the criteria of $1034.25 \mathrm{kN} / \mathrm{m}^{2}$ required for apposite lime stabilization of soil.

\subsection{Bio-oil utilization}

A study by Zhang et al. (2017) evaluated the utilization of waste cooking oil in rejuvenating asphalt. The results indicated that the quality of the waste cooking oil significantly influenced the behavior of aged asphalt. In a study carried out by Zhang et al. (2019), bio-oil produced from sawdust was used as rejuvenator for aged asphalt binder recycling and its effect was analysed. In the research, the performance graded asphalts PG 58-28 and PG 64-22 were picked as the base binders. The bio-oil constituents were $10 \%$, $15 \%$ and $20 \%$ of the total binder by weight. Characterization of the properties of the bio-rejuvenated asphalts as well as virgin control asphalts mix was carried out through some basic tests. Result showed that, the bio-rejuvenator reduced the viscosity and activation energy, while the temperature susceptibility and the content of viscous components of the aged asphalts increased. The aged asphalt became softened by introduction of the bio-rejuvenator oil. Subsequently, the bio-oil restored the low temperature crack resistance of the aged asphalts PAV PG 58-28 and PAV PG 64-22 to a comparable value to that of virgin asphalts. Alattieh et al. (2020) assessed the performance of bio-modified asphalt binder with the use of bio-oil obtained from date seeds waste. The asphaltic concrete was prepared with $0.0 \%, 1.5 \%$, and $2.5 \%$ of date seed oil alongside bitumen of penetration grade of 60/70. Several rheological and other upgraded analysis were carried out at various temperatures to evaluate the various performance constants and correlate it to the Superpave specified requirements. The outcome of the study indicated that the fatigue resistance of the modified asphalt binder produced improved with the addition of the bio-oil obtained from date seeds wastes. Production of bio-asphalt from biodiesel was carried out by Santos et al. (2020) in their research. They evaluated the properties of derived bio-asphalt mix employing $2 \%-10 \%$ of the residue. It was noticed that the bio-oil at $6 \%$ mixed with the residue of asphalt gave a bio-binder with physical characteristics likened to a conventional 35/50 pen asphalt.

Ingrassia et al. (2020) worked on replacing bitumen partially with wood bio-oil at $80^{\circ} \mathrm{C}, 90^{\circ} \mathrm{C}, 105^{\circ} \mathrm{C}, 120^{\circ} \mathrm{C}, 135^{\circ} \mathrm{C}, 150^{\circ} \mathrm{C}$. They characterized the Chemical, morphology and rheology of the bitumen derived by mixing a conventional 50/70 bitumen with 0 , $5 \%, 10 \%$ and $15 \%$ of a viable bio-oil, created as a remnant in the conversion of wood into pulp and paper. From their result, it was discovered that the bio-oil showed a high performance, leading to improved low-temperature characteristics and fatigue resistance.

Abdel Raouf and Williams (2010) utilized the bio-oil derived from switchgrass as bio-binder for replacement of petroleum based asphalt binder. The properties of the bio-binders with 2 and $4 \%$ of each of the 3 polymer modifiers which consist of the blends of polyethylene with different properties and without polymer modifier were compared with that of the petroleum based asphalt binder. The test results showed that the increase in temperature resulted in increase in viscosity of the bio-oil binder which was similar to that of the control asphalt binder. Thus, the temperature had significant influence on the viscosity of the bio-oil blends than shear rate while the polymer modifiers also contributed to the change in rheological properties of the bio-oil blends. However, the effect of polymer type and blending percentage on viscosity temperature depend on the shear rate. Further, the activation energy values of the bio-binders were higher than that of control asphalt binder which indicate that the bio-binders are more susceptible to temperature changes than the control asphalt binder. It was concluded that switchgrass based bio-oil is a viable renewable alternative to petroleum based asphalt binder.

Mohammad et al. (2013) studied the effect of bio-oil derived from pine trees as replacement for petroleum-based asphalt binders. The bio-binders are produced by adding 20, 25.5, 30 and $50 \%$ bio-oil content. The laboratory tests carried out on the biobinder are rutting performance, moisture resistance, fracture performance test, modified lottman test, semi-circular bending test and thermal stress restrained test. The test results showed that the bio-binders exhibited similar or improved rutting resistance compared to the conventional asphalt binder. The addition of biooil reduced the fracture resistance of asphalt binder compared to the conventional asphalt binder. With respect to moisture susceptibility, all the binder mixture exceeded the $80 \%$ tensile strength ratio except the mixtures without anti-stripping agent. Furthermore, the low temperature fracture performance of asphalt binders with bio-oil was improved compared to those without bio-oil. It was concluded that the use of bio-oil derived from pine trees is effective for enhancement of petroleum-based asphalt binders.

Fini et al. (2012) investigated the use of bio-binder produced from thermochemical conversion of swine manure as an alternative to the conventional asphalt binder. Asphalt binder was modified with bio-oil at 2, 5 and $10 \%$ by weight of base binder to produce biomodified binders (BMB). The results revealed that BMB exhibited lower viscosity compared to base binder and the decrease in the viscosity is proportional to increase in the content of bio-oil. Also, the cracking temperature of base binder decreased as the bio-oil content increases. It was concluded that the addition of BMB with bio-oil derived from manure is effective for enhancing the performance of asphalt binder to an acceptable level.

Yang et al. (2014) evaluated the mechanical performance of asphalt binder modified with bio-oils derived from waste wood resources. The properties petroleum asphalt binders replaced by the three different types of bio-oils (original bio-oil, dewatered biooil and polymer-modified bio-oil) at 5 and $10 \%$ by weight of base binder were compared with unmodified asphalt binder. The results showed that the modulus of elasticity of the modified asphalt binders were higher compared to unmodified asphalt binders which indicate that the presence of bio-oil increased the stiffness of petroleum asphalt binders. In addition, the rutting depth and fatigue life of the modified asphalt binders were higher compared to unmodified asphalt binders. It was concluded that bio-oil derived waste wood resources is a good extender and modifier for petroleum asphalt binder when it is added in low quantity.

Azahar et al. (2016) further explored waste cooking oil as bitumen modifier. The outcomes revealed that the mechanical performance of bituminous blends improved at $5 \%$ of waste cooking oil addition level. Many other studies have been performed on the utilization of waste cooking oil in the modification of the chemical, physical, and rheological characteristics of binders in bioasphalt. The conclusions drawn from these studies indicates a minimal optimum content of waste cooking oil. Also, pre-treatment 
of waste cooking oil before addition to bituminous mixes was highly recommended (Al-Sabaeei et al., 2020; Jalkh et al., 2018; Setyawan et al., 2016; Sun et al., 2016).

The use of Castor oil in modifying the properties of asphalt binders have also been explored. A little amount of castor oil improved the visco-elastic and physical properties of asphalt binders with respect to viscosity, penetration index, and softening point, among other parameters. Nonetheless, larger quantities of castor oil influenced the rheological and physical properties of binders negatively, while atomic force microscopy additionally revealed an improvement in the binders' susceptibility to thermal and rheological variations (Nayak and Sahoo, 2017; Zeng et al., 2016). Canola oil was also utilized as a modifier for bitumen. In such studies, the incorporation of canola oil reduced the asphalt binder's rotational viscosity, which further led to a decrease in the mixing and compaction temperature requirement; Additionally, it was observed that with increasing percentages of oil content, the asphalt's performance at high temperatures declined, while the performance at lower temperatures was enhanced (Babadagli and Ozum, 2012; Sun et al., 2016a). Raman et al. (2015) investigated the use of bio-oil from the pyrolysis of empty bunches of palm fruit as a modifier. The resultant bio-asphalt exhibited higher softness compared to conventional asphalt with increasing percentages of bio-oil. Also, blends with lesser quantities of bio-oil yielded considerable declines in the grade of asphalt.

The combined utilization of sunflower and soybean oil was assessed as asphalt modifier, the resultant bio-asphalt turned out to be considerably softer than natural asphalt, also, the resistance to cracking at reduced temperatures was improved (Król et al., 2016; Somé et al., 2016). Bio-oil from linseeds was utilized in rejuvenating aged asphalt binder, here, the ageing behavior of reclaimed asphalt was bio-restored; as such, studies concluded that linseed bio-oils showed the potential fir use as binder for fresh asphalt (Barco Carrión et al., 2017; Podolsky et al., 2017). The utilization of bio-oil from pine wood alongside resin resulted in the improvement of asphalt binder due to the reduced temperature of the rejuvenated bio-binder (Porot et al., 2017; Yang et al., 2017). The rheological characteristics of corn stover-based bio-asphalts were adversely influenced after ageing, even though these characteristics were said to be unaffected in the pre-ageing stage (Fini et al., 2017). Furthermore, pongamia oil utilized as a rejuvenator for aged asphalt's rheological, chemical and thermal behaviours. The results showed that at a $5 \%$ bio-oil addition level, the rutting and fatigue resistances were more desirable compared to natural binders. Nonetheless, it was emphasized that the results can only be confirmed sequel to mix performance assessments (Nayak and Sahoo, 2017). Bio-oils from soap stock was incorporated improve the adhesion property of biobinders obtained from vegetable oils. Here, improvements in the adhesion behavior of bitumen was achieved with oil contents between $0.9 \%$ and $1.1 \%$ (Pivsaev et al., 2015).

\subsection{Incineration bottom ash utilization}

Mohamedzein and Al-Aghbari (2012) investigated the influence of the use of municipal solid waste incineration ash for stabilization of Dune sand. The soil mixtures were prepared by adding $10,20,30$, $40,50,60,70$ and $80 \%$ incineration ash by dry weight of Dune sand. The laboratory tests carried out were compaction test, unconfined compressive strength test, direct shear box test and hydraulic conductivity test. The results revealed that the optimum moisture content the sand increased with increase in incineration ash content while the maximum dry density was relatively constant up to $30 \%$ replacement level before increasing with higher content of incineration ash in sand. The unconfined compressive strength and angle of friction increased up to 30\% replacement level before decreasing with higher content of incineration ash in sand. Further, the cohesion decreased for all the contents of incineration ash added to sand. However, low hydraulic conductivity values were found for all the sand admixed with incineration ash. Therefore, the optimum content of incineration ash in the range of $30-40 \%$ was suggested as the most suitable for stabilization of Dune sand.

Toraldo et al. (2013) evaluated the suitability of stabilized bottom ash obtained by treating unsorted municipal solid waste in hybrid-supplied incinerator and stabilized at $1200{ }^{\circ} \mathrm{C}$ for $12 \mathrm{~h}$ for bound layers of road pavement. The cement-bound mixes prepared consist of 4 amounts of stabilized bottom ash at $0,10,20$ and $30 \%$ on dry weight basis and 3 amounts of cement at $0,3,4$ and $5 \%$ on dry weight basis. The properties of asphalt concretes produced from cement-bound mixes investigated were voids, self-compacting and workability, Marshall Stability and stiffness, elastic stiffness, unconfined compressive strength, indirect tensile strength and leaching behavior. The results showed the asphalt concrete containing the cement-bound mix with $10 \%$ stabilized bottom ash and $5 \%$ cement contents satisfied the requirement for road pavement application based on the tests results. Furthermore, the leachate from stabilized bottom ash contained the parameters which are in the acceptable range and exhibited satisfactory performance for road pavement application. Thus, the optimum of with $10 \%$ stabilized bottom ash and $5 \%$ cement contents was specified for use as the cement-bound mixes in aspalt concrete.

Luo et al. (2017) studied the properties of open-graded asphalt concrete containing incinerator bottom ash. The aggregate mixtures were prepared by replacing the fine aggregate with incinerator bottom ash at $0,20,40,60,80$ and $100 \%$ on dry weight basis and the maximum asphalt content was evaluated for the optimum aggregate mixture. The laboratory tests carried out on open-graded asphalt concrete with and without incinerator bottom ash were indirect tensile strength test, static creep, dynamic creep, tensile strength ratio and resilience modulus test. The results showed that the open-graded asphalt concrete with incinerator bottom ash exhibited higher indirect tensile strength and tensile strength ratio compared to the control without incinerator bottom ash. The static creep of open-graded asphalt concrete with incinerator bottom ash were also higher compared to the control and the highest value was found for open-graded asphalt concrete with $80 \%$ incinerator bottom ash. In contrast to static creep, decreasing trend was observed for dynamic creep compared to the control and the lowest found for open-graded asphalt concrete with $80 \%$ incinerator bottom ash. This implied that the presence of incinerator bottom ash in opengraded asphalt concrete is effective in reducing the rutting deformation caused by dynamic loadings. It was concluded that the incinerator bottom ash should be less than $80 \%$ to reduce the risks of degrading the engineering properties and durability of opengraded asphalt concrete.

\section{Sustainability implications of waste utilization}

The utilization of waste materials in the road construction industry poses certain implications on the state of sustainability especially in the environmental, economic, and performance aspects. These implications are discussed in this section.

\subsection{Environmental implications}

Based on the fact that nearly $93 \%$ of paved roads worldwide are flexible pavements, polymer-based waste materials such as PET and SBS are suitable for the modification of asphaltic concrete (Sojobi et al., 2016). As such, the adoption of these materials in the construction and rehabilitation of flexible pavements will meaningfully ease-out numerous metric tons of PET and SBS from the 
surrounding environment. Thereby resulting in reduced pollution from littered plastics and rubber, improved capacity of drainage systems, sustained serviceability of landfills, and most importantly, conservation of natural aggregates. This can also enhance the balance in the ecosystem as a significant fraction of non-biodegradable waste is removed. Hence, preventing polymer-bioaccumulation in the food chain. Table 1 presents prospects and pitfalls of the utilization of selected waste materials on the environment. However, to adequately quantify the environmental implications of reutilizing solid wastes in highway facilities over its whole design life, life cycle appraisal techniques are developed.

\subsubsection{Life cycle appraisal (LCA)}

The life cycle of a highway facility includes production of raw materials, construction, utilization, maintenance and rehabilitation, and end-of-life stages as illustrated in Fig. 11. ISO 14044 describes LCA as an assessment technique scientifically adopted in the quantitative analysis of the environmental implications of a specified system over its entire design life cycle, from the stage of extraction of raw materials to the stage of final disposal (Balaguera et al., 2018; Li et al., 2019). The process of LCA entails four distinct phases as illustrated in Fig. 11. Phase 1 defines clearly, the goal and scope, indicating the necessity and expected outcomes of the assessment, while presenting a description of the project with respect to the set boundaries, units of functionality, and period of analysis (Finnveden et al., 2009). All inputs and outputs are linked to the functional unit. It forms the basis for the comparison of LCA results for different project alternatives. Dependent on the application intended, the set boundaries guide the determination of unit processes to be incorporated in the LCA, the established hypothesis, and minimum conditions. The period of analysis significantly affects the LCA outcomes as a result of the amount of energy consumed during the operating activities. Furthermore, it is essential to consider highly, the quality of data, as it controls the credulity of the results from LCAs. To increase the dependability of LCA results, while supporting reproducibility, it is encouraged that all assumptions and constraints encountered during the LCA be specified (Li et al., 2019).

Phase 2 involves an analysis of the life cycle inventory (LCI). The LCI is focused on sourcing and collection of data, curation, computation of all input and output in the project boundaries, and apportionment. The inputs of the LCI analysis phase are constituted by these results. Three common techniques are adopted in LCI: 1) the process $\mathrm{LCI}, 2$ ) the input/output $\mathrm{LCI}$, and 3 ) the fusion $\mathrm{LCI}$ (Zhang et al., 2011). The conventional method is the process LCI, it was established by the US EPA and the Society of Environmental Toxicology and Chemistry (SETAC). It is aimed at environmentally quantifying each input and output of all the separate processes within the project's life cycle boundaries. Input/output LCI is an enhanced approach which was first used in 1998. It incorporates the entire supply chain for the construction of a specified project under varying economic situations and on the basis of economic input/output principles. The fusion LCI is a hybrid technique that involves the combination of process and input/output LCIs. It is essential to note that these different techniques can influence the LCA results significantly as a result of their difference in approach (Balaguera et al., 2018).

Phase 3 involves the life cycle impact evaluation (LCIE). LCIE is focused on deeply understanding the environmental implications of LCI results by regrouping its outputs under various categories of impact, such as acidification and global warming potential. LCIE constitutes three essential aspects: 1 ) impact category selection, 2) allotment of $\mathrm{LCI}$ results to the different impact categories selected, and 3 ) the modelling of indicators for selected categories. In some cases, optional aspects such as grouping, normalization, and weightage are also incorporated in the LCIE stage depending on user preference and project specifications (Park et al., 2019).

The final phase is interpretation, its principal function is to identify, summarize, and appraise the LCI AND LCIE outputs, in order to establish inferences for the assessed projects. The interpretation phase generally consists of three aspects: 1) the identification of sensitive issues with regards to results from the $\mathrm{LCI}$ and LCIE, 2) appraisal of the criticality of the issues highlighted, alongside completeness and consistency checks, and 3) establishment of conclusions, limitations, and recommendations for the project (Li et al., 2019).

4.1.1.1. LCA types for pavements. Three LCA types as illustrated in Fig. 12 are associated with the reutilization of solid waste materials in road pavements. They include: 1 ) the cradle-to-gate, which only covers the stages of material extraction and construction; 2) the cradle-to-grave, covering from extraction of materials to the endof-life disposal stage and; 3 ) the cradle-to-cradle, a closed loop which further ensures that the solid waste generated both during the construction and end-of-life stages are reutilized in new constructions rather than being landfilled (Li et al., 2019).

Table 1

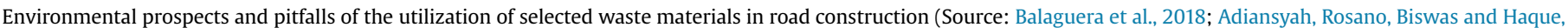
2017).

\begin{tabular}{|c|c|c|}
\hline Material & Prospects & Pitfalls \\
\hline PET/Waste rubber tire & $\begin{array}{l}\text { Reduction in emission of gases during construction as a result } \\
\text { of reduced usage of raw materials. } \\
\text { Reduced effect on landfills } \\
\text { Availability in large quantity for mass usage }\end{array}$ & $\begin{array}{l}\text { Rubberized asphalt may be of higher costs as its processed at higher } \\
\text { temperatures. } \\
\text { Requires more resources for its conversion into suitable material for asphalt } \\
\text { mix. }\end{array}$ \\
\hline Glass waste & $\begin{array}{l}\text { Reduces adverse effects of recycling for new glass products on } \\
\text { the environment. } \\
\text { Reduced usage of conventional materials }\end{array}$ & $\begin{array}{l}\text { Reduced energy conservation; glass usage as alternative aggregate requires } \\
\text { extra energy thus, more } \mathrm{CO}_{2} \text { emission compared to landfilling. }\end{array}$ \\
\hline $\begin{array}{l}\text { Recycled C and D waste, } \\
\text { asphalt shingles }\end{array}$ & $\begin{array}{l}\text { Reduces the exploration of natural materials and } \\
\text { indiscriminate disposal in landfill. } \\
\text { Global warming potential (GWP) and energy consumption } \\
\text { decreases }\end{array}$ & $\begin{array}{l}\text { Possibility of soil contamination from pollutant leaching from asphaltic } \\
\text { pavements. } \\
\text { High tendency of cracks occurring under very cold climates. }\end{array}$ \\
\hline Steel slag & Reduced environmental pollution as landfill material & Increased energy required in the process of crushing. \\
\hline Fly ash & $\begin{array}{l}\text { Reduced effect on GWP and less acidification potency. } \\
\text { Natural resource conservation and reduced disposal in landfill. }\end{array}$ & Uncertainty in the characterization and concentration of leachate emission. \\
\hline $\begin{array}{l}\text { Colliery spoils/CKD/other } \\
\text { Industrial solid wastes }\end{array}$ & $\begin{array}{l}\text { Reduces the consumption of natural aggregates, asphalt } \\
\text { processing, and accrual in landfills and water streams. }\end{array}$ & Groundwater and soil pollution from leaching of heavy metals. \\
\hline Mine Tailings & $\begin{array}{l}\text { Reduces the exploration of natural materials and } \\
\text { indiscriminate disposal in landfill. }\end{array}$ & Land and water contamination, habitat fragmentation. \\
\hline
\end{tabular}




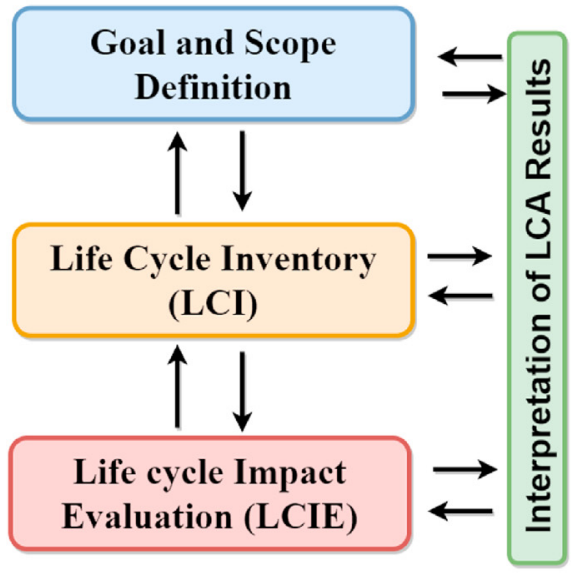

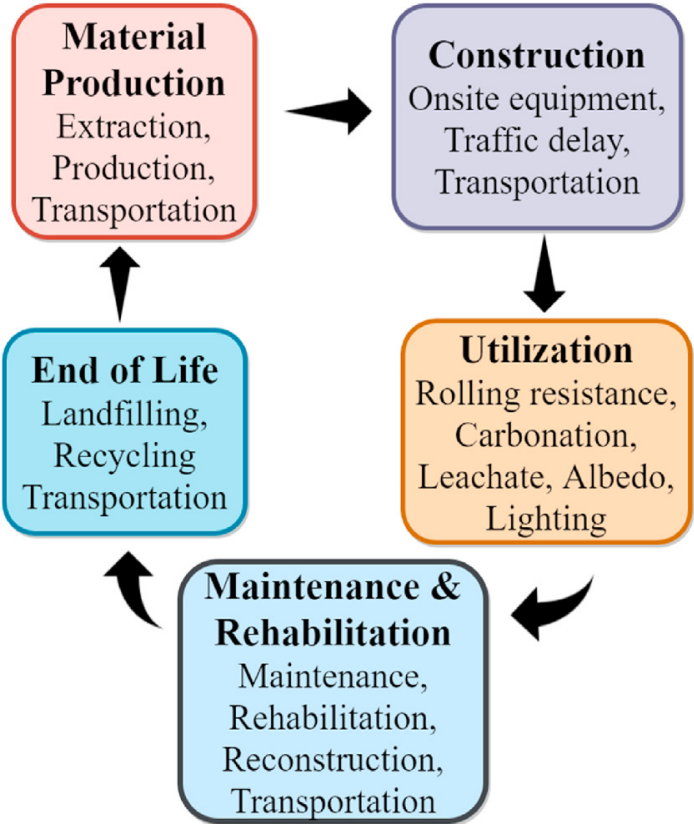

Fig. 11. [a] LCA process [b] life cycle of a typical pavement (Source: Balaguera et al., 2018; Li et al., 2019).

4.1.1.2. LCA tools for highway facilities. Several tools and computer programs have been developed for highway facility LCA by different institutions in the past few decades. These tools differ from basic spreadsheets in which data is inputted manually, to fully automated computer programs. A synthesis of the widely adopted highway LCA tools is presented in Table 2.
4.1.2. LCA implications on highway construction with waste materials

4.1.2.1. LCA on waste glass reutilization. As stated earlier, waste glass can be utilized in road construction. Huang et al. (2009) assessed the environmental impacts of the glass waste recycled along a portion of the Heathrow 5th Terminal pavement in London. A 30,000 square meter functional unit of asphalt surfacing was adopted. The LCA results showed that the production of natural aggregate, bitumen, and asphalt led to energy consumptions of

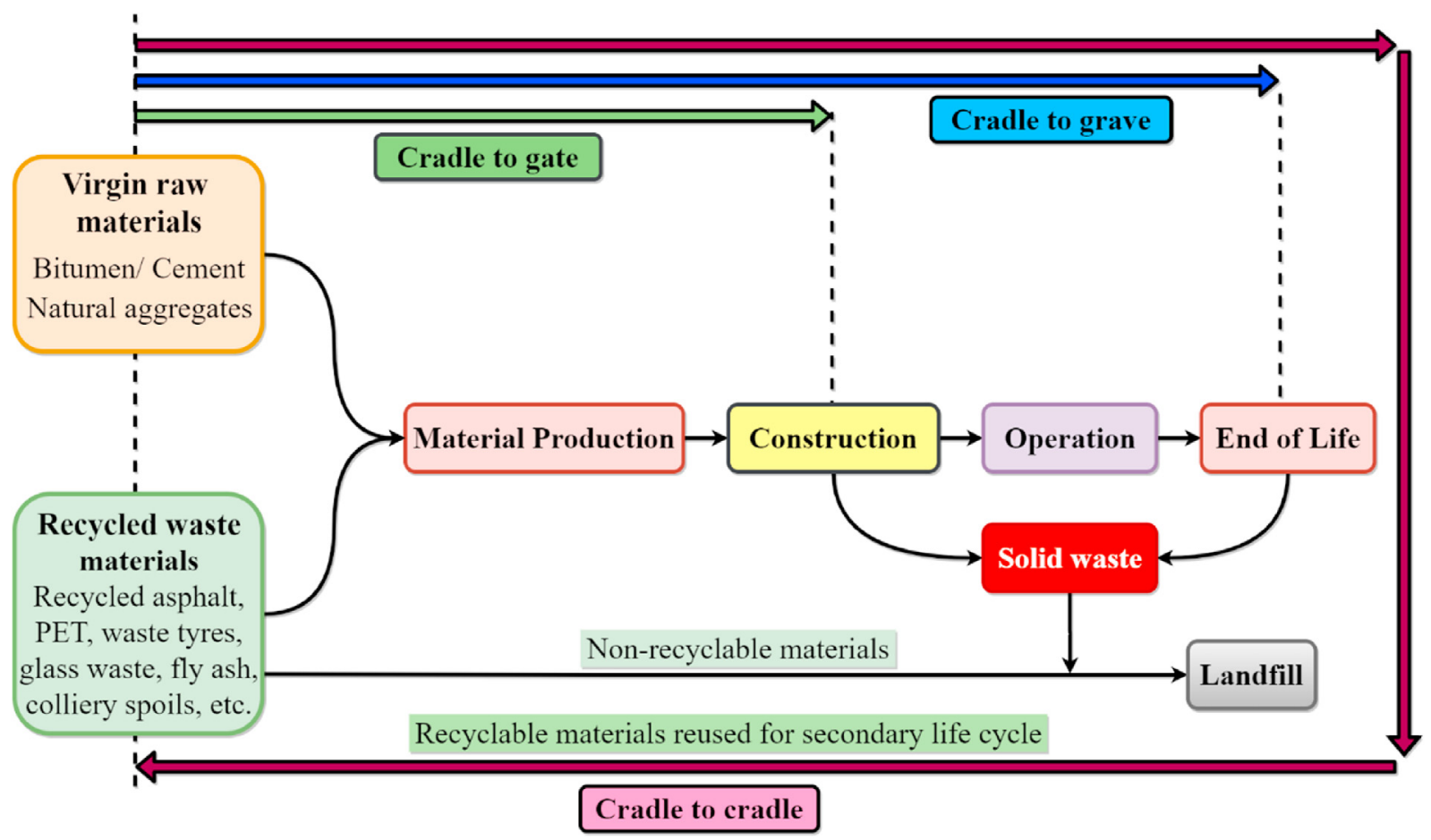

Fig. 12. Flowchart for three typical pavement LCAs (Adapted from Li et al., 2019). 
about 6, 23, and 62\%, respectively, and increased emissions. Whereas, it was noticed that the reutilization of waste glass reduced the asphalt production energy consumption level by about $7 \%$. However, waste glass integration was noticed result in higher energy usage and emissions, due to the increased rate of fuel consumption during collection (glass waste: $442 \mathrm{MJ} /$ ton against natural aggregate: $42 \mathrm{MJ} /$ ton). Furthermore, the quantity of natural aggregates used reduced, 579 tons of glass waste was used instead of 5766 tons of aggregate. The global warming potential (GWP) was also less with glass waste mixture (869 tons- $\left.\mathrm{CO}_{2}\right)$ compared to mixes with natural aggregate ( 888 tons- $\mathrm{CO}_{2}$ ) (Huang et al., 2009).

Another LCA by Chiu et al. (2008) considered the reutilization of waste glass under an analysis period of 40 years. Results indicated an increase in the potential adverse environmental impacts of by $19 \%$ with the utilization of waste glass. The identified increase was ascribed to the reduced durability and higher frequency of maintenance and rehabilitation operations when glass waste is incorporated. Consequently, the production of new HMA overlay required higher temperatures and more binder content which largely resulted in the increased environmental burden (Chiu et al., 2008).

4.1.2.2. LCA on waste tire reutilization. Generally, waste tires have been reutilized as 'ground tire rubber' or 'crumb rubber' additives in asphaltic and cement concrete pavements (via the wet or dry process). An LCA reported by Farina et al. (2017) on HMA mixtures with crumb rubber incorporated showed that crumb rubber modified HMAs required much higher temperatures than conventional HMAs. However, the integration of crumb rubber showed the potentials of reducing the maintenance and rehabilitation requirements, and extension of the pavement's serviceable life. LCA results further indicated that crumb rubber integration reduced the adverse life cycle environmental impacts by up to $23 \%$. The crumb rubber-based mixtures produced via the wet process yielded considerable advantages compared to the control mixtures. These advantages include: reduced energy consumption and global warming potential during the phases of material production and construction in the range of 36\%-45\%. Nonetheless, when adopting the dry process, no substantial impact was noticed. As such, from an environmental stand point, the wet process was recommended (Farina et al., 2017).

4.1.2.3. LCA on $C$ and $D$ waste reutilization. The most common applications of reutilized asphalt pavements include: hot in-place recycling, hot in-plant recycling, cold in-place recycling, cold inplant recycling, and asphalt reuse as illustrated in Fig. 13. Among these applications, asphalt reuse is seen as a down-cycling technique because it involves the reutilization of RAP as unbound materials in the subbase and base layers of pavements, leading to reduced performance and functionality (Anthonissen et al., 2016; Harvey et al., 2010). Cold in-place recycling incorporates both surface layer and full-depth recycling of asphaltic pavements (Xiao et al. 2018). A comparative LCA was conducted on cold in-place recycled and conventionally constructed pavements. The LCA results from the phases of material production and construction indicated that cold in-place recycling offers reduced impacts on the environment. Energy consumed, acidification, and abiotic depletion was seen to be lessened by $16 \%, 18 \%$ and $15 \%$, respectively. Nonetheless, the potential for global warming had very slight variation, with the conventional alternative having preferred impact on GHG emissions (Turk et al. 2016).

Hot in-place recycling entails either of the following: 1) Remixing by heating, lacerating, blending with fresh asphalt and laying out on the exact roadway as a new layer. 2) Repaving by heating up the existing asphalt layer, lacerating, and then levelling the surface prior to the addition of a fresh layer of HMA (Li et al., 2019). An LCA by Miliutenko et al. (2013) assessed hot in-place recycling and hot in-plant recycling. LCA results proved that both

Table 2

Synthesis of the widely adopted highway LCA tools.

\begin{tabular}{|c|c|c|c|c|}
\hline Tool & Year & Developer & Description & Reference \\
\hline $\begin{array}{l}\text { ECO-comparator for Road Construction } \\
\text { and Maintenance (ECORCE) }\end{array}$ & 2014 & $\begin{array}{l}\text { French Institute of Science and } \\
\text { Technology in Transportation, } \\
\text { Planning and Networks }\end{array}$ & $\begin{array}{l}\text { A tool that uses the JAVA platform for assessing environmental } \\
\text { impacts of highway construction and maintenance, aimed at } \\
\text { material, water, and energy conservation }\end{array}$ & $\begin{array}{l}\text { Jullien et al. } \\
\text { (2015) }\end{array}$ \\
\hline Eco-friendly concrete (EcoConcrete) & 2013 & Joint Project Group & $\begin{array}{l}\text { An interactive spreadsheet-based tool for environmentally } \\
\text { quantifying the life cycle of rigid pavements }\end{array}$ & $\begin{array}{l}\text { Evangelista } \\
\text { and De Brito } \\
(2007)\end{array}$ \\
\hline Project Emission Estimator (PE-2) & 2012 & Michigan Technological University & $\begin{array}{l}\text { A project-based tool for pavement greenhouse gas emission } \\
\text { monitoring }\end{array}$ & $\begin{array}{l}\text { Mukherjee } \\
\text { and Cass } \\
(2012)\end{array}$ \\
\hline $\begin{array}{l}\text { Asphalt Pavement Embodied Carbon Tool } \\
\text { (AsPECT) }\end{array}$ & 2012 & Transport Research Laboratory & A tool for determining $\mathrm{CO}_{2}$ equivalent emissions in asphalt mixtures & $\begin{array}{l}\text { Nicuț;ă } \\
(2011)\end{array}$ \\
\hline Roadprint & 2012 & University of Washington & $\begin{array}{l}\text { An online open-access tool for new and renovated pavements, } \\
\text { basically a version upgrade for PaLATE }\end{array}$ & $\begin{array}{l}\text { Muench et al. } \\
\text { (2014) }\end{array}$ \\
\hline Beneficial Reuse Model (BenReMod) & 2009 & Raja Chowdhury \& Defne Apul & Adopted for LCA concerning reutilized materials in pavements & $\begin{array}{l}\text { Li et al. } \\
\text { (2019) }\end{array}$ \\
\hline $\begin{array}{l}\text { Calculator for Harmonized Assessment } \\
\text { and Normalization of GHG Emissions } \\
\text { for Roads (CHANGER) }\end{array}$ & 2009 & International Road Federation & $\begin{array}{l}\text { A computation tool to monitor, measure, evaluate, and normalize } \\
\text { GHG emissions resulting from road construction processes. }\end{array}$ & $\begin{array}{l}\text { Huang et al. } \\
\text { (2013) }\end{array}$ \\
\hline $\begin{array}{l}\text { Road construction and residue disposal } \\
\text { (ROAD-RES) }\end{array}$ & 2005 & Technical University of Denmark & $\begin{array}{l}\text { A tool that is focused on the utilization of the remains from waste } \\
\text { incineration processes }\end{array}$ & $\begin{array}{l}\text { Muench } \\
(2010)\end{array}$ \\
\hline $\begin{array}{l}\text { Pavement Life cycle Assessment Tool for } \\
\text { Environmental and economic Effects } \\
\text { (PaLATE) }\end{array}$ & 2003 & University of California, Berkeley & $\begin{array}{l}\text { A Microsoft excel-based LCA tool for pavement environmental and } \\
\text { economic impact evaluations. }\end{array}$ & $\begin{array}{l}\text { Muench } \\
(2010)\end{array}$ \\
\hline Athena Impact Estimator & 2002 & $\begin{array}{l}\text { Athena Sustainable Material } \\
\text { Institute }\end{array}$ & $\begin{array}{l}\text { An open source computer program for measuring and providing LCA } \\
\text { results for highway construction and maintenance in the US and } \\
\text { Canada }\end{array}$ & $\begin{array}{l}\text { Stek et al. } \\
(2011)\end{array}$ \\
\hline Elementary Road Modulus (ERM) & 1998 & $\begin{array}{l}\text { Central Laboratory of Bridges and } \\
\text { Roads }\end{array}$ & $\begin{array}{l}\text { A parameter-based environmental assessment tool that replicates } \\
\text { conventional LCA and adapts it to the highway framework. }\end{array}$ & $\begin{array}{l}\text { Hoang et al. } \\
(2005)\end{array}$ \\
\hline $\begin{array}{l}\text { Tool for Reduction and Assessment of } \\
\text { Chemical and other environmental } \\
\text { Impacts (TRACI) }\end{array}$ & 1995 & $\begin{array}{l}\text { US Environmental Protection } \\
\text { Agency }\end{array}$ & $\begin{array}{l}\text { An LCA software package built on the basis of SimaPro with specified } \\
\text { locations in the US as input parameters. }\end{array}$ & Bare (2011) \\
\hline
\end{tabular}




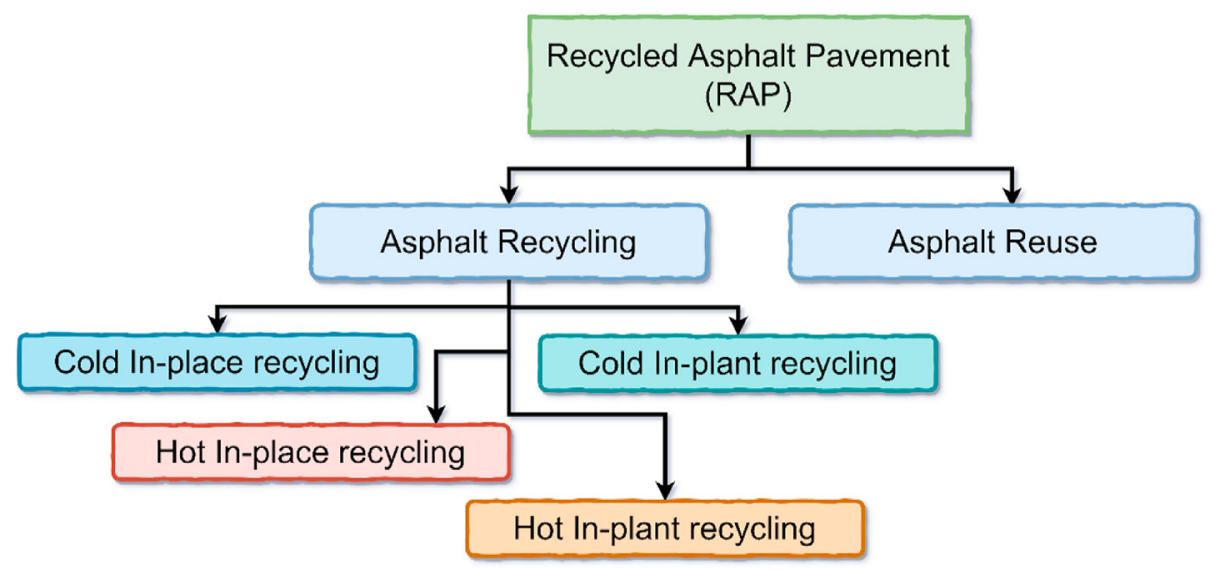

Fig. 13. Applications of reutilized asphalt pavements.

methods significantly lessened environmental impacts. However, the hot in-place technique performed preferably in terms of global warming potential and energy consumption (Miliutenko et al., 2013). Another study by Aurangzeb et al. (2014) employed the hybrid LCA, considering the phases of material production, construction, and maintenance to evaluate the environmental impacts of RAP blends with of up to $50 \%$. The LCA results showed substantial decreases in energy usage and emission of GHG with increasing contents of RAP. The study further revealed that the construction phase had the least environmental impact among the phases evaluated (Aurangzeb et al., 2014).

Since the asphalt reuse technique requires no further processing, there are only a few existing literatures addressing its life cycle impacts on the environment, as the recycling techniques are more preferable. However, Miliutenko et al. (2013) performed an LCA comparing the asphalt reuse and asphalt recycling methods. The LCA results indicated no efficiency in terms of global warming potential and energy consumption (Miliutenko et al., 2013).

As for Recycled Concrete Pavements (RCP), which are extensively adopted as aggregates in road subbase and base courses, it was observed that reusing RCP decreases the environmental burdens of pavement construction, compared to conventional materials (Mroueh et al., 2000). Contrary to this, in 2010, another study concluded that the use of RCP offered greater impacts in terms of global warming potential, energy usage, and acidification potential compared to conventional materials (Chowdhury et al., 2010). Notwithstanding, these results were only valid under the specified functional units, haulage distance and construction conditions. As such a further LCA on the impact of haulage distance were conducted. These study showed that with a haulage distance ratio greater than 1:4 for RCP to conventional materials, RCP offers reduced environmental impacts compared to conventional aggregates (Chowdhury et al., 2010; Marinković et al. 2013).

4.1.2.4. LCA on asphalt shingle utilization. Another extensively reused solid waste is RAS. In existing literatures on LCA, RAS generally, was reutilized alongside RAP, and this is majorly resultant of the fact that both waste materials are basically composed of solid fractions held together by bituminous binder. A comparison of the environmental burdens of different recycled mixtures incorporating RAS and RAP at varying ratios to natural aggregates was conducted by Booz et al. (2013). The LCA results presented in Fig. 14 revealed that there were considerable environmental advantages associated with the combined incorporation of RAS and RAP into asphaltic blends for road construction, yielding reductions in GHG emissions of up to $16 \%$ with the $20 \%$ RAP $+7 \%$ RAS blend (Booz et al.,
2013). Yang et al. (2015) conducted a similar LCA considering all the phases of an asphaltic pavement's life cycle. The result from the LCA presented in Fig. 15 indicates that in comparing the recycled asphalt blends with asphalt-binder (A/B) ratios of $25 \%-60 \%$, to natural aggregate mixtures, the energy consumption and GHG emission was generally reduced with higher asphalt-binder ratios (Yang et al., 2015).

4.1.2.5. LCA on steel slag and fiber reutilization. Steel slag have been reutilized as partial substitutes for coarse aggregate in asphaltic blends. The prime benefits of this practice were associated with the reduced pressures on landfills and conservation of natural minerals. An LCA conducted by Mladenovič et al. (2015) showed that EAF slag aggregate production consumed less energy compared to conventional aggregates, which indicated a substantial decrease in the environmental impacts. Nonetheless, because of steel slag's high porosity, larger amounts of asphalt of asphalt were needed. Furthermore, the ready-mixed asphalt blend had a higher mass, which led to an increased rate of fuel consumption during material haulage. As such, a slight advantages were observed with the slagbased asphalts in terms of energy usage, global warming potential, abiotic and ozone layer depletion, and photochemical oxidation (Mladenovič et al., 2015).

In addition, a past study noted the need for careful measurements of the physical and chemical properties of steel slag, further suggesting the need for the establishment of a comprehensive relationship between the percentage of steel slag replacement, the technical requirement, and the impacts in the environment (Ferreira et al., 2016). Another LCA study assessed the environmental impact of steel slag modification in rigid pavements. The LCA results were unsatisfactory with respect to the emission of GHGs. The environmental savings of steel slag was seen to be greatly reliant on the haulage distance, as such, it was concluded that steel slag is only suitable in cases of short haulage distances (Anastasiou et al., 2015).

Recycled steel fibers have also been reutilized as reinforcements in rigid concrete pavements in attempts to enhance fatigue and tensile properties. Such concrete pavements have been termed steel fiber reinforced concrete (SFRC) (Li et al., 2019). Nonetheless, many existing literatures have focused on its mechanical properties rather than the environmental implications. An LCA was performed comparing five varieties of pavements, the LCA results are presented in Fig. 16. The airborne emission and energy consumption of in the entire life cycle of the SFRC pavement were significantly reduced (up to 40\%) in comparison with the other pavement alternatives, particularly conventional asphalt pavement. This was 


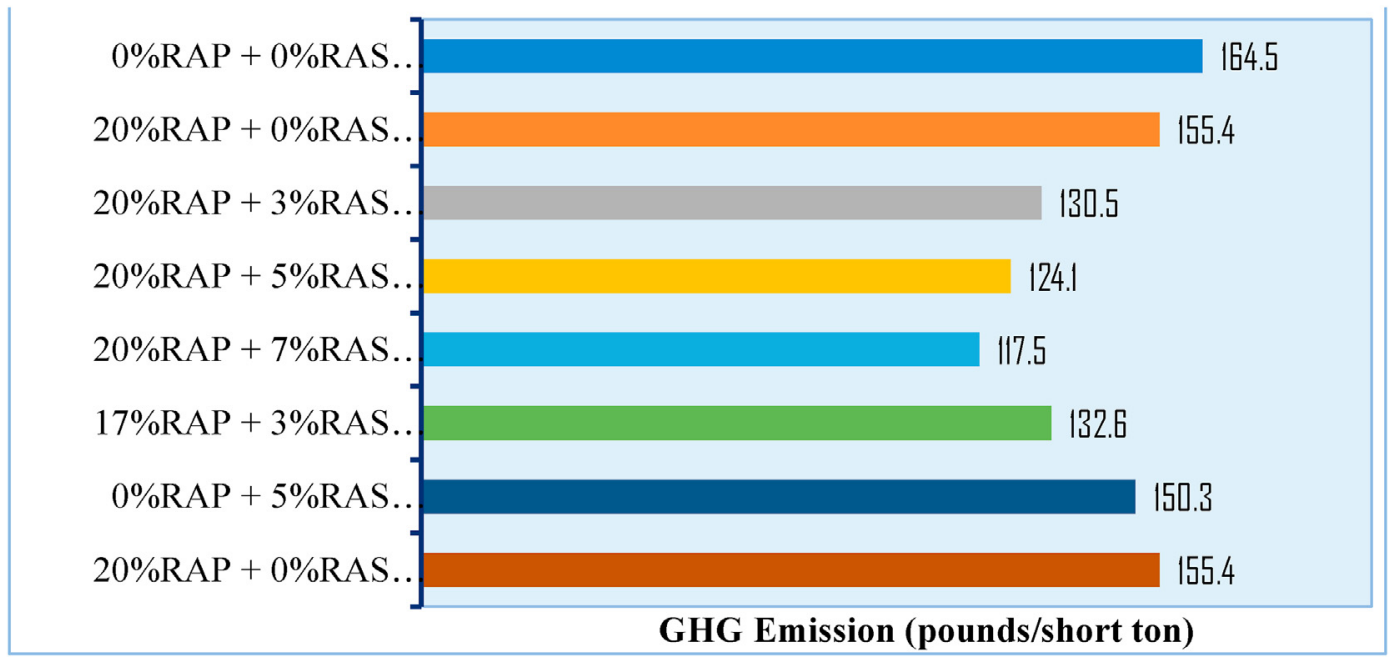

Fig. 14. LCA results from a US EPA study (Source: Booz et al., 2013).

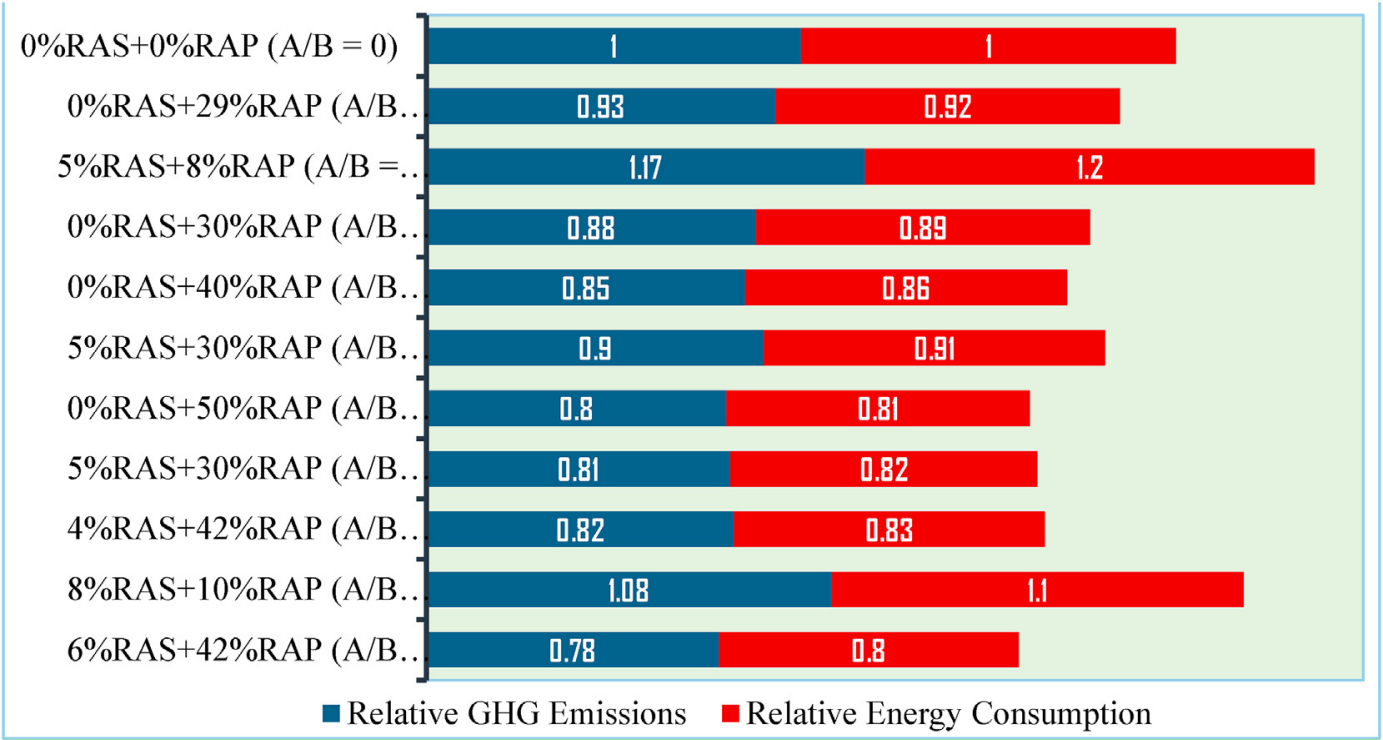

Fig. 15. The LCA results showing Relative GHG Emissions and Relative Energy Consumption.

primarily ascribed to the fact that the SFRC reduced the thickness requirement of the rigid slab (Achilleos et al., 2011).

4.1.2.6. LCA on waste PET reutilization. Waste PET have been incorporated in the surface courses of highway pavements. The variation in environmental behavior of asphalt mixtures with little quantities of PET were assessed by Azhar Butt (2014). The LCA indicated that the reductions in the depth of the asphalt surface layers reduces energy consumption and emissions. Nonetheless, with PET integration, considerations should be given to the rate of emissions produced during material production and haulage. Three blends of PET-based asphalt were evaluated in varying proportions. A $1 \mathrm{~km}$ asphalt pavement was taken as the functional unit and the period of analysis was 25 years. The LCA focused on energy consumption in material production, fuel consumption during haulage, and the quantity of $\mathrm{CO}_{2}$ produced per blend. The LCA outcomes revealed benefits in terms of energy savings, reduced emission of GHGs, and improved resistance to cracks, thereby reducing maintenance requirements (Azhar Butt, 2014). A similar LCA study was performed on PET-based pavement construction. The LCA was focused on evaluating the energy consumption level and global warming potential at the construction and utilization phases. The asphalt blends chosen include: a layer of a blend of traditional asphalts; a blend of asphalt slightly softer, produced with PET; a traditional asphalt binder and a base mixture of natural bitumen; and a blend of recycled asphalt and/or a base mixture composed of 50\% RAP (Araújo et al., 2014).

4.1.2.7. LCA on fly ash reutilization. FA has been predominantly reutilized in rigid pavements as a substitute for ordinary Portland cement (OPC). An LCA was conducted by Anastasiou et al. (2015) on FA-based concrete pavement construction, substituting cement by up to $50 \%$. The LCA results showed that the reutilization of FA led to the least emission of GHGs, this is because FA production contributes considerably in decreasing the environmental burdens cement production for pavement construction (Anastasiou et al., 2015). Another LCA performed by Tait and Cheung (2016) similarly observed that the incorporation of FA into OPC could considerably 


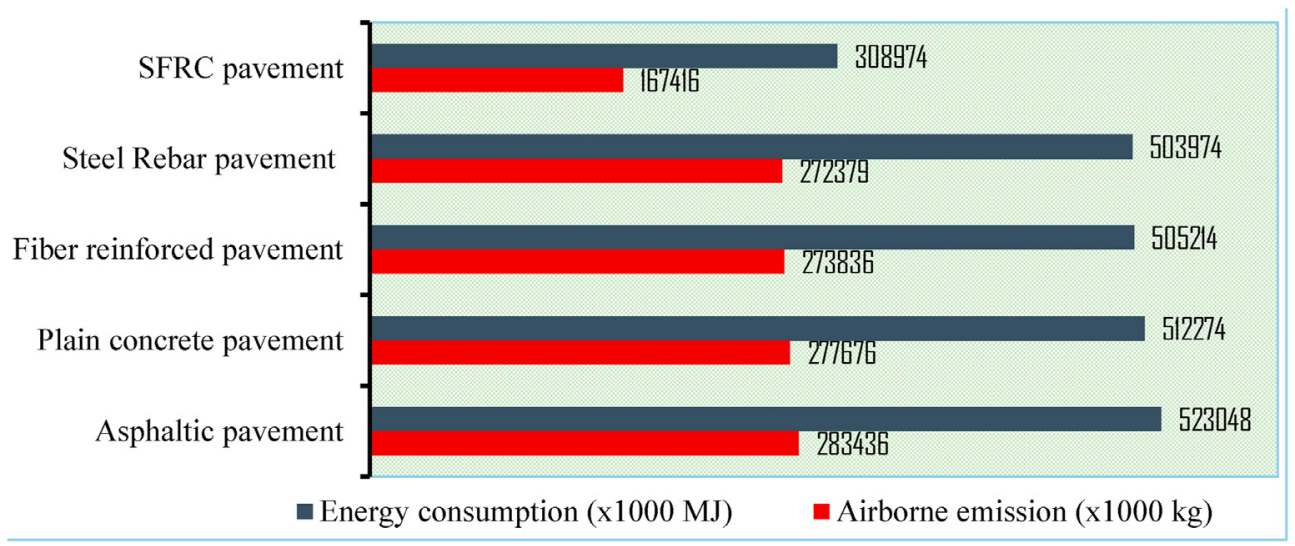

Fig. 16. LCA results on different highway pavement types (Source: Achilleos et al., 2011).

reduce the gross emission of GHGs, thereby offering a more sustainable rigid pavement. Nonetheless, the study further reported that ground granulated blast furnace slag worked more preferably, and offered more environmental advantages, compared to FA (Tait and Cheung, 2016). On the contrary, an LCA on FA replacement of natural aggregates conducted by Chowdhury et al. (2010) showed that in terms of global warming and acidification potential, FA was more suitable. However, it was seen to possess higher levels of human toxicity compared to natural aggregates (Chowdhury et al., 2010). As such, with regards to public health, the grave impacts of FA require more study.

\subsection{Summary on environmental implications}

In a nutshell, most LCAs emphasized the environmental implications of reutilizing solid waste materials in highway facility construction and maintenance. Based on these literatures, the governing criteria under which the practice of reutilization of these waste materials is advantageous can be approximately computed using Equation (1) (Anthonissen et al., 2017).

$R E_{E I}+T P_{E I}<P R O_{E I}+D I_{E I}$

The criterion presented in Equation (1) indicates that if the weight of the combined environmental impact from the reutilization $\left(R E_{E I}\right)$ and transportation $\left(T P_{E I}\right)$ processes are less than the combined environmental impacts from the processes of natural material production $\left(P R O_{E I}\right)$ and solid waste disposal $\left(D I_{E I}\right)$, the reutilization of the waste material under scrutiny should be recommended. Additionally, it can be summarized that the most adopted environmental impact criterion were energy consumption and global warming potential, since road construction operations mostly induce substantial impacts on GHG emissions and consumption of fossil fuels. Nonetheless, certain impact criteria, including: ecotoxicity and toxicity that are well associated with solid waste materials were widely understudied. This was majorly as a result of the unavailability of reliable data and requisite models for conversion to aid in the estimation of such environmental impacts (Inyim et al., 2016). Furthermore, a majority of the existing LCAs were conducted on flexible pavements rather than rigid pavements. This was ascribed to the growing popularity of asphaltic pavements in the highway construction sector due to the prevailing rate of RAP reutilization (Azarijafari et al., 2015).

\subsection{Economic implications}

The life cycle of a highway facility considers material acquisition, construction, usage, continuous maintenance, and end-of-design life (EODL) stage. To quantitatively evaluate the economic implications of the selected waste materials on highway construction in its design life, a life cycle cost analysis (LCCA) method is adopted (Li et al., 2019).

\subsection{Life cycle cost analysis process}

LCCA is an economic appraisal tool built on deep-rooted economic principles and techniques to aid in assessing the long-run costs of multiple project alternatives over a specified period ( $\mathrm{Li}$ et al., 2019). However, performing a robust LCCA can be challenging for reasons such as accurate simulation of roadway design life and proper prediction of total traffic on the roadway over its design life (Pranav et al., 2020). Fig. 17 illustrates the process flowchart for LCCA.

The key elements in the LCCA process as highlighted and described by the Federal Highway Administration (FHWA) include;

i. Conception of design alternatives: involving the definition of project scope, outlining different viable alternatives, highlighting timely plans for initial construction and future maintenance activities, probabilistic and deterministic assessment of alternatives (Ozbay et al., 2003)

ii. Estimating discount rate and Analysis period: the period should pavement design life and at least one rehabilitation operation. A proper discount rate must be selected based on socioeconomic status as the value of money may change over the period of analysis (Jawad and Ozbay, 2006).

iii. Determining Agency cost: LCC can be influenced by users, transport agencies, and the general society. Society costs are the external costs of the alternatives on the environment and populace and are highly recognized but rarely included in LCCA due to variations. Agency costs include all direct costs incurred by agencies over the life cycle of the project (Li et al., 2019).

iv. Determining user costs: includes all internal costs borne by highway facility users such as tolls, discomfort, travel delay costs (TDC), and vehicle operating costs (VOC). Most LCCA consider only TDC and VOC for simplification of analysis. Fig. 18 shows the fundamental costs considered in LCCA (Wilde et al., 1999).

v. Establishing cost streamline (or cash flow) diagrams: based on value appraisal of each phase of the project, a cost streamline as shown in Fig. 19 illustrates the benefits and expenditures resulting from each alternative (Ozbay et al., 2003). 


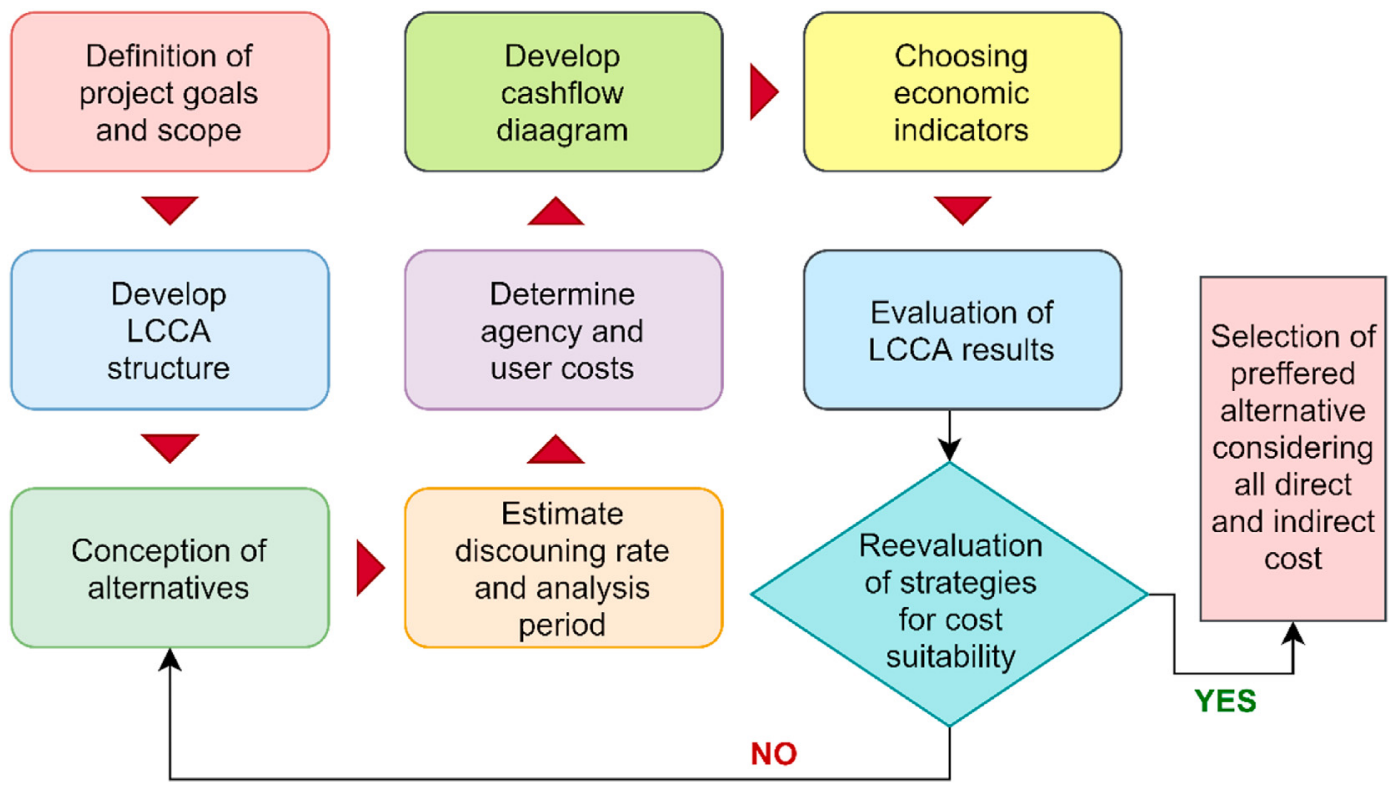

Fig. 17. Basic LCCA framework for pavement highway projects.

vi. Choosing economic indicators: several indicators such as cost/benefit ratio (C/B), net present value (NPV), equivalent uniform annual cost (EUAC), and internal rate of return (IRR) amongst others, can be adopted (Babashamsi et al., 2016).

vii. Final evaluation of LCCA results: after analyzing both direct internal costs on agencies and users, the most economical alternative based on cost-efficiency is determined using the probabilistic or deterministic approach (Rangaraju et al., 2005).

4.4.1. LCCA parameters and tools

4.4.1.1. Period of analysis. Highway pavements are built to service generations, the use of various waste material as design alternatives may each offer different service lives. As such, LCCA makes use of a common time period in evaluating these alternatives fairly. Different studies adopted an analysis period ranging between 20 and 50 years. There are no standard specifications for this. However, the FHWA guideline suggests that an analysis period of at least 35 years be adopted in new-construction, re-construction, and rehabilitation of highway pavements (U.S. Department of Transportation, 2002). While the use of certain waste materials may indicate increased LCC in LCCAs of shorter analysis periods (say 20 years), it may however, offer huge cost savings in the long run (say 50 years). This was the case in a study on rubberized asphaltic pavement (Hicks and Epps, 2000). Fig. 20 illustrates the service-life

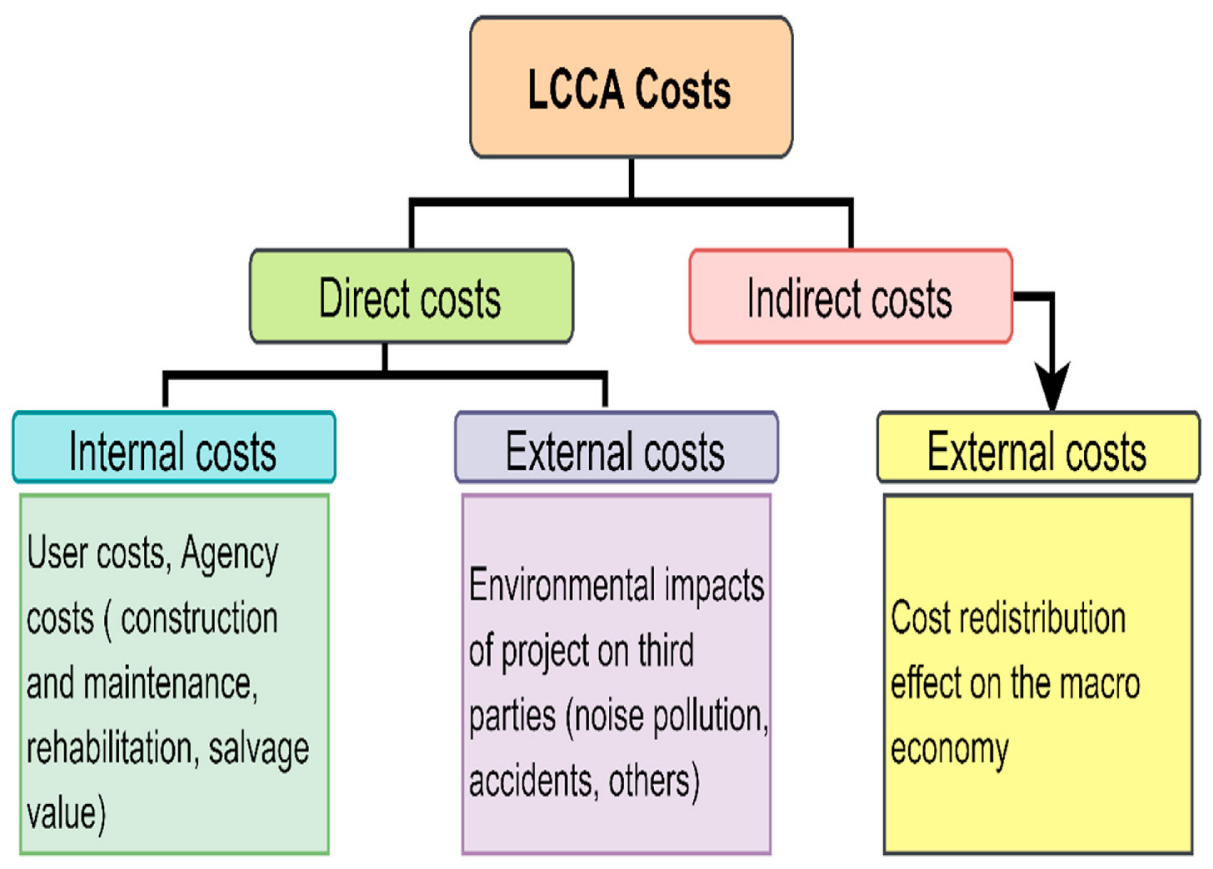

Fig. 18. Costs considered in LCCA. 


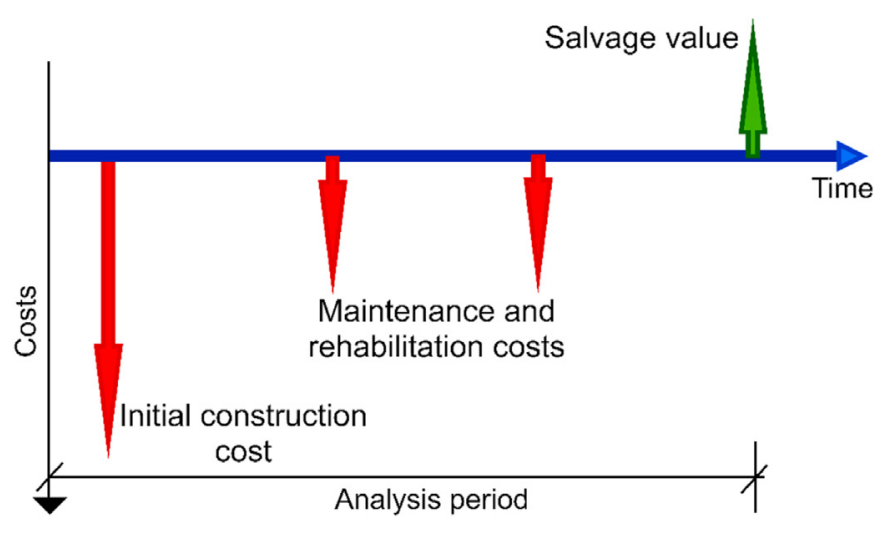

Fig. 19. Cost streamline diagram sample.

requirement for analysis period.

4.4.1.2. Economic indicators and discount rate. The selection of economic indicators for LCCA in highway projects is highly dependent on context and obtainable data. The EUAC indicator is often suitable in cases of indefinite analysis periods for pavement serviceability, whereas the IRR is most preferred in evaluating projects in developing countries where discounting rates are extremely uncertain (Li et al., 2019; Bamigboye et al., 2017). Table 3 describes the common economic indicators adopted in the LCCA of highway projects.

When considering long-run LCCA of highway facilities, costs are equated at various points in time with appropriate discounting (Jawad and Ozbay, 2006). The future value of money is considered lower than its present value, which brings about the time-value of money. The discount rate is essential in converting benefits and costs at various points in time into a time-unanimous benefit and cost (Ferreira and Santos, 2013).

An LCCA studied the effect of varying discount rates over a selected analysis period. A 3.5\% discount rate was adopted for the first 30-year period, and 3.0\% was used for the next 40-year period. Results indicated that the discount rate had a very significant effect on LCC (Morrissey and Horne, 2011). Ddamba (2011) performed a sensitivity assessment using RAS and RAP. LCC was evaluated at three discount rates: 3,5 , and $7 \%$. Results showed that the future cost was significantly influenced by the discount rate. Similarly, a study on five pavement base course maintenance projects using cold-in-place-recycling (CIPR) was carried out by Zhang et al. (2011). Five different discount rates: $2.0 \%, 4.0 \%, 6.0 \%, 8.0 \%$, and

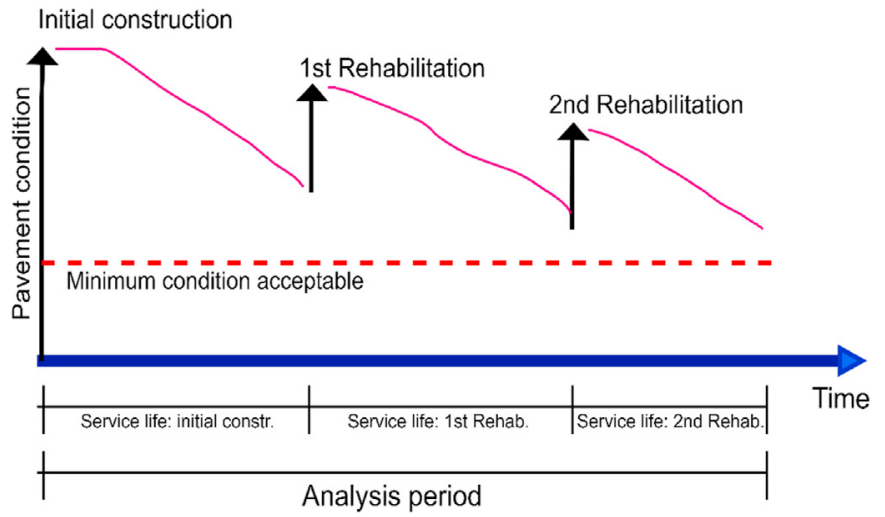

Fig. 20. Sample life-cycle analysis period of one alternative (Source: U.S. Department of Transportation, 2002).
$10 \%$ were used in the LCCA, lower discount rate values were seen to result in increased LCC. Fig. 21 illustrates the results obtained and indicates significant variation in LCC due to varying discount rates (Zhang et al., 2011).

4.4.1.3. LCCA tools for highway pavements. Various transportation agencies, organizations, and research institutions have developed LCCA models and computer programs in the past few decades, to simplify the LCC evaluation process. These tools take into consideration at least one cost/benefit parameter which includes the salvage value and all direct costs: agency costs (initial construction cost and rehabilitation cost) and user cost. Fig. 22 shows the nominated LCCA tools used for evaluating pavement construction and maintenance alternatives.

\subsubsection{LCCA implications on waste materials in highway construction}

Several LCCA studies involving the use of waste materials in highway facility construction have been done. In a nutshell, the reuse of some solid waste materials indicated satisfactory savings in costs majorly because of its relatively low price compared to virgin materials. However, LCCA studies on highway construction available considered only $\mathrm{C}$ and $\mathrm{D}$ wastes, Waste rubber tires, Fly ash, and asphalt shingles. Hence deeper LCCA studies are recommended into other waste materials.

4.4.2.1. LCCA on recycled waste rubber tires and waste polymer. The LCC of Crumb rubber modified (CRM) asphalt was compared to that of traditional asphalt pavement at a 25-year analysis period and a discount rate of $4 \%$ with the use of HDM- 4 and MicroBENCOSTrM computer programs. Results showed that CRM was significantly more economical while considering all direct costs (Jung et al., 2002). Another study by Nazzal et al. (2016) compared ground tire rubber (GTR) to SBS modified asphaltic pavements, here the GTR blends recorded higher LCC than SBS. The high cost in GTR blends was attributed to the higher cost of GTR processing. Additionally, a study by Kumar et al. (2019) reported by Li et al. (2019) assessed LCC for traditional surface courses and compared with four compositions of waste rubber blends (CRM, natural rubber, SBS, and waste plastic) as pavement surface course. A road length of $5 \mathrm{~km}$ and a lane width of $7 \mathrm{~m}$ was measured and LCC expressed as per NPV. Results obtained indicated reduction in LCC with rubber modifications, details of the results are presented in Table 4. Moreover, the SBS modified blend gave the least LCC.

Another LCCA conducted on SBS and polypropylene (PP) modified mixtures was estimated using the DARWIN 3.1 ${ }^{\mathrm{TM}}$ software, results were compared to that of the conventional method. The LCC calculated was US $\$ 160,000$, US $\$ 220,000$, and US $\$ 270,000$ for SBS-, PP-enhanced, and conventional mixes, respectively. Giving accost saving of over 59\% with SBS addition (Qadir et al., 2018).

4.4.2.2. $L C C A$ on recycled $C$ and $D$ wastes. Studies report that recycled aggregate from $C$ and $D$ waste are about $60-80 \%$ cheaper than natural aggregates, assuming transportation cost remains constant (Ohemeng and Ekolu, 2020). The LCCA on the use of Recycled asphalt pavement (RAP) of percentages up to $50 \%$ combined with virgin aggregate was conducted considering direct agency and user costs by Aurangzeb et al. (2014) over a 45-year analysis period. Significant LCC savings were recorded with increasing RAP content. Another study by Visintine (2011) considered the initial cost of construction, future costs of maintenance and rehabilitation, and salvage value in the LCCA of 30 - and $40 \%$ RAP mixtures. Results recorded LCC savings of $19 \%$ and $40 \%$ for the 30- and 40\%-RAP mixtures, respectively. Furthermore, the PaLATE $^{\text {TM }}$ software was used in assessing the LCCA of CIPR of RAP in 
Table 3

Description of common economic indicators (Source: Babashamsi et al., 2016; Ozbay et al., 2003).

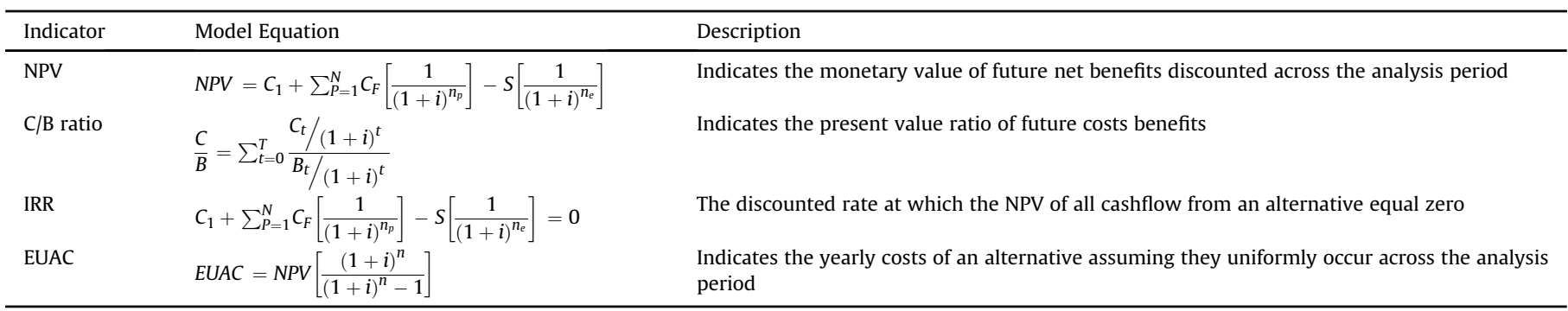

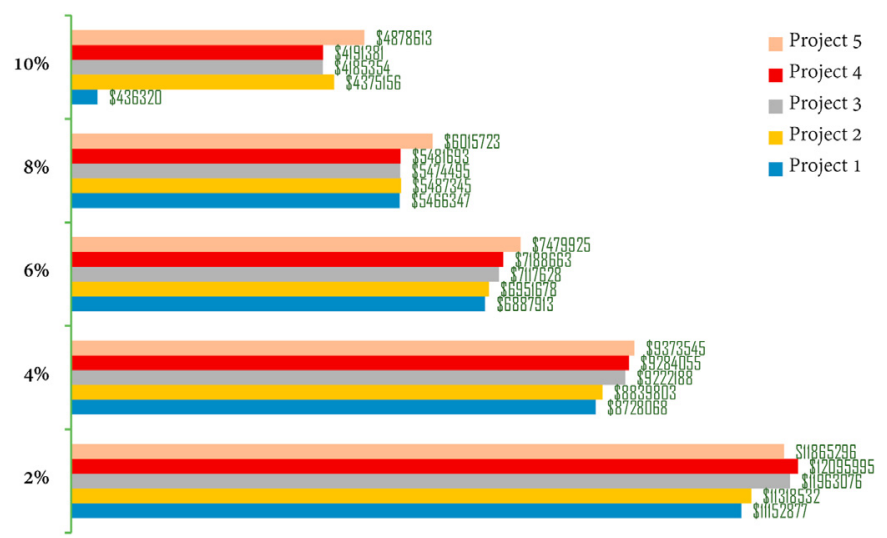

Fig. 21. LCC (US\$) of waste-integrated projects with varying discount rates (Source: Zhang et al., 2011). recorded reduced economic sustainability as the LCC for RCA mixes was $0.11 \%$ higher than that of PCC as a result of the cost of material haulage. RCA-paved surfaces also tend to impose higher user costs from increased tire wearing and fuel consumption resulting in increased rolling resistance on pavement surfacing. However, this economic implication seems insignificant due to the high level of environmental sustainability it offers (Shi et al., 2019).

4.4.2.3. LCCA on recycled fly ash and asphalt shingles. An LCCA was performed on a series of HMA blends with varying percentages of RAS and RAP. Initial production costs were recorded to decrease by up to $15 \%$ with an increase in RAS and RAP percentage (Yang et al., 2015). Similarly, Bloom et al. (2017) studied the LCC of various recycled waste materials (including RAS) along a $2.4-\mathrm{km}$ section of the Beltline roadway, Wisconsin. RAS was adopted as a replacement for virgin aggregate in the HMA mix and offered significant cost

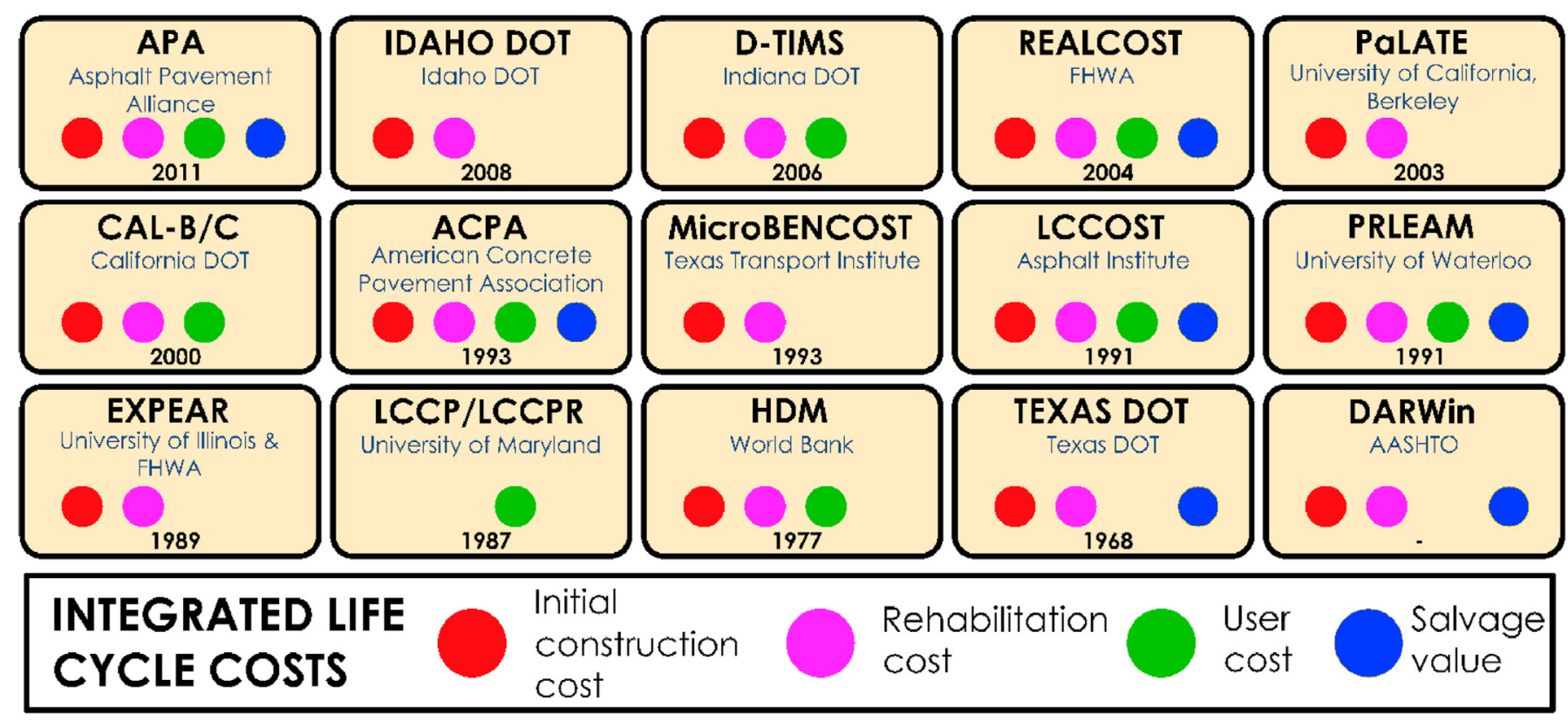

Fig. 22. LCCA tools for assessment of pavement alternatives (Source: Babashamsi et al., 2016; Li et al., 2019).

base course rehabilitation in the Nanhuan road in Handan, China. Costs considered in the LCCA was material costs, transportation costs, and waste disposal costs. The resultant LCCA gave cost savings from CIPR-RAP of over US\$4.8 million while utilizing over $272,000 \mathrm{~m}^{3}$ of RAP materials (Zhang et al., 2011). Another study evaluated the LCC of using recycled concrete aggregates (RCA) in contrast to plain cement concrete (PCC) in road pavements. Results savings. Another study using RAS and RAP in pavement construction assessed LCC over a 20 -year period using 3, 5, and 7\% discount rates. The 3\%RAS/25\%RAP mixture obtained LCC savings in initial construction cost up to 11.9\% (Ddamba, 2011).

FA was used as a supplementary material in mixes with foundry sand for pavement base and subbase. The LCCA considered agency costs and user costs and indicated cost savings of up to $21 \%$ 
Table 4

LCCA results from waste rubber enhanced pavements (Source: Li et al., 2019).

\begin{tabular}{|c|c|c|c|c|c|}
\hline Material type & Initial Costs (US\$) & $M \& R$ costs (US\$) & Salvage value (US\$) & NPV-LCC (\$) & $\mathrm{C} / \mathrm{B}$ ratio \\
\hline Traditional & 532,589 & 348,915 & 532,570 & 857,733 & 1.00 \\
\hline SBS & 552,840 & 149,727 & 552,820 & 689,303 & 0.80 \\
\hline Waste plastic & 542,715 & 263,135 & 814,050 & 781,070 & 0.91 \\
\hline CRM & 542,715 & 263,135 & 814,050 & 781,070 & 0.91 \\
\hline Natural rubber & 542,715 & 311,541 & 162,810 & 785,945 & 0.92 \\
\hline
\end{tabular}

compared to conventional mixes (Li et al., 2019). Another study combined FA with RCP in producing concrete for road routine maintenance operations, LCCA recorded reduced maintenance cost of up to RMB13.6 million in the FA-CRP mix when compared to conventional mixes. Hence, offering cost savings throughout the pavement life cycle (Wu and $\mathrm{Xu}, 2010$ ).

\subsubsection{Summary on economic implications}

In a nutshell, the economic implications of the reutilization of solid waste materials in road pavement construction and maintenance can be said to be satisfactory in terms of cost savings. This is basically as a result of its low initial cost compared to natural materials. Nonetheless, compared to the existing literatures on reutilized solid waste LCAs, corresponding LCCA literatures were rare. Furthermore, a majority of the LCCA literatures were based on RAS, RAP and waste rubber wastes which have been applied in road pavements for years, whereas only a few economic appraisals involving other solid waste materials had been performed. As such, deeper and more extensive LCCA researches are thus concurrently recommended.

\subsection{Performance implications}

Several studies have identified certain effects of the utilization of solid waste materials on the structural, physical, mechanical, and general performance of road pavement and embankment structures. Some performance parameters assessed include CBR, resilient modulus, indirect tensile strength, marshal stability, and LA abrasion, amongst others. Table 5 presents some of these performance implications in detail.

\section{Discussions}

Based on the reviewed studies utilizing different waste materials in highway works, this section presents three facets of the literature to guide utilization practices: the prospects driving the incorporation of these wastes in pavement applications, the challenges faced during practice, and recommendations to avoid or reduce certain challenges.

\subsection{Prospects}

The benefits of utilizing waste materials in pavement construction and maintenance are quite clear and satisfactory. Most of these wastes are renewable resources and generally less costly because they are often locally sourced and manufactured (AlSabaeei et al., 2020); they are eco-friendly and consume less energy compared to conventional pavement materials (Balaguera et al., 2018; Li et al., 2019; Somé et al., 2016). The ever-rising demand for bitumen and other natural materials for highway applications, fluctuating costs of petroleum-based asphalts, and the necessity to improve eco-friendly practices has been consequential in the steady efforts aimed at developing alternative highway materials; as such, utilizing the selected waste materials can improve the effectiveness road construction in terms of costs and performance (Al-Sabaeei et al., 2020; Fernandes et al., 2019; Gedik, 2020). Waste materials naturally convert $\mathrm{CO}_{2}$ and as such, free greenhouse gases. Likewise, the utilization of these waste materials have significantly reduced the requirement for landfills, which helps in reducing the emission of greenhouse gases (Stehlik et al., 2015; Zhang et al., 2019). Furthermore, for surface courses, utilizing wastes that support the WMA-based techniques such as PET, $\mathrm{CR}$, and bio-oils helps in reducing the temperature requirements for mixing and compaction processes. This alternative is more preferable than the petroleum-based WMA technique; hence, the adoption of this approach will substantially lessen energy use and emission rates (Król et al., 2016). Bio-oils and CR are one of the most suitable alternative materials for rejuvenating aged asphalt properties both with natural aggregates and RAP materials. However, in terms of cost, bio-oils are efficient than other asphalt rejuvenators (Al-Sabaeei et al., 2020). Waste materials also offer potentials for use in novel, self-healing, and other innovative sustainable technologies, to aid in mitigating the adverse impacts of highway facility construction and maintenance. The combined utilization of two or more of these waste materials, for example CR, RAP, FA, RAS have also been reported to yield acceptable outcomes, as such there is a promise for new trends of research to ensure the sustainability of eco-friendly highway pavement applications.

\subsection{Challenges}

Several challenges have been faced both in research and in the practical implementation of practices involving the reutilization of these waste materials. Some of these challenges stem from the issues of waste resource availability and the behavior of these waste materials when used as alternative for natural pavement materials. The core challenges limiting these practices have been categorized and discussed in the following sections.

\subsubsection{Challenges in research}

A major limitation in this research subject is the search for a renewable, sustainable, cost-effective, and eco-friendly substitute for petroleum-based asphalt surfaces. This requirement is paramount in meeting the ever-rising demand as reserves for fossil fuel depletes and cost increase. Likewise, pavement construction workers are often exposed to fumes of high toxicity during asphalt mixing and laying operations (Al-Sabaeei et al., 2020; Oldham et al., 2015; Rahman and Wahab, 2013). Another limitation is in finding an alternative binder material able to bear dissimilar environmental and loading conditions of pavements across the globe (Arulrajah et al., 2017). Regrettably, even the finest designed and built highway pavements still endure deterioration with time as a result of traffic impacts and weathering (Porot et al., 2017). Another issue is in determining ways to possibly utilize large amounts of these waste materials under multiple applications, for instance, in asphalt binders, surface courses, underlying courses, and as embankment fillers to reduce water and land pollution, and towards totally substituting petroleum-based asphalts, while also enhancing blend performance (Han et al., 2016; Zhang et al., 2019).

One of the critical problems that results in pavement distress 
Table 5

Implications of selected waste materials on highway facility performance.

\begin{tabular}{|c|c|c|c|c|c|}
\hline Material & Performance criterion & Application & Sample composition & Reported performance & Source \\
\hline \multirow[t]{3}{*}{$\begin{array}{l}\text { Waste } \\
\text { Rubber } \\
\text { tires }\end{array}$} & Mechanical: Resilient modulus (RM) & $\begin{array}{l}\text { Pavement base and } \\
\text { subbase layers }\end{array}$ & Waste rock (WR)+SBS & $\begin{array}{l}\text { RM obtained conforms with recommended values, } \\
\text { RM of } 70 \% \text { OMC blends are higher than that of } 90 \% \\
\text { OMC, SBS addition reduces the rigidity thereby } \\
\text { offering higher resistance to cracking under loading. }\end{array}$ & $\begin{array}{l}\text { Arulrajah et al. } \\
\text { (2019b) }\end{array}$ \\
\hline & $\begin{array}{l}\text { Mechanical: Resistance and vertical } \\
\text { deformation }\end{array}$ & $\begin{array}{l}\text { Pavement subbase } \\
\text { layer }\end{array}$ & $\begin{array}{l}2 \mathrm{~mm} \text { thick Rubber cell } \\
\text { mesh reinforcement }\end{array}$ & $\begin{array}{l}30 \% \text { Increase in load-bearing capacity of modeled } \\
\text { pavement compared to conventional methods }\end{array}$ & $\begin{array}{l}\text { Manjula Devi } \\
\text { and Chore } \\
\text { (2019) }\end{array}$ \\
\hline & $\begin{array}{l}\text { Mechanical: Indirect tensile strength } \\
\text { (ITS), Appearance. }\end{array}$ & $\begin{array}{l}\text { Pervious concrete } \\
\text { pavement }\end{array}$ & $\begin{array}{l}\text { Fine rubber (FR), coarse } \\
\text { rubber (CR) }\end{array}$ & $\begin{array}{l}\text { FR increases concrete density while reducing } \\
\text { permeability and ITS. CR obtained increases ITS and } \\
\text { yields suitable density. Increased FR content } \\
\text { produces dark-colored concrete. }\end{array}$ & $\begin{array}{l}\text { Bonicelli et al. } \\
\text { (2017) }\end{array}$ \\
\hline \multirow[t]{2}{*}{ PET } & $\begin{array}{l}\text { Mechanical: Marshall stability (MS), air } \\
\text { void }(A V) \text {, void in mineral aggregate } \\
\text { (VMB) }\end{array}$ & $\begin{array}{l}\text { Bituminous } \\
\text { Asphaltic concrete } \\
\text { (BAC) surface } \\
\text { course }\end{array}$ & $\begin{array}{l}\text { PET-coated aggregate } \\
\text { (PCA), PET-modified } \\
\text { bitumen (PMB) }\end{array}$ & $\begin{array}{l}\text { MS values increased by up to } 4425 \text { and } 4320 \mathrm{~kg} \text { for } \\
\text { PMB- and PCA-BACs respectively indicating } \\
\text { improved stability. PET was seen to reduce flow by } \\
\text { up to } 4.31 \% \text { compared to conventional BACs. PCA } \\
\text { increased AV while PMB reduced AV. VMA was found } \\
\text { to increase in both PMB- and PCA-BACs by up to } \\
141.03 \% \text {. }\end{array}$ & $\begin{array}{l}\text { Sojobi et al. } \\
\text { (2016) }\end{array}$ \\
\hline & $\begin{array}{l}\text { Mechanical: LA abrasion, compaction, } \\
\text { permeability, CBR, and repeated load } \\
\text { triaxial test (RLT). Geo-environmental: } \\
\text { pH value }\end{array}$ & $\begin{array}{l}\text { Pavement base and } \\
\text { subbase layers }\end{array}$ & $\begin{array}{l}\text { PET, recycled concrete } \\
\text { aggregate (RCA), } \\
\text { crushed bricks }(\mathrm{CB})\end{array}$ & $\begin{array}{l}\text { LA abrasion loss increases with added PET and fell } \\
\text { below allowable limits. OMC increases while MDD } \\
\text { decreases with increasing PET however, values fall } \\
\text { within an acceptable range. PET blends exhibit } \\
\text { higher permeability compared to control mixes. CBR } \\
\text { values reduces with increasing PET. RLT results for } \\
\text { RCA/PET performs better than CB/PET, RM decreases } \\
\text { with increasing PET. pH values were above 7, } \\
\text { indicating alkalinity. }\end{array}$ & $\begin{array}{l}\text { Perera et al. } \\
(2019)\end{array}$ \\
\hline \multirow[t]{2}{*}{ Glass waste } & $\begin{array}{l}\text { Mechanical: Frost protection, } \\
\text { Permeability, compressive strength }\end{array}$ & $\begin{array}{l}\text { Pervious Subgrade } \\
\text { and subbase layers }\end{array}$ & $\begin{array}{l}\text { Granulated expanded } \\
\text { glass aggregate } \\
\text { (GEGA), cement grout. }\end{array}$ & $\begin{array}{l}\text { Results show that GEGA yields high permeability } \\
\text { indicating improved subsurface drainage, } \\
\text { compressive strength tests show that GEGA usage } \\
\text { achieves acceptable load-bearing values while } \\
\text { offering improved frost protection to overlying } \\
\text { layers in cold climates. }\end{array}$ & $\begin{array}{l}\text { Kurpinska et al. } \\
\text { (2019) }\end{array}$ \\
\hline & $\begin{array}{l}\text { Mechanical: Wheel track test (WTT), } \\
\text { dynamic stability (DS), ITS, MS }\end{array}$ & $\begin{array}{l}\text { Cold bituminous } \\
\text { emulsions (CBEM) } \\
\text { for surface course }\end{array}$ & $\begin{array}{l}\text { Fine glass aggregate- } \\
\text { (FGA) enhanced CBEM }\end{array}$ & $\begin{array}{l}\text { DS and WTT results on FGA-CBEM gave } \\
\text { improvements in resistance to rutting and } \\
\text { permanent deformation of up to } 4.35 \text { times that of } \\
\text { traditional hot mix asphalt (HMA). ITS results show a } \\
\text { minor decline in crack resistance compared to HMA. } \\
\text { MS tests indicate poor adhesion between the binder } \\
\text { and the FGA as values decreased with increasing FGA }\end{array}$ & $\begin{array}{l}\text { Kadhim et al. } \\
\text { (2019) }\end{array}$ \\
\hline \multirow[t]{3}{*}{$\begin{array}{l}\text { C and D } \\
\text { waste }\end{array}$} & $\begin{array}{l}\text { Mechanical: compaction, unconfined } \\
\text { compression strength (UCS), } \\
\text { Geo-environmental: leachability }\end{array}$ & $\begin{array}{l}\text { Pavement base } \\
\text { course material }\end{array}$ & $\begin{array}{l}\text { Recycled asphalt } \\
\text { pavement (RAP), Fly } \\
\text { ash (FA) }\end{array}$ & $\begin{array}{l}\text { MDD of } 100 \% \text { RAP blends was unresponsive to } \\
\text { increasing water content and yielded lower values } \\
\text { compared to RAP/FA blends with suitable compact } \\
\text { ability. UCS of RAP/FA blends even at } 7 \text { days records } \\
\text { values higher than standard limits. However, UCS } \\
\text { improves with longer curing times. RAP/FA } \\
\text { geopolymer effectively reduces metal concentration } \\
\text { leachability based on toxic characteristic leaching } \\
\text { procedure (TCLP). }\end{array}$ & $\begin{array}{l}\text { Hoy et al. } \\
\text { (2016) }\end{array}$ \\
\hline & $\begin{array}{l}\text { Mechanical: Elastic moduli (EM), } \\
\text { resilience modulus (MR). }\end{array}$ & $\begin{array}{l}\text { Pavement base } \\
\text { course material }\end{array}$ & $\begin{array}{l}\text { Cement-bound- } \\
\text { concrete-waste } \\
\text { granular mixtures } \\
(\mathrm{CBGM})\end{array}$ & $\begin{array}{l}\text { Results indicate that CBGM mixes achieve EM values } \\
\text { within recommended limits as natural materials, } \\
\text { optimal mix was recorded as CBGM with } 5 \% \text { cement. } \\
\text { Correlation between EM and MR was established to } \\
\text { aid predictions in the future. }\end{array}$ & $\begin{array}{l}\text { Stehlik et al. } \\
\text { (2015) }\end{array}$ \\
\hline & $\begin{array}{l}\text { Mechanical: Permanent deformation, } \\
\text { Resilience modulus (MR). }\end{array}$ & $\begin{array}{l}\text { Highway } \\
\text { embankment }\end{array}$ & $\begin{array}{l}100 \% \mathrm{C} \text { and } \mathrm{D} \text { waste } \\
\text { material }\end{array}$ & $\begin{array}{l}\text { When compared to conventional clay, permanent } \\
\text { deformation of C and D was less sensitive to } \\
\text { increasing wetness, C and D material continually } \\
\text { offered less cumulated permanent strain than clay, } \\
\text { thereby indicating higher rutting resistance as } \\
\text { embankment material. MR values of embankment } \\
\text { clay were also found to be lower than that of C and D } \\
\text { materials at all measured stress levels thereby } \\
\text { providing improved structural to upper layers under } \\
\text { loading cycles. }\end{array}$ & $\begin{array}{l}\text { Zhang et al. } \\
\text { (2019) }\end{array}$ \\
\hline Steel slag & Mechanical: Rutting resistance, & $\begin{array}{l}\text { Bituminous } \\
\text { courses, Base } \\
\text { course, subbase } \\
\text { course, rigid } \\
\text { pavement }\end{array}$ & $\begin{array}{l}\text { Steel slag aggregates } \\
\text { (SSA), natural } \\
\text { aggregates (NA) }\end{array}$ & $\begin{array}{l}\text { Samples with higher SSA content gave higher MR } \\
\text { and tensile strength values, and less deformation and } \\
\text { susceptibility to wetness than samples of NA as a } \\
\text { surfacing material. As for Base and Subbase, an } \\
\text { increase in MR up to } 500 \text { MPa was achieved in SSA } \\
\text { samples compared to NA. In concrete pavements, } \\
\text { SSA mixes offered highly-dense heavy-weight } \\
\text { concrete with high resistance to abrasion. However, } \\
\text { improved results can only be obtained with proper } \\
\text { conditioning to eradicate expansion potential. }\end{array}$ & $\begin{array}{l}\text { Washington } \\
\text { State } \\
\text { Department of } \\
\text { Transport } \\
\text { (2015) } \\
\end{array}$ \\
\hline
\end{tabular}


Table 5 (continued)

\begin{tabular}{|c|c|c|c|c|c|}
\hline Material & Performance criterion & Application & Sample composition & Reported performance & Source \\
\hline \multirow{3}{*}{ Fly ash (FA) } & $\begin{array}{l}\text { Mechanical: Durability } \\
\text { Geo-environmental: ground } \\
\text { improvement. }\end{array}$ & $\begin{array}{l}\text { Road base course, } \\
\text { Ground } \\
\text { Improvement }\end{array}$ & BF slag, BOF slag & $\begin{array}{l}\text { BF slag Improves stress distribution hence, pavement } \\
\text { durability under traffic loading. BOF slag resists soil } \\
\text { expansion due to hydration of } \mathrm{CaO} \text {. Slag improves } \\
\text { the behavior of soft and sticky soils similar to the } \\
\text { conventional soil compaction pile method. }\end{array}$ & $\begin{array}{l}\text { Malhotra } \\
\text { (2019) }\end{array}$ \\
\hline & $\begin{array}{l}\text { Mechanical: UCS, CBR, triaxial shear } \\
\text { strength (TSS) }\end{array}$ & Pavement subbase & $\begin{array}{l}\text { FA-Lime (FAL), FA- } \\
\text { granulated blast } \\
\text { furnace slag (FAG) }\end{array}$ & $\begin{array}{l}\text { FAL mixes showed large UCS improvements } \\
\text { compared to NA than FAG blends with extended } \\
\text { curing periods due to the pozzolanic nature of lime. } \\
\text { CBR values for both FAL and FAG blends yielded } \\
\text { improvements up to } 57 \% \text { compared to NA at just } 7 \\
\text { days of curing. TSS test at all curing periods gave } \\
\text { higher deviator stress value at failure in FAL and FAG } \\
\text { blends than NA. FAL blends achieved an } \\
\text { improvement of over } 4 \text { times the value of NA and is } \\
\text { recommended for subbase. }\end{array}$ & $\begin{array}{l}\text { Bakare et al. } \\
\text { (2019) }\end{array}$ \\
\hline & $\begin{array}{l}\text { Mechanical: Resilience, splitting } \\
\text { strength, UCS, drying shrinkage, setting } \\
\text { time }\end{array}$ & Road base stabilizer & $\begin{array}{l}\text { Varying FA-clinker- } \\
\text { gypsum -percentages } \\
\text { in road base course } \\
\text { binder }(\mathrm{RBCB})\end{array}$ & $\begin{array}{l}\text { RBCB with an optimal proportion of } 45 \% \text { FA: } 45 \% \\
\text { clinker: } 10 \% \text { gypsum offered strength increase up to } \\
15 \%, 10-15 \% \text { in cement savings, and resistance to } \\
\text { splitting. However, it reduces setting time by over } \\
180 \text { min compared to ordinary portland cement } \\
\text { (OPC). RBCB gave a lesser dry shrinkage ratio than } \\
\text { OPC thereby reducing reflect cracks by } 82 \% \text { and } \\
\text { increasing pavement design life. }\end{array}$ & Li et al. (2019) \\
\hline $\begin{array}{l}\text { Colliery } \\
\text { spoils } \\
\text { (CS) }\end{array}$ & $\begin{array}{l}\text { Geo-environmental: Toxicity, } \\
\text { Mechanical: CBR }\end{array}$ & $\begin{array}{l}\text { Subbase for Low- } \\
\text { traffic road }\end{array}$ & $\begin{array}{l}\text { Unbound CS, CS-lime, } \\
\text { CS-cement }\end{array}$ & $\begin{array}{l}\text { CS was classified as inert and poses no risk of heavy } \\
\text { metal leaching on the environment CS exceeds CBR } \\
\text { requirements for use as subbase material in both } \\
\text { unbound CS and CS-cement blends. CS-lime blends } \\
\text { had no significant strength improvements and is not } \\
\text { recommended. }\end{array}$ & $\begin{array}{l}\text { Suescum- } \\
\text { Morales et al. } \\
\text { (2019) }\end{array}$ \\
\hline \multirow[t]{2}{*}{$\begin{array}{l}\text { Cement } \\
\text { kiln dust } \\
\text { (CKD) }\end{array}$} & Mechanical: CBR, UCS & $\begin{array}{l}\text { Clay improvement } \\
\text { for Subbase }\end{array}$ & $\begin{array}{l}\text { Soaked and dry CKD- } \\
\text { Locust bean waste ash- } \\
\text { (LBWA) clay }\end{array}$ & $\begin{array}{l}\text { Dry CKD-LBWA addition gave an increase in CBR } \\
\text { from the original } 4 \%-75 \% \text { while soaked blends } \\
\text { achieved } 70 \% \text { CBR values. Statistical analysis showed } \\
\text { that CKD had a greater effect on the clay's } \\
\text { improvement than LBWA. UCS requirements for } \\
\text { subbase materials was achieved with CKD-LBWA } \\
\text { addition after } 14 \text { and } 28 \text { days of curing. }\end{array}$ & $\begin{array}{l}\text { Eberemu et al. } \\
\text { (2019) }\end{array}$ \\
\hline & $\begin{array}{l}\text { Mechanical: Compressive strength, } \\
\text { Abrasion resistance }\end{array}$ & $\begin{array}{l}\text { Interlocking } \\
\text { pavement units }\end{array}$ & $\begin{array}{l}\text { CKD-OPC mixes with } \\
\text { air-cooled blast furnace } \\
\text { slag (ACS) aggregate }\end{array}$ & $\begin{array}{l}\text { The compressive strength decreased with CKD } \\
\text { additions. However, the } 20 \% \text { CKD-ACS mix gained } \\
\text { suitable compressive strength values of } 34 \text { and } \\
48.3 \mathrm{~N} / \mathrm{mm}^{2} \text { after } 7 \text { - and } 28 \text {-days curing, respectively } \\
\text { thereby exceeding minimum requirement. LA } \\
\text { abrasion results showed all CKD samples, except } \\
\text { CKD } 40 \% \text {, exhibited high resistance to abrasion. And } \\
\text { as such is recommended for use as interlocking } \\
\text { paving units on low traffic road sections. }\end{array}$ & $\begin{array}{l}\text { Abdel-Ghani } \\
\text { et al. (2018) }\end{array}$ \\
\hline $\begin{array}{l}\text { Mine } \\
\text { Tailings }\end{array}$ & Mechanical: Compaction, CBR & Pavement subgrade & $\begin{array}{l}\text { Cement stabilized mine } \\
\text { tailings (marl, } \\
\text { limestone, and iron } \\
\text { ore) }\end{array}$ & $\begin{array}{l}\text { Tailings were classified as angular-shaped well- } \\
\text { graded-gravel with silt and sand tailings cement } \\
\text { stabilization of the tailings improved the MDD. } \\
\text { Tailing mix with } 4 \% \text { cement increased CBR of tailings } \\
\text { by up to } 100 \% \text { making the mix suitable for subgrade }\end{array}$ & $\begin{array}{l}\text { Djellali et al. } \\
\text { (2019) }\end{array}$ \\
\hline & Mechanical: ITS, MR, dynamic creep, MS & $\begin{array}{l}\text { Flexible pavement } \\
\text { surface }\end{array}$ & $\begin{array}{l}\text { Electric arc furnace } \\
\text { (EAF) slag, copper mine } \\
\text { tailing (CMT) }\end{array}$ & $\begin{array}{l}\text { EAF/CMT mix improved MS with higher bitumen } \\
\text { content compared to the control mix. EAF/CMT mix } \\
\text { exhibited a higher angle of internal friction }(\phi) \\
\text { providing better-interlocked aggregates. The EAF/ } \\
\text { CMT mix also achieved the highest ITS, dynamic } \\
\text { creep, and MR values. As such, EAF/CMT is } \\
\text { recommended for pavement surfacing. }\end{array}$ & $\begin{array}{l}\text { Oluwasola } \\
\text { et al. (2015) }\end{array}$ \\
\hline \multirow[t]{2}{*}{$\begin{array}{l}\text { Aluminium } \\
\text { Dross } \\
\text { (AD) }\end{array}$} & $\begin{array}{l}\text { Mechanical: MS, retained stability (RS), } \\
\text { ITS, ITSM }\end{array}$ & $\begin{array}{l}\text { Pavement cold } \\
\text { bituminous } \\
\text { emulsions (CBEM) }\end{array}$ & OPC, AD, NA, Emulsion & $\begin{array}{l}\text { MS values for the } 2 \% \text { AD blend yielded optimum MS } \\
\text { among AD mixes. AD addition marginally increased } \\
\text { MS compared to control mixes. All AD mixtures } \\
\text { exceeded the minimum RS requirement of } 50 \% \text { the } \\
3 \% A D \text { mix gave the best RS results. ITS test values of } \\
\text { mixes with AD were higher than unmodified } \\
\text { samples, ITS increased with increasing AD } \\
\text { percentage. AD mixtures gave lower ITSM values } \\
\text { compared to control mixes. However, the use of AD } \\
\text { in replacing fine aggregate in CBEM is } \\
\text { recommended. }\end{array}$ & $\begin{array}{l}\text { Jadhav and } \\
\text { Kakade (2019) }\end{array}$ \\
\hline & $\begin{array}{l}\text { Mechanical: Atterberg limits, } \\
\text { compaction, CBR }\end{array}$ & $\begin{array}{l}\text { Pavement geo- } \\
\text { material }\end{array}$ & Lateritic soil, AD, water & $\begin{array}{l}\text { AD addition reduced the plasticity index of the soil, } \\
\text { indicating improvement in strength. Plastic and } \\
\text { liquid limits increased with AD addition. Increasing } \\
\text { AD content led to a decrease in MDD. Nonetheless, } \\
\text { the } 8 \% \text { AD blend achieved the highest MDD. Soil CBR } \\
\text { values improve with AD addition. Hence, AD was }\end{array}$ & $\begin{array}{l}\text { Busari et al. } \\
\text { (2019) }\end{array}$ \\
\hline
\end{tabular}


Table 5 (continued)

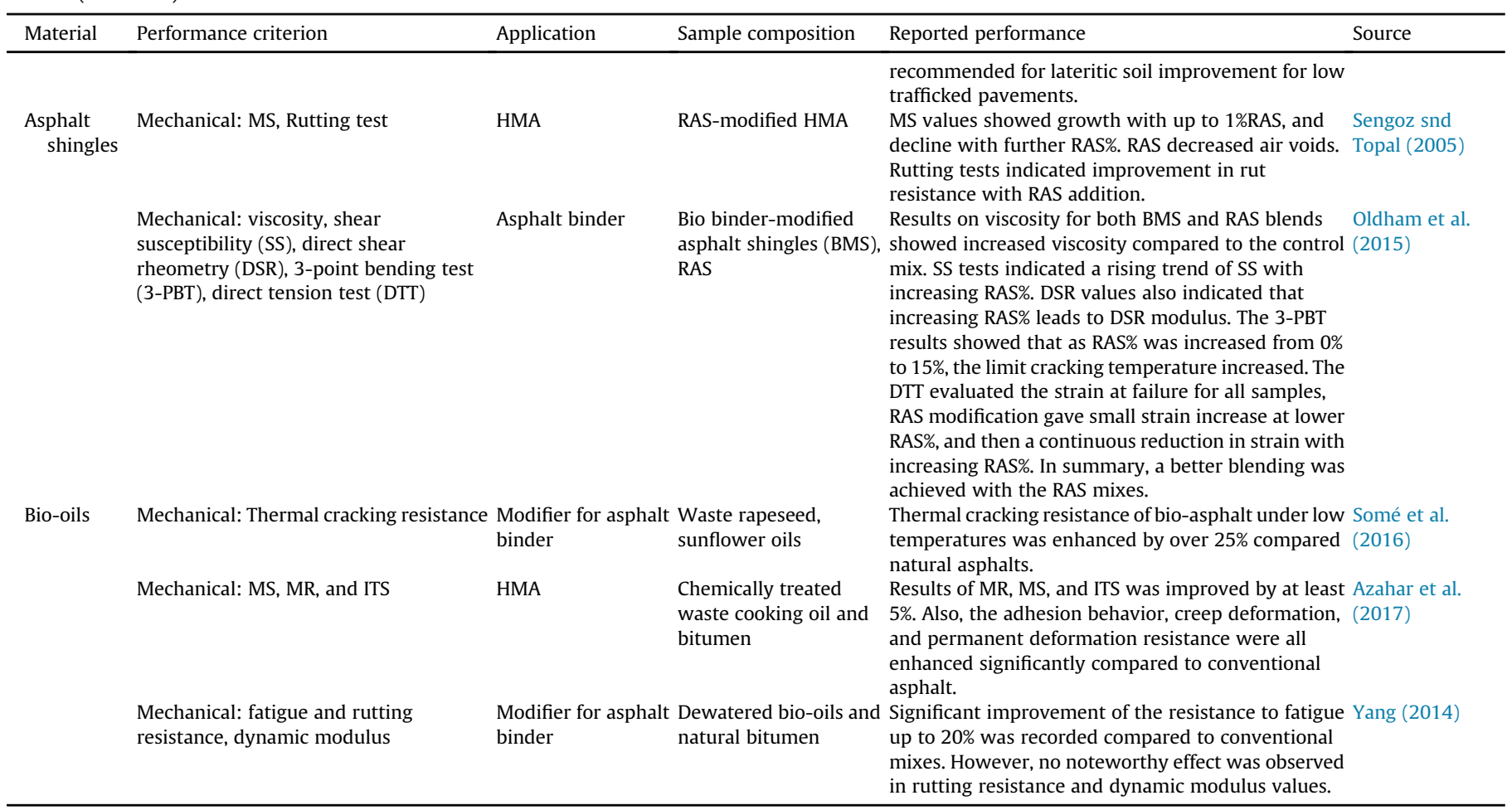

and reduced serviceability is the asphalt ageing (Mturi et al., 2014; Nayak and Sahoo, 2017). The high level of dissimilarity in the composition of different waste materials in terms of morphology, rheology, and physicochemical characteristics, have resulted in massive variations in the performance and resistivity to thermal and oxidative ageing (Kakar et al., 2015; Somé et al., 2016). The low understanding of the ageing, microstructural and elemental composition, and compatibility of these waste materials with various kinds of naturally occurring materials remains an issue in literature that still requires addressing (Yang et al., 2017). Another identified issue in the utilization of wastes such as bio-oils and CR in modifying asphalt binders is the viscosity decline when compared to conventional binders; this effect limits the performance of waste-modified binders, thereby hindering its large-scale use (Al-Sabaeei et al., 2020). Also, the resistance to rutting of asphalts made from bio-oil blends remains an unresolved research issue (Azahar et al., 2017).

A good percentage of pavement failures result from moisture related hitches and reduced adhesion between asphalt constituents. Though the ageing performance and rheology of waste-based asphalts have been extensively studied, only a hand-full of studies have assessed the adhesiveness of waste-based asphalt binders. This gap in literature limits the wide utilization of waste materials in highway pavements (Gong et al., 2017). The presence of moisture and compounds of high volatility is dependent on the waste material's source; this phenomenon is also a limitation in the replacement of asphalt with bio-oil-based binders. Also the adoption of non-standardized traditional techniques for appraisal, which may not properly represent the real-time resistance to moisture of these alternatives is serious challenge; as such, new and reliable methods, such as surface-free energy should be encouraged (Al-Sabaeei et al., 2020; Cuadri et al., 2015; Gedik, 2020).

\subsubsection{Challenges in practical adoption}

Over the years, the practical application of these solid waste materials in construction has not been effectively adopted by most contractors despite recommendations and encouragement from various researches. Some of the reasons for this include:

i. Rigidity of Designers and Contractors: Most engineering design firms and contractors have become accustomed to the use of conventional materials and are not willing to change methods that have worked for them for several years.

ii. Lack of Research and Development in Small scale construction Firms: Small scale engineering firms handle a great percentage of local constructions in most developing nations. Such firms barely conduct research and as such may not be aware of recent trends in materials and methods for ecofriendly cost-effective construction.

iii. Lack of quality control and ready-availability of Waste Materials: Due to inadequate waste management systems in most developing nations, the collection and sorting of these wastes is rarely properly handled. It can be challenging to get an adequate volume of a required waste material that has not been compromised by other organic or inorganic waste matter.

iv. Lack of fixed replacement ratios: Several researchers have proposed numerous possible mix ratios for the waste integration with both natural aggregates and other waste materials. This is as a result of the variations in the chemical and mechanical properties of these waste materials due to location, handling, parent material composition, etc.

v. Lack of Solid-waste integration in Design standards: Designs are often specified in accordance to standards. Contractors may not be ready to adopt waste materials as these are not expressly specified in most design codes, to avoid any legal action or additional costs in the case of poor performance of constructed works. 


\subsection{Recommendations}

The key recommendations highlighted to address the aforesaid limitations and aid in developing eco-friendly, safe, durable, and cost-efficient pavement materials are abridged in this section. These recommendations present a detailed reference to guide future studies and industrial applications involving the incorporation of wastes as alternatives to conventional natural aggregates and bituminous binders.

For asphalt pavements, it is required that the ageing index for waste-based asphalt binders is determined rather than the pressure ageing vessels and rolling thin film oven (RTFO), because in many cases, they don't properly represent waste materials and field ageing conditions (Aziz et al., 2015). Additionally, interpretation of the mechanism of ageing for waste-based asphalt binders is recommended. Under varying conditions, the long-standing ageing performance of waste-based asphalt should be evaluated (AlSabaeei et al., 2020). Further studies targeted towards the reduction of the ageing of asphalts composed of each selected waste assessed in this study must be undertaken to understand the critical quantity of each waste material that may result in blend incompatibility; the mass loss in polymerization during the sequence of ageing of waste-based binders must be determined (Gedik, 2020). Also, the visco-elastic behavior of waste-based asphalt binders, including the thermal and chemical parameters, developed under various techniques should be comparatively assessed to aid in the development of a more suitable method for producing high-grade waste-based asphalts. The optimal content of wastebased binder for producing hybrid binders, and the adhesion properties should also be identified to enhance the rheological characteristics, and understand the relationship between wastebased asphalts and conventional asphalts.

Further LCA and LCCA research on the use of PET, CKD waste glass, and other waste materials not highlighted in this study is recommended. Finally, to drive the practical adoption of these waste materials in construction, Governments can enact binding legislation or introduce incentives to motivate contractors.

\section{Conclusions}

Several researchers have studied methods in which various solid waste materials can be utilized in the road construction industry. Adequate practical utilization of these materials will lead to significant improvements in the recycling rate of these municipal and industrial solid waste. This concept effectively reduces land requirements for landfills, preserves natural aggregates against depletion, and reduces construction and maintenance costs while improving certain performance criteria. Nonetheless, waste materials must be carefully tested and free from hazardous matter to prevent long-term adverse effects on the environment. Specific deductions are stated as follows:

i. Out of the selected waste materials, only PET, CR, RAP, RAS, steel slag, and bio-oils have been utilized in asphaltic layers, all others were used in pavement sub-layers, or for ground improvement works.

ii. Bio-oil utilization enhanced resistance to fatigue but adversely affected the performance of bio-asphalt blends under high temperatures.

iii Utilization of C and D waste as filler materials for highway embankments is highly efficient in consuming these wastes due to the high-volume requirement. However, its utilization in pavement sublayers is also highly encouraged because of their high load bearing strength. iv Also, steel slag has showed promising signs to be more economical if employed in urban roads in comparison to its usage in rural roads as a result of transportation charges. Adequate data on the geotechnical properties to determine proper utilization of steel slag in road construction is needed, therefore more research is recommended in this area.

$v$ From an economic stand point, a series of LCCAs performed on pavements and other highway facility integrating some of these wastes have been seen to yield significant savings in initial and total life cycle costs, indicating the economic sustainability of these alternative. However, ensuring bulk availability and compositional homogeneity of waste matter to be used is highly recommended before adoption especially if the waste matter had been accumulated for prolonged periods in landfills.

vi A majority of the existing LCAs were conducted on flexible pavements rather than rigid pavements. The most adopted environmental impact criteria assessed were energy consumption and global warming potential. Nonetheless, certain impact criteria, including: ecotoxicity and toxicity that are well associated with solid waste materials were widely understudied.

\section{Declaration of competing interest}

The authors declare that they have no known competing financial interests or personal relationships that could have appeared to influence the work reported in this paper.

\section{Acknowledgments}

The authors wish to thank the chancellor and the management of Covenant University for the platform made available for this research work.

\section{References}

Abukhettala, M., 2016. May). Use of recycled materials in road construction. Proceedings of the 2nd International Conference on Civil, Structural and Transportation Engineering (ICCSTE'16) 138, 1-8.

Abdel-Ghani, N.T., El-Sayed, H.A., El-Habak, A.A., 2018. Utilization of by-pass cement kiln dust and air-cooled blast-furnace steel slag in the production of some "green" cement products. HBRC J. 14 (3), 408-414. https://doi.org/10.1016/ j.hbrcj.2017.11.001.

Abdel Raouf, M., Williams, C.R., 2010. General Rheological Properties of Fractionated Switchgrass Bio-Oil as a Pavement Materials. Road Materials and Pavement Design, EATA, pp. 325-353.

Abdul Rahman, N.R., Hainin, M.R., Abdul Hassan, N., Ani, F.N., 2015. A review on the application of bio-oil as an additive for asphalt. Jurnal Teknologi 72 (5), 105-110.

Achilleos, C., Hadjimitsis, D., Neocleous, K., Pilakoutas, K., Neophytou, P.O., Kallis, S., 2011. Proportioning of steel fibre reinforced concrete mixes for pavement construction and their impact on environment and cost. Sustainability 3 (7), 965-983. https://doi.org/10.3390/su3070965.

Adiansyah, J.S., Rosano, M., Biswas, W., Haque, N., 2017. Life cycle cost estimation and environmental valuation of coal mine tailings management. J. Sus. Min. 16 (3), 114-125. https://doi.org/10.1016/j.jsm.2017.10.004.

Alattieh, S.A., Al-Khateeb, G.G., Zeiada, W., Shanableh, A., 2020. Performance assessment of bio-modified asphalt binder using extracted bio oil from date seeds waste. Int. J. Sys. Ass. Eng. Manag. 1-11.

Alhassan, H.M., Tanko, A.M., 2012. Characterization of solid waste incinerator bottom ash and the potential for its use. Int. J. Eng. Res. Afr. 2 (4), 516-522.

Al-Homidy, A.A., Dahim, M.H., Abd El Aal, A.K., 2017. Improvement of geotechnical properties of sabkha soil utilizing cement kiln dust. J. Rock Mech. Geotech. Eng. 9 (4), 749-760. https://doi.org/10.1016/j.jrmge.2016.11.012.

Al-Sabaeei, A.M., Napiah, M.B., Sutanto, M.H., Alaloul, W.S., Usman, A., 2020. March 10). A systematic review of bio-asphalt for flexible pavement applications: coherent taxonomy, motivations, challenges and future directions. J. Clean. Prod. 249, 119357. https://doi.org/10.1016/j.jclepro.2019.119357.

American Coal Ash Association, 2018. Ash around the world. In: Ash at Work; Applications, Science, and Sustainability of Coal Ash.

Anastasiou, E.K., Liapis, A., Papayianni, I., 2015. Comparative life cycle assessment of concrete road pavements using industrial by-products as alternative materials. Resour. Conserv. Recycl. 101, 1-8. https://doi.org/10.1016/ j.resconrec.2015.05.009.

Anthonissen, J., Van den bergh, W., Braet, J., 2016, September 1. Review and 
environmental impact assessment of green technologies for base courses in bituminous pavements. Environ. Impact Assess. Rev. 60, 139-147. https:// doi.org/10.1016/j.eiar.2016.04.005.

Anthonissen, J., Van den bergh, W., Braet, J., 2017, April 1. Reuse of bituminous pavements: a mini-review of research, regulations and modelling. Waste Manag. Res. 35, 357-366. https://doi.org/10.1177/0734242X16678064.

Araújo, J.P.C., Oliveira, J.R.M., Silva, H.M.R.D., 2014. The importance of the use phase on the LCA of environmentally friendly solutions for asphalt road pavements. Transport. Res. Transport Environ. 32, 97-110. https://doi.org/10.1016/ j.trd.2014.07.006.

Arulrajah, A., Mohammadinia, A., D’Amico, A., Horpibulsuk, S., 2017. Cement kiln dust and fly ash blends as an alternative binder for the stabilization of demolition aggregates. Construct. Build. Mater. 145, 218-225. https://doi.org/10.1016/ j.conbuildmat.2017.04.007.

Arulrajah, A., Mohammadinia, A., Maghool, F., Horpibulsuk, S., 2019a. Tire derived aggregates as a supplementary material with recycled demolition concrete for pavement applications. J. Clean. Prod. 230, 129-136. https://doi.org/10.1016/ j.jclepro.2019.05.084

Arulrajah, A., Mohammadinia, A., Maghool, F., Horpibulsuk, S., 2019b. Tyre derived aggregates and waste rock blends: resilient moduli characteristics. Construct. Build. Mater. 201, 207-217. https://doi.org/10.1016/j.conbuildmat.2018.12.189.

Aurangzeb, Q., Al-Qadi, I.L., Ozer, H., Yang, R., 2014. Hybrid life cycle assessment for asphalt mixtures with high RAP content. Resour. Conserv. Recycl. 83 (1), 77-86. https://doi.org/10.1016/j.resconrec.2013.12.004.

Astup, T., Muntoni, A., Polettini, A., Pomi, R., Van Gerven, T., Van Zomeren, A., 2016. Treatment and Reuse of incineration bottom ash. In: Prasad, M.N.V., Kaimin, K. (Eds.), Environmental Materials and Waste, Resource Recovery and Pollution Prevention. Academic Press, London. https://doi.org/10.1016/B978-0-12803837-6.00024-X.

Azahar, W.N.A.W., Jaya, R.P., Hainin, M.R., Bujang, M., Ngadi, N., 2016. Chemical modification of waste cooking oil to improve the physical and rheological properties of asphalt binder. Construct. Build. Mater. 126, 218-226. https:// doi.org/10.1016/j.conbuildmat.2016.09.032.

Azahar, W.N.A.W., Jaya, R.P., Hainin, M.R., Bujang, M., Ngadi, N., 2017. Mechanical performance of asphaltic concrete incorporating untreated and treated waste cooking oil. Construct. Build. Mater. 150, 653-663. https://doi.org/10.1016/ j.conbuildmat.2017.06.048.

Azarijafari, H., Yahia, A., Amor, B., 2015. Life Cycle Assessment of Concrete and Asphalt Pavements: a Case Study in the Province of Quebec (Canada).

Azhar Butt, A., 2014. Life cycle assessment of asphalt roads. KTH Royal Institute of Technology, Stockholm. Retrieved from. https://www.diva-portal.org/smash/ record.jsf?pid=diva2:763875.

Aziz, M.M.A., Rahman, M.T., Hainin, M.R., Bakar, W.A.W.A., 2015. June 1). An overview on alternative binders for flexible pavement. Construct. Build. Mater. 84, 315-319. https://doi.org/10.1016/j.conbuildmat.2015.03.068.

Babadagli, T., Ozum, B., 2012. BioDiesel as additive in high pressure and temperature steam recovery of heavy oil and bitumen. Oil \& Gas Science and Technology - Revue d'IFP Energies Nouvelles 67 (3), 413-421. https://doi.org/ $10.2516 /$ ogst/2011164.

Babashamsi, P., Md Yusoff, N.I., Ceylan, H., Md Nor, N.G., Salarzadeh Jenatabadi, H., 2016, July 1. Evaluation of pavement life cycle cost analysis: review and analysis. Int. J. Pave. Res. Technol. 9, 241-254. https://doi.org/10.1016/j.ijprt.2016.08.004.

Bamigboye, G.O., Ngene, B.U., Ademola, D., Jolayemi, J.K., 2019. Experimental study on the use of waste polyethylene terephthalate (PET) and river sand in roof tile production. In: J. Phys. Conf., 1378. IOP Publishing, 042105. https://doi:10.1088/ 1742-6596/1378/4/042105.

Bamigboye, G.O., Ede, A.N., Raheem, A.A., Olofinnade, O.M., Okorie, U., 2016. Economic exploitation of gravel in place of granite in concrete production. In: Materials Science Forum, 866. Trans Tech Publications Ltd, pp. 73-77.

Bakare, M.D., Pai, R.R., Patel, S., Shahu, J.T., 2019. Environmental sustainability by bulk utilization of fly ash and GBFS as road subbase materials. Journal of Hazardous, Toxic, and Radioactive Waste 23 (4), 1-10. https://doi.org/10.1061/ (ASCE)HZ.2153-5515.0000450.

Balaguera, A., Carvajal, G.I., Albertí, J., Fullana-i-Palmer, P., 2018. Life cycle assessment of road construction alternative materials: a literature review. Resour. Conserv. Recycl. 132 (December 2017), 37-48. https://doi.org/10.1016/ j.resconrec.2018.01.003.

Bao, D.X., Yu, Y.Y., Zhao, Q.M., 2019. Evaluation of the chemical composition and rheological properties of bio-asphalt from different biomass sources. In: Road Materials and Pavement Design. https://doi.org/10.1080/14680629.2019.1568287.

Barco Carrión, A. J. del, Lo Presti, D., Pouget, S., Airey, G., Chailleux, E., 2017. Linear viscoelastic properties of high reclaimed asphalt content mixes with biobinders. Road Mater. Pavement Des. 18, 241-251. https://doi.org/10.1080/ 14680629.2017.1304253.

Bare, J., 2011. Traci 2.0: the tool for the reduction and assessment of chemical and other environmental impacts 2.0. Clean Technol. Environ. Policy 13 (5), 687-696. https://doi.org/10.1007/s10098-010-0338-9.

Bloom, E., Canton, A., Ahlman, A.P., Edil, T., 2017. Life Cycle Assessment of Highway Reconstruction: A Case Study.

Bonicelli, A., Fuentes, L.G., Dawd Bermejo, I.K., 2017. Laboratory investigation on the effects of natural fine aggregates and recycled waste tire rubber in pervious concrete to develop more sustainable pavement materials. IOP Conf. Ser. Mater. Sci. Eng. 245 (3) https://doi.org/10.1088/1757-899X/245/3/032081.

Booz, Allen, Hamilton, 2013. Analysis of recycling of asphalt shingles in pavement mixes from a life cycle perspective. In: U.S. Environmental Protection Agency,
Region 8 Resource Conservation and Recovery Program Industrial Materials Recycling. Retrieved from. http://www.asphaltpavement.org/PDFs/EPA Analysis_of_Recycling_of_Asphalt_Shingles_in_Pavement_Mixes.pdf.

BP Statistical Review of World Energy, 2019. BP statistical review of world energy. In: BP Statistical Review of World Energy 68th Edition. Retrieved from. https:// www.bp.com/content/dam/bp/business-sites/en/global/corporate/pdfs/energyeconomics/statistical-review/bp-stats-review-2019-full-report.pdf.

Busari, A.A., Akinwumi, I.I., Awoyera, P.O., Olofinnade, O.M., Tenebe, T.I., Nwanchukwu, J.C., 2018. Stabilization effect of aluminum dross on tropical lateritic soil. Int. J. Eng. Res. Afr. 39, 86-96. https://doi.org/10.4028/www. scientific.net/JERA.39.86.

Busari, A., Joseph, F., Ajayi, S., Alayande, T., Nwachukwu, J., Agbama, D., 2019. Index properties of aluminum dross modified pavement geo-material. J. Phys. Conf. 1378 (2) https://doi.org/10.1088/1742-6596/1378/2/022102.

Butler, J.H., Hooper, P.D., 2019. Chapter 15 - glass waste. In: Waste, second ed. https://doi.org/10.1016/B978-0-12-815060-3.00015-3

Center for Health Environment \& Justice, 2011. Cement kilns. FactPACK - P040 https://doi.org/10.1201/ebk1420085280-c31.

Chen, S., Lin, D., Luo, H., Lin, Z., 2017. Application of reclaimed basic oxygen furnace slag asphalt pavement in road base aggregate. Construct. Build. Mater. 157, 647-653. https://doi.org/10.1016/j.conbuildmat.2017.09.136.

Chen, D., Gao, D., Capareda, S.C., Huang, S., Wang, Y., 2019. Effects of hydrochloric acid washing on the microstructure and pyrolysis bio-oil components of sweet sorghum bagasse. Bioresour. Technol. 277, 37-45.

Claisse, P.A., 2016. Civil Engineering Materials. Elsevier B.H. Waltham, MA 02451, USA.

Chiu, C. Te, Hsu, T.H., Yang, W.F., 2008. Life cycle assessment on using recycled materials for rehabilitating asphalt pavements. Resour. Conserv. Recycl. 52 (3), 545-556. https://doi.org/10.1016/j.resconrec.2007.07.001.

Chowdhury, R., Apul, D., Fry, T., 2010. A life cycle based environmental impacts assessment of construction materials used in road construction. Resour. Conserv. Recycl. 54 (4), 250-255. https://doi.org/10.1016/j.resconrec.2009.08.007.

Cuadri, A.A., Partal, P., Ahmad, N., Grenfell, J., Airey, G., 2015. Chemically modified bitumens with enhanced rheology and adhesion properties to siliceous aggregates. Construct. Build. Mater. 93, 766-774. https://doi.org/10.1016/ j.conbuildmat.2015.05.098.

Ddamba, S., 2011. Evaluation of the effect of recycled asphalt shingles on ontario hot mix pavement. University of Waterloo, Ontario, Canada. Retrieved from. http:// hdl.handle.net/10012/6285.

Delongui, L., Matuella, M., Núñez, W.P., Fedrigo, W., Carlos, L., Filho, S., et al., 2018. Construction and demolition waste parameters for rational pavement design. Construct. Build. Mater. 168, 105-112. https://doi.org/10.1016/ j.conbuildmat.2018.02.086.

Ding, Y., Huang, B., Hu, W., Tang, B., Yu, M., 2019. Utilizing recycled asphalt shingle into pavement by extraction method. J. Clean. Prod. 236 https://doi.org/10.1016/ j.jclepro.2019.117656.

Djellali, A., Laouar, M.S., Saghafi, B., Houam, A., 2019. Evaluation of cementstabilized mine tailings as pavement foundation materials. Geotech. Geol. Eng. 37 (4), 2811-2822. https://doi.org/10.1007/s10706-018-00796-8.

Donnelly, L.J., Bell, F.G., 2011. Geotechnical and environmental problems. Coal and spontaneous combustion. In: Coal and Peat Fires: A Global Perspective, pp. 83-100. https://doi.org/10.1016/B978-0-444-52858-2.00005-0.

Duangburong, J., Tantayanon, S., Bhandhubanyong, P., 2015. A breakthrough challenge with tyre waste management: Thailand perspective. Int. J. Soc. Sci. Humanit. 5 (9), 768-772. https://doi.org/10.7763/ijssh.2015.v5.553.

Eberemu, A.O., Osinubi, K.J., Ijimdiya, T.S., Sani, J.E., 2019. Cement kiln dust: locust bean waste ash blend stabilization of tropical black clay for road construction. Geotech. Geol. Eng. 37 (4), 3459-3468. https://doi.org/10.1007/s10706-01800794-W.

Ebrahim, A., Behiry, A.E., 2013. Evaluation of steel slag and crushed limestone mixtures as subbase material in flexible pavement. Ain Shams Engineering Journal 4 (1), 43-53. https://doi.org/10.1016/j.asej.2012.07.006.

Ede, A.N., 2014. Cumulative damage effects of truck overloads on Nigerian road pavement. Int. J. Civ. Environ. Eng. 14, 21-26, 01.

Etim, R.K., Eberemu, A.O., Osinubi, K.J., 2017. Stabilization of black cotton soil with lime and iron ore tailings admixture. Transportation Geotechnics 10, 85-95. https://doi.org/10.1016/j.trgeo.2017.01.002.

Evangelista, L., De Brito, J., 2007. Environmental Life Cycle Assessment of Concrete Made with Fine Recycled Concrete Aggregates. Portugal SB 2007 - Sustainable Construction, Materials and Practices: Challenge of the Industry for the New Millennium, pp. 789-794.

Farina, A., Zanetti, M.C., Santagata, E., Blengini, G.A., 2017. Life cycle assessment applied to bituminous mixtures containing recycled materials: crumb rubber and reclaimed asphalt pavement. Resour. Conserv. Recycl. 117, 204-212. https:// doi.org/10.1016/j.resconrec.2016.10.015.

Fernandes, S., Silva, H.M.R.D., Oliveira, J.R.M., 2019. Mechanical, surface and environmental evaluation of stone mastic asphalt mixtures with advanced asphalt binders using waste materials. Road Mater. Pavement Des. 20 (2), 316-333. https://doi.org/10.1080/14680629.2017.1387169.

Ferreira, A., Santos, J., 2013. Life-cycle cost analysis system for pavement management at project level: sensitivity analysis to the discount rate. Int. J. Pavement Eng. 14 (7), 655-673. https://doi.org/10.1080/10298436.2012.719618.

Ferreira, V.J., Sáez-De-Guinoa Vilaplana, A., García-Armingol, T., Aranda-Usón, A., Lausín-González, C., López-Sabirón, A.M., Ferreira, G., 2016. Evaluation of the steel slag incorporation as coarse aggregate for road construction: technical 
requirements and environmental impact assessment. J. Clean. Prod. 130, 175-186. https://doi.org/10.1016/j.jclepro.2015.08.094.

Fini, E.H., Hosseinnezhad, S., Oldham, D.J., Chailleux, E., Gaudefroy, V., 2017. Source dependency of rheological and surface characteristics of bio-modified asphalts. Road Mater. Pavement Des. 18 (2), 408-424. https://doi.org/10.1080/ 14680629.2016.1163281.

Fini, E.H., Al-Qadi, I.L., You, Z., Zada, B., Mills-Beale, J., 2012. Partial replacement of asphalt binder with bio-binder: characterization and modification. Int. J. Pavement Eng. 13 (6), 515-522.

Finnveden, G., Hauschild, M.Z., Ekvall, T., Guinée, J., Heijungs, R., Hellweg, S., et al., 2009, October. Recent developments in life cycle assessment. J. Environ. Manag. 91, 1-21. https://doi.org/10.1016/j.jenvman.2009.06.018.

Ganiron, T.U.J., 2014. Waste tire as an asphalt cement modifier for road pavement. International Journal of $U$ - and e-Service, Science and Technology 7 (5), 181-194. https://doi.org/10.14257/ijunesst.2014.7.5.17.

Gao, J., Sha, A., Wang, Z., Tong, Z., Liu, Z., 2017. Utilization of steel slag as aggregate in asphalt mixtures for microwave deicing. J. Clean. Prod. 152, 429-442. https:// doi.org/10.1016/j.jclepro.2017.03.113.

Garside, M., 2019. • Sand and gravel production global by country 2018 | Statista. Retrieved December 2, 2019, from. https://www.statista.com/statistics/376665/ industrial-sand-and-gravel-production-by-top-countries/.

Gautam, P.K., Kalla, P., Jethoo, A.S., Agrawal, R., 2018. Sustainable use of waste in flexible pavement : a review. Construct. Build. Mater. 180, 239-253. https:// doi.org/10.1016/j.conbuildmat.2018.04.067.

Gedik, A., 2020. A review on the evaluation of the potential utilization of construction and demolition waste in hot mix asphalt pavements. Resour. Conserv. Recycl. 161, 104956. https://doi.org/10.1016/j.resconrec.2020.104956.

Ghataora, G.S., Ghazireh, N., Hall, N., 2015. Remediation of acid generating colliery spoil using steel slag - case studies. Studia Geotechnica Mech. 37 (2), 75-84. https://doi.org/10.1515/sgem-2015-0024.

Gökalp, I., Uz, V.E., Saltan, M., Tutumluer, E., 2018. Technical and environmental evaluation of metallurgical slags as aggregate for sustainable pavement layer applications. Transportation Geotechnics 14, 61-69. https://doi.org/10.1016/ j.trgeo.2017.10.003.

Gong, M., Zhu, H., Pauli, T., Yang, J., Wei, J., Yao, Z., 2017. Evaluation of bio-binder modified asphalt's adhesion behavior using sessile drop device and atomic force microscopy. Construct. Build. Mater. 145, 42-51. https://doi.org/10.1016/ j.conbuildmat.2017.03.114.

Government of India-Ministry of Steel, 2019. Strategy on resource efficiency in steel sector. In: NITI Aayog, 53. https://doi.org/10.1017/CBO9781107415324.004.

Goyal, H.B., Seal, D., Saxena, R.C., 2008, February 1. Bio-fuels from thermochemical conversion of renewable resources: a review. Renew. Sustain. Energy Rev. 12, 504-517. https://doi.org/10.1016/j.rser.2006.07.014.

Günay, E., Kara, M., Kavakli, B., Tayfur, S., Eren, K., Yildirim, S.A., 2004. Steel slag and waste management. Key Eng. Mater. 264-268 (III), 2481-2484. https://doi.org/ 10.4028/www.scientific.net/kem.264-268.2481.

Haas, E., Ericson, C.L., Bennert, T., 2019. Laboratory designed hot mix asphalt mixtures with post-consumer Recycled Asphalt Shingles (RAS) utilizing AASHTO PP78. Construct. Build. Mater. 226, 662-672. https://doi.org/10.1016/ j.conbuildmat.2019.07.314.

Hassan, K.E., Elghali, L., Soerby, C.R., 2004. Development of New Materials for Secondary and Recycled Aggregates in Highway Infrastructure. TRL Limited. TRL Report TRL598.

Han, L., Zheng, M., Wang, C., 2016, December 15. Current status and development of terminal blend tyre rubber modified asphalt. Construct. Build. Mater. 128, 399-409. https://doi.org/10.1016/j.conbuildmat.2016.10.080.

Hao, H., Geng, Y., Hang, W., 2016. GHG emissions from primary aluminum production in China: regional disparity and policy implications. Appl. Energy 166, 264-272. https://doi.org/10.1016/j.apenergy.2015.05.056.

Harder, J., 2018. Glass recycling - current market trends. Retrieved December 4, 2019, from Recovery: Recycling Technology Worldwide website: https://www. recovery-worldwide.com/en/artikel/glass-recycling-current-market-trends_ 3248774.html.

Harvey, J.T., Kendall, A., Lee, I., Santero, N., Van Dam, T., T, W., 2010. Pavement life cycle assessment workshop: discussion summary and guidelines. Ucprc.Ucdavis.Edu (UCPRC-TM-2010-03), 29. Retrieved from. http://www.uest.gr/suscon/ Progress-Results/progress-results.html.

Heidrich, C., Feuerborn, H., Weir, A., 2013. Coal combustion Products : a global perspective. In: World of Coal Ash (WOCA) Conference. Retrieved from. http:// www.flyash.info/\%0ACoal.

Hicks, R.G., Epps, J.A., 2000. Life cycle cost analysis OF asphalt-rubber paving materials. World of Asphalt Pavements, 1st International Conference. Retrieved from. https://trid.trb.org/view/690169.

Hoang, T., Jullien, A., Ventura, A., Crozet, Y., 2005. A global methodology for sustainable road - application to the environmental assessment of French highway. In: International Conference on Durability of Building Materials and Components. April.

Hopewell, J., Dvorak, R., Kosior, E., 2009. July 27). Plastics recycling: challenges and opportunities. Phil. Trans. Biol. Sci. 364, 2115-2126. https://doi.org/10.1098/ rstb.2008.0311.

Hoy, M., Horpibulsuk, S., Rachan, R., Chinkulkijniwat, A., Arulrajah, A., 2016. Recycled asphalt pavement - fly ash geopolymers as a sustainable pavement base material: strength and toxic leaching investigations. Sci. Total Environ. 573, 19-26. https://doi.org/10.1016/j.scitotenv.2016.08.078.

Huang, Y., Bird, R., Heidrich, O., 2009. Development of a life cycle assessment tool for construction and maintenance of asphalt pavements. J. Clean. Prod. 17 (2), 283-296. https://doi.org/10.1016/j.jclepro.2008.06.005.

Huang, Y., Bird, R.N., Heidrich, O., 2007. A review of the use of recycled solid waste materials in asphalt pavements. Resour. Conserv. Recycl. 52 (1), 58-73. https:// doi.org/10.1016/j.resconrec.2007.02.002.

Huang, Y., Hakim, B., Zammataro, S., 2013. Measuring the carbon footprint of road construction using CHANGER. Int. J. Pavement Eng. 14 (6), 590-600. https:// doi.org/10.1080/10298436.2012.693180.

Indian Road Congress, 2012. Tentative guidelines for the design of flexible pavements. In: Indian Road Congress.

Ingrassia, L.P., Lu, X., Ferrotti, G., Canestrari, F., 2020. Chemical, morphological and rheological characterization of bitumen partially replaced with wood bio-oil: towards more sustainable materials in road pavements. J. Traffic Transport. Eng. 7 (2), 192-204.

Inyim, P., Pereyra, J., Bienvenu, M., Mostafavi, A., 2016, July 1. Environmental assessment of pavement infrastructure: a systematic review. J. Environ. Manag. 176, 128-138. https://doi.org/10.1016/j.jenvman.2016.03.042.

Jadhav, A., Kakade, V., 2019. Study of aluminium dross and ordinary Portland cement modified cold bituminous emulsion mix. Proc. Inst. Civ. Eng.: Construction Materials 172 (3), 164-169. https://doi.org/10.1680/jcoma.17.00050.

Jala, S.K., Sharma, P., 2019. Effect of cement kiln dust and RBI grade 81 on engineering properties of plastic clay. In: Lecture Notes in Civil Engineering, 32, pp. 37-49. https://doi.org/10.1007/978-981-13-7017-5_5.

Jalkh, R., El-Rassy, H., Chehab, G.R., Abiad, M.G., 2018. Assessment of the physicochemical properties of waste cooking oil and spent coffee grounds oil for potential use as asphalt binder rejuvenators. Waste and Biomass Valorization 9 (11), 2125-2132. https://doi.org/10.1007/s12649-017-9984-z.

Javali, S., Chandrashekar, A.R., Naganna, S.R., Manu, D.S., Hiremath, P., Preethi, H.G., Vinod Kumar, N., 2017. Eco-concrete for sustainability: utilizing aluminium dross and iron slag as partial replacement materials. Clean Technol. Environ. Policy 19 (9), 2291-2304. https://doi.org/10.1007/s10098-017-1419-9.

Jawad, D., Ozbay, K., 2006. The discount rate in life cycle cost analysis of. 85th Annual Meeting of the Transportation Research Board 1-19.

Johnson, G.K., 2017. The asphalt shingle recycling process | general kinematics. Retrieved May 2, 2020, from. https://www.generalkinematics.com/blog/ asphalt-shingle-recycling-process/.

Jullien, A., Dauvergne, M., Proust, C., 2015. Road LCA: the dedicated ECORCE tool and database. Int. J. Life Cycle Assess. 20 (5), 655-670. https://doi.org/10.1007/ s11367-015-0858-y.

Jung, S., Santagata, M., 2014. Expansive behavior of coal mine spoils treated with calcium-based stabilizers. Eng. Geol. 175, 46-57. https://doi.org/10.1016/ j.enggeo.2014.03.013.

Kadhim, M.A., Al-Busaltan, S., Almuhanna, R.R., 2019. An evaluation of the effect of crushed waste glass on the performance of cold bituminous emulsion mixtures. Int. J. Pave. Res. Technol. 12 (4), 396-406. https://doi.org/10.1007/s42947-0190047-7.

Kakar, M.R., Hamzah, M.O., Valentin, J., 2015. A review on moisture damages of hot and warm mix asphalt and related investigations. J. Clean. Prod. 99, 39-58. https://doi.org/10.1016/j.jclepro.2015.03.028.

Kokh, S.N., Sokol, E.V., Sharygin, V.V., 2015. Ellestadite-group minerals in combustion metamorphic rocks. In: Coal and Peat Fires: A Global Perspective, 3, pp. 543-562. https://doi.org/10.1016/B978-0-444-59509-6.00020-X.

Kousis, I., Fabiani, C., Ercolanoni, L., Pisello, A.L., 2020. Using bio-oils for improving environmental performance of an advanced resinous binder for pavement applications with heat and noise island mitigation potential. Sustainable Energy Technologies and Assessments 39. https://doi.org/10.1016/j.seta.2020.100706.

Król, J.B., Kowalski, K.J., Niczke, Ł., Radziszewski, P., 2016. Effect of bitumen fluxing using a bio-origin additive. Construct. Build. Mater. 114, 194-203. https:// doi.org/10.1016/j.conbuildmat.2016.03.086.

Kumar, V., Panwar, R.S., 2019. Mitigation of greenhouse gas emissions by fly ash stabilization and sisal fibre reinforcement of clay subgrade for road construction. IOP Conf. Ser. Earth Environ. Sci. 219 (1) https://doi.org/10.1088/17551315/219/1/012020.

Kurpinska, M., Grzyl, B., Pszczola, M., Kristowski, A., 2019. The application of granulated expanded glass aggregate with cement grout as an alternative solution for sub-grade and frost-protection sub-base layer in road construction. Materials 12 (21). https://doi.org/10.3390/ma12213528.

Leite, C., Motta, S., Vasconcelos, K.L., Bernucci, L., 2011. Laboratory evaluation of recycled construction and demolition waste for pavements. Construct. Build. Mater. 25, 2972-2979. https://doi.org/10.1016/j.conbuildmat.2010.11.105.

Li, Jiangwei, Shen, W., Zhang, B., Ji, X., Chen, X., Ma, W., et al., 2019. Investigation on the preparation and performance of clinker-fly ash-gypsum road base course binder. Construct. Build. Mater. 212, 39-48. https://doi.org/10.1016/ j.conbuildmat.2019.03.253.

Lo Presti, Davide, 2013, December 1. Recycled Tyre Rubber Modified Bitumens for road asphalt mixtures: a literature review. Construct. Build. Mater. 49, 863-881. https://doi.org/10.1016/j.conbuildmat.2013.09.007.

Presti, Lo Davide, Airey, G., Partal, P., 2012. Manufacturing terminal and field bitumen-tyre rubber blends: the importance of processing conditions. Procedia - Social and Behavioral Sciences 53, 485-494. https://doi.org/10.1016/ j.sbspro.2012.09.899.

López-Alonso, M., Martinez-Echevarria, M.J., Garach, L., Galán, A., Ordoñez, J., Agrela, F., 2019. Feasible use of recycled alumina combined with recycled aggregates in road construction. Construct. Build. Mater. 195, 249-257. https:// doi.org/10.1016/j.conbuildmat.2018.11.084. 
Luo, H.-L., Chen, S.-H., Lin, D.-F., Cai, X.-R., 2017. Use of incinerator bottom ash in open-graded asphalt concrete. Construct. Build. Mater. 149, 497-506.

Lozano, D.C.P., Ramírez, C.X., Chaparro, J.A.S., Thomas, M.J., Gavard, R., Jones, H.E., et al., 2020. Characterization of bio-crude components derived from pyrolysis of soft wood and its esterified product by ultrahigh resolution mass spectrometry and spectroscopic techniques. Fuel 259, 116085.

Maharaj, R., Maharaj, C., Mahase, M., 2019. The performance and durability of polyethylene terephthalate and crumb rubber-modified road pavement surfaces. Prog. Rubber Plast. Recycl. Technol. 35 (1), 3-22. https://doi.org/10.1177/ 1477760618798425

Mahinroosta, M., Allahverdi, A., 2018, October 1. Hazardous aluminum dross characterization and recycling strategies: a critical review. J. Environ. Manag. 223, 452-468. https://doi.org/10.1016/j.jenvman.2018.06.068.

Majer, S., Budziński, B., 2018. Utilization of recycled materials in road construction. Sofia. International Multidisciplinary Scientific GeoConference : SGEM 18 (4.2), 247-253. https://doi.org/10.5593/sgem2018/4.2/S18.032.

Malhotra, K., 2019. Iron and steel slag Utilization : a comprehensive analysis. International Journal of Engineering Science Invention (IJESI) 8, 69-74, 08.

Manjula Devi, B., Chore, H.S., 2019. Use of reclaimed rubber cell in highway pavement: an experimental research. Int. J. Innovative Technol. Explor. Eng. 8 (6 Special Issue 4), 1047-1052. https://doi.org/10.35940/ijitee.F1216.0486S419.

Marinković, S.B., Ignjatović, I., Radonjanin, V., 2013. Life-cycle assessment (LCA) of concrete with recycled aggregates (RAs). In: Handbook of Recycled Concrete and Demolition Waste, pp. 569-604. https://doi.org/10.1533/ 9780857096906.4.569.

Martinez-Arguelles, G., Acosta, M.P., Dugarte, M., Fuentes, L., 2019. Life cycle assessment of natural and recycled concrete aggregate production for road pavements applications in the northern region of Colombia: case study. Transport. Res. Rec. 2673 (5), 397-406. https://doi.org/10.1177/ 0361198119839955.

McGraw, J., Zofka, A., Krivit, D., Schroer, J., Olson, R., Marasteanu, M., 2007. Recycled asphalt shingles in hot mix asphalt. Asphalt Paving Technology: Association of Asphalt Paving Technologists-Proceedings of the Technical Sessions 76, 235-274.

Miliutenko, S., Björklund, A., Carlsson, A., 2013. Opportunities for environmentally improved asphalt recycling: the example of Sweden. J. Clean. Prod. 43, 156-165. https://doi.org/10.1016/j.jclepro.2012.12.040.

Mladenovič, A., Turk, J., Kovač, J., Mauko, A., Cotič, Z., 2015. Environmental evaluation of two scenarios for the selection of materials for asphalt wearing courses. J. Clean. Prod. 87 (C), 683-691. https://doi.org/10.1016/j.jclepro.2014.10.013.

Modarres, A., Ayar, P., 2014. Coal waste application in recycled asphalt mixtures with bitumen emulsion. J. Clean. Prod. 83, 263-272. https://doi.org/10.1016/ j.jclepro.2014.07.082.

Mohammad, L.N., Elseifi, M., Cooper, S.B., Challa, H., Naidoo, P., 2013. Laboratory Evaluation of Asphalt Mixtures Containing Bio-Binder Technologies, Airfield and Highway Pavement: Sustainable and Efficient Pavements. ASCE, pp. 128-152.

Mohamedzein, Y.-A., Al-Aghbari, M.Y., 2012. The use of municipal solid waste incinerator ash to stabilize dune sands. Geotechnics and Geological Engineering 30, 1335-1344.

Morrissey, J., Horne, R.E., 2011. Life cycle cost implications of energy efficiency measures in new residential buildings. Energy Build. 43 (4), 915-924. https:// doi.org/10.1016/j.enbuild.2010.12.013.

Mroueh, U.M., Laine-Ylijoki, J., Eskola, P., 2000. Life-cycle impacts of the use of industrial by-products in road and earth construction. Waste Manag. 1 (C), 438-448. https://doi.org/10.1016/S0713-2743(00)80055-0.

Mturi, G.A.J., O'Connell, J., Zoorob, S.E., De Beer, M., 2014. A study of crumb rubber modified bitumen used in South Africa. Road Mater. Pavement Des. 15 (4), 774-790. https://doi.org/10.1080/14680629.2014.910130.

Muench, S.T., 2010. Roadway construction sustainability impacts. Transport. Res. Rec.: Journal of the Transportation Research Board 2151 (1), 36-45. https:// doi.org/10.3141/2151-05.

Muench, S.T., Lin, Y.Y., Katara, S., Armstrong, A., 2014. Roadprint: practical pavement life cycle assessment (LCA) using generally available data. In: International Symposium on Pavement LCA 2014, 249-262. Retrieved from. http://www. ucprc.ucdavis.edu/P-LCA2014/media/pdf/Papers/LCA14 Roadprint LCA pdf.

Mukherjee, A., Cass, D., 2012. Project emissions estimator. Transport. Res. Rec.: Journal of the Transportation Research Board 2282 (1), 91-99. https://doi.org/ $10.3141 / 2282-10$

Nayak, P., Sahoo, U.C., 2017. Rheological, chemical and thermal investigations on an aged binder rejuvenated with two non-edible oils. Road Mater. Pavement Des. 18 (3), 612-629. https://doi.org/10.1080/14680629.2016.1182058.

Nazzal, M.D., Iqbal, M.T., Kim, S.S., Abbas, A.R., Akentuna, M., Quasem, T., 2016. Evaluation of the long-term performance and life cycle costs of GTR asphalt pavements. Construct. Build. Mater. 114, 261-268. https://doi.org/10.1016/ j.conbuildmat.2016.02.096.

Nie, X., Li, Z., Yao, H., Hou, T. Zhou, X., Li, C., 2020. Waste bio-oil as a compatibilizer for high content SBS modified asphalt. Petrol. Sci. Technol. 38 (4), 316-322.

Nicuță, A., 2011. Life cycle assessment study for new and recycled asphalt pavements. In: Bulletin of the Polytechnic Institute of Iasi - Construction. Retrieved from. https://www.researchgate.net/publication/311261589.

Ohemeng, E.A., Ekolu, S.O., 2020. A review on the reactivation of hardened cement paste and treatment of recycled aggregates. Mag. Concr. Res. 72 (10), 526-539. https://doi.org/10.1680/jmacr.18.00452.

Ojuri, O.O., Adavi, A.A., Oluwatuyi, O.E., 2017. Geotechnical and environmental evaluation of lime-cement stabilized soil-mine tailing mixtures for highway construction. Transportation Geotechnics 10, 1-12. https://doi.org/10.1016 j.trgeo.2016.10.001.

Okolie, J.A., Nanda, S., Dalai, A.K., Berruti, F., Kozinski, J.A., 2020. A review on subcritical and supercritical water gasification of biogenic, polymeric and petroleum wastes to hydrogen-rich synthesis gas. Renew. Sustain. Energy Rev. 11

Oldham, D.J., Fini, E.H., Chailleux, E., 2015. Application of a bio-binder as a rejuvenator for wet processed asphalt shingles in pavement construction. Construct. Build. Mater. 86, 75-84. https://doi.org/10.1016/j.conbuildmat.2015.03.085.

Oluwasola, E.A., Hainin, M.R., Aziz, M.M.A., 2015. Evaluation of asphalt mixtures incorporating electric arc furnace steel slag and copper mine tailings for road construction. Transportation Geotechnics 2, 47-55. https://doi.org/10.1016/ j.trgeo.2014.09.004.

Oluwasola, E.A., Hainin, M.R., Aziz, M.M.A., 2016. Comparative evaluation of densegraded and gap-graded asphalt mix incorporating electric arc furnace steel slag and copper mine tailings. J. Clean. Prod. 122, 315-325. https://doi.org/10.1016/ j.jclepro.2016.02.051.

Opiso, E.M., Supremo, R.P., Perodes, J.R., 2019. Effects of coal fly ash and fine sawdust on the performance of pervious concrete. Heliyon 5 (11), e02783. https:// doi.org/10.1016/j.heliyon.2019.e02783.

Ozbay, K., Parker, N.A., Jawad, D., 2003. Guidelines for life cycle cost analysis Retrieved from. http://cait.rutgers.edu/files/FHWA-NJ-2003-012.pdf.

Ozer, C., Boysan, F., Cırık, S., 2015. Technical note, recycling of glass waste - an application for the esentepe campus of sakarya university. Procedia Earth and Planetary Science 15, 602-606. https://doi.org/10.1016/j.proeps.2015.08.111.

Park, J.Y., Lee, D.E., Kim, B.S., 2019. Environmental performance analysis and economic perspectives of concrete girders. KSCE Journal of Civil Engineering 23 (11), 4592-4600. https://doi.org/10.1007/s12205-019-0812-9.

Patra, S., Whaung, S.T., Kwan, W.L., 2017. Analysis of heavy metals in incineration bottom ash in Singapore and potential impact of pre-sorting on ash quality. Energy Procedia 143, 454-459. https://doi.org/10.1016/j.egypro.2017.12.710.

Perera, S., Arulrajah, A., Wong, Y.C., Horpibulsuk, S., Maghool, F., 2019. Utilizing recycled PET blends with demolition wastes as construction materials. Construct. Build. Mater. 221, 200-209. https://doi.org/10.1016/ j.conbuildmat.2019.06.047.

Picado-Santos, L.G., Capitão, S.D., Neves, J.M.C., 2020. June 30). Crumb rubber asphalt mixtures: a literature review. Construct. Build. Mater. 247, 118577. https://doi.org/10.1016/j.conbuildmat.2020.118577.

Pivsaev, V.Y., Krasnikov, P.E., Pimenov, A.A., Bykov, D.E., 2015. Enhancement of adhesive properties of road asphalts, waste oil processing products. Petrol. Chem. 55 (1), 80-83. https://doi.org/10.1134/S0965544115010119.

Podolsky, J.H., Buss, A., Williams, R.C., Hernández, N., Cochran, E.W., 2017. Rejuvenation of vacuum tower bottoms through bio-derived materials for use in paving flexible roadways. J. Clean. Prod. 143, 1081-1093. https://doi.org/ 10.1016/j.jclepro.2016.12.011.

Porot, L., Broere, D., Wistuba, M., Grönniger, J., 2017. Asphalt and binder evaluation of asphalt mix with $70 \%$ reclaimed asphalt. Road Mater. Pavement Des. 18, 66-75. https://doi.org/10.1080/14680629.2017.1304259.

Pranav, S., Aggarwal, S., Yang, E.H., Kumar Sarkar, A., Pratap Singh, A., Lahoti, M. 2020. Alternative materials for wearing course of concrete pavements: a critical review. Construct. Build. Mater. 236, 117609. https://doi.org/10.1016 j.conbuildmat.2019.117609.

Presti, D Lo, Airey, G., Liberto, M. Di, Noto, S., Mino, G. Di, Blasl, A., et al., 2017. AllBack2Pave: towards a sustainable recycling of asphalt in wearing courses. Transport Infrastructure and Systems 1-8. https://doi.org/10.1201/9781315281896-17.

Qadir, A., Gazder, U., Ali, S., 2018. Comparison of SBS and PP fibre asphalt modifications for rutting potential and life cycle costs of flexible pavements. Road Mater. Pavement Des. 19 (2), 484-493. https://doi.org/10.1080/14680629.2016.1259124.

Rad, S.A.M., Modarres, A., 2017. Durability properties of non-air entrained roller compacted concrete pavement containing coal waste ash in presence of deicing salts. Cold Reg. Sci. Technol. 137, 48-59. https://doi.org/10.1016/ j.coldregions.2017.02.006.

Rahman, W.M.N.W.A., Wahab, A.F.A., 2013. Green pavement using recycled Polyethylene Terephthalate (PET) as partial fine aggregate replacement in modified asphalt. Procedia Eng. 53,124-128. https://doi.org/10.1016/j.proeng.2013.02.018.

Raman, N.A.A., Hainin, M.R., Hassan, N.A., Ani, F.N., 2015. A review on the application of bio-oil as an additive for asphalt. Jurnal Teknologi 72 (5), 105-110 https://doi.org/10.11113/jt.v72.3948.

Rodríguez-Fernández, I., Tarpoudi Baheri, F., Cavalli, M.C., Poulikakos, L.D. Bueno, M. 2020. Microstructure analysis and mechanical performance of crumb rubber modified asphalt concrete using the dry process. Construct. Build. Mater. 259 https://doi.org/10.1016/j.conbuildmat.2020.119662.

Roque, A.J., Martins, I.M., Freire, A.C., Neves, J.M., Antunes, M.L., 2016. Assessment of environmental hazardous of construction and demolition recycled materials ( C \& DRM ) from laboratory and field leaching tests application in road pavement layers. Procedia Eng. 143 (Ictg), 204-211. https://doi.org/10.1016/ j.proeng.2016.06.026.

Saberian, M., Li, J., 2019. Long-term permanent deformation behaviour of recycled concrete aggregate with addition of crumb rubber in base and sub-base applications. Soil Dynam. Earthq. Eng. 121 (December 2018), 436-441. https:// doi.org/10.1016/j.soildyn.2019.03.029.

Saberian, M., Li, J., Cameron, D., 2019. Effect of crushed glass on behavior of crushed recycled pavement materials together with crumb rubber for making a clean green base and subbase. J. Mater. Civ. Eng. 31 (7), 1-7. https://doi.org/10.1061/ (ASCE)MT.1943-5533.0002765.

Saberian, M., Li, J., Setunge, S., 2019. Evaluation of permanent deformation of a new 
pavement base and subbase containing unbound granular materials, crumb rubber and crushed glass. J. Clean. Prod. 230, 38-45. https://doi.org/10.1016/ j.jclepro.2019.05.100.

Santos, C.R., Pais, J.C., Ribeiro, J., Pereira, P., 2020. Evaluating the properties of bioasphalt produced with bio-oil derived from biodiesel production. In: Proceedings of the 9th International Conference on Maintenance and Rehabilitation of Pavements-Mairepav9. Springer, Cham, pp. 397-407.

Sengoz, B., Topal, A., 2005. Use of asphalt roofing shingle waste in HMA. Construct. Build. Mater. 19 (5), 337-346. https://doi.org/10.1016/j.conbuildmat.2004.08.005.

Seo, M., Lee, S.-Y., Lee, C., Cho, S.-S., 2019. Recycling of cement kiln dust as a raw material for cement. Environments 6 (10), 113. https://doi.org/10.3390/ environments6100113.

Setyawan, A., Djumari, Legowo, S.J., Widiharjo, B., Zai, A.K.S., Pradana, A.A.W., et al., 2016. Design and characterization of renewable bioasphalt containing damar resin, fly ash, wasted cooking oil and latex, 197012057 IOP Conf. Ser. Mater. Sci. Eng. 36 (1), 10-12. https://doi.org/10.1088/1757-899X.

Shatnawi, S., 2010. Comparisons of rubberized asphalt binders. In: Asphalt-Rubber and Terminal Blend-Rubber Pavements Association.

Shi, X., Mukhopadhyay, A., Zollinger, D., Grasley, Z., 2019. Economic input-output life cycle assessment of concrete pavement containing recycled concrete aggregate. J. Clean. Prod. 225, 414-425. https://doi.org/10.1016/ j.jclepro.2019.03.288.

Silva, L.F.O., Oliveira, M.L.S., 2014. Nanominerals and ultrafine particles from Brazilian coal fires. In: Coal and Peat Fires: A Global Perspective, 3, pp. 38-55. https://doi.org/10.1016/B978-0-444-59509-6.00002-8.

Situmorang, Y.A., Zhao, Z., Yoshida, A., Abudula, A., Guan, G., 2020. Small-scale biomass gasification systems for power generation ( $<200 \mathrm{~kW}$ class): a review. Renew. Sustain. Energy Rev. 117, 109486.

Sojobi, A.O., Nwobodo, S.E., Aladegboye, O.J., 2016. Recycling of polyethylene terephthalate (PET) plastic bottle wastes in bituminous asphaltic concrete. Congent Eng. 3 (1), 1-28. https://doi.org/10.1080/23311916.2015.1133480.

Somé, S.C., Pavoine, A., Chailleux, E., 2016. Evaluation of the potential use of waste sunflower and rapeseed oils-modified natural bitumen as binders for asphalt pavement design. Int. J. Pave. Res. Technol. 9 (5), 368-375. https://doi.org/ 10.1016/j.ijprt.2016.09.001.

Stehlik, D., Dasek, O., Hyzl, P., Coufalik, P., Krcmova, I., Varaus, M., 2015. Pavement construction using road waste building material - from a model to reality. Road Mater. Pavement Des. 16 (May 2015), 314-329. https://doi.org/10.1080/ 14680629.2015.1029680.

Stek, E., Delong, D., McDonnell, T., Rodriguez, J., 2011. Life cycle assessment using ATHENA $®$ impact estimator for buildings: a case study. Structures Congress 2011 - Proceedings of the 2011 Structures Congress 483-494. https://doi.org/ $10.1061 / 41171(401) 42$.

Suescum-Morales, D., Romero-Esquinas, Á., Fernández-Ledesma, E., Fernández, J.M., Jiménez, J.R., 2019. Feasible use of colliery spoils as subbase layer for low-traffic roads. June 2017 Construct. Build. Mater. 229, 116910. https://doi.org/10.1016/ j.conbuildmat.2019.116910.

Sugiyanto, G., 2017. Characterization of asphalt concrete produced from scrapped tire rubber. Eng. J. 21 (4), 193-206. https://doi.org/10.4186/ej.2017.21.4.193.

Sun, X., Wu, S., Yang, J., Yang, R., 2020. Mechanical properties and crack resistance of crumb rubber modified cement-stabilized macadam. Construct. Build. Mater. 259 https://doi.org/10.1016/j.conbuildmat.2020.119708.

Sun, Z., Yi, J., Huang, Y., Feng, D., Guo, C., 2016a. Investigation of the potential application of biodiesel by-product as asphalt modifier. Road Mater. Pavement Des. 17 (3), 737-752. https://doi.org/10.1080/14680629.2015.1096819.

Tahami, S.A., Mirhosseini, A.F., Dessouky, S., Mork, H., Kavussi, A., 2019. The use of high content of fine crumb rubber in asphalt mixes using dry process. Construct. Build. Mater. 222, 643-653. https://doi.org/10.1016/ j.conbuildmat.2019.06.180.

Tait, M.W., Cheung, W.M., 2016. A comparative cradle-to-gate life cycle assessment of three concrete mix designs. Int. J. Life Cycle Assess. 21 (6), 847-860. https:// doi.org/10.1007/s11367-016-1045-5.

Tayh, S., Muniandy, R., Hassim, S., Mohd Jakarni, F., Aburkaba, E., 2014. An overview of utilization of bio-oil in hot mix asphalt. WALIA Journal 30 (S3), 131-141.

Thompson, R.C., Moore, C.J., Saal, F.S.V., Swan, S.H., 2009. July 27). Plastics, the environment and human health: current consensus and future trends. Phil. Trans. Biol. Sci. 364, 2153-2166. https://doi.org/10.1098/rstb.2009.0053.

Turk, J., Mauko Pranjić, A., Mladenovič, A., Cotič, Z., Jurjavčič, P., 2016. Environmental comparison of two alternative road pavement rehabilitation techniques: cold-in-place-recycling versus traditional reconstruction. J. Clean. Prod. 121, 45-55. https://doi.org/10.1016/j.jclepro.2016.02.040.

Toraldo, E., Saponaro, S., Careghini, A., Mariani, E., 2013. Use of stabilized bottom ash bound layers of road pavement. Journal of Environmental Mnagement 121, $117-123$.

U.S. Department of Transportation, 2002. Life-cycle cost analysis primer life-cycle cost analysis primer. In: Management.

UN Environment, 2018. \#BeatPlasticPollution this world environment day. Retrieved December 3, 2019, from World Environment Day website: https:// www.unenvironment.org/interactive/beat-plastic-pollution/.

UNEP, 2018. Single-use plastic: a roadmap for sustainability. In: United Nation Environment Programme. Retrieved from. https://www.unenvironment.org/ resources/report/single-use-plastics-roadmap-sustainability.
US Environmental Protection Agency (EPA), 2017. Advancing Sustainable Materials Management: 2017 Fact Sheet. https://doi.org/10.1017/CB09781107415324.004.

US Environmental Protection Agency (EPA), 2019. Glass: material-specific data US EPA. Retrieved December 4, 2019, from Facts and Figures about Materials, Waste and Recycling website: https://www.epa.gov/facts-and-figures-aboutmaterials-waste-and-recycling/glass-material-specific-data.

Venturini, L., Baccellieri, L., Giustozzi, F., 2017. Asphalt binder rejuvenation for recycling road materials. In: World Conference on Pavement and Asset Management, WCPAM 2017, pp. 443-451. Milan, Italy.

Vignesh, H., Ramesh Babu, N., Manivasagan, V., Saganya, S., Eajas Basha, M., 2013. Emerging trends in greener pavements. Int. J. Eng. Res. Technol. 2 (1), 1-4. https://doi.org/10.1177/2393957514555052.

Vijayakumar, A., Naveen Kumar, S., Tejareddy, P.A., 2019. Utilization of waste materials for the strengthening of pavement subgrade-a research. Int. J. Innovative Technol. Explor. Eng. 8 (9 Special Issue 2), 209-212. https://doi.org/10.35940/ ijitee.I1041.0789S219.

Visintine, B., 2011. An Investigation of Various Percentages of Reclaimed Asphalt Pavement on the Performance of Asphalt Pavements. North Carolina State University.

Wang, D., Tawk, M., Indraratna, B., Heitor, A., Rujikiatkamjorn, C., 2019. A mixture of coal wash and fly ash as a pavement substructure material. Transportation Geotechnics 21, 100265. https://doi.org/10.1016/j.trgeo.2019.100265.

Washington State Department of Transport, 2015. WSDOT strategies regarding use of steel slag aggregate in pavements. In: A Report to the State Legislature in Response to 2ESHB 1299.

Weber, B., Kroll, J., 2019. Global Recycling, 24. The Magazine for Business Opportunities \& International Markets.

Wen, Y., Wang, Y., Zhao, K., Chong, D., Huang, W., Hao, G., Mo, S., 2018. The engineering, economic, and environmental performance of terminal blend rubberized asphalt binders with wax-based warm mix additives. J. Clean. Prod. 184, 985-1001. https://doi.org/10.1016/j.jclepro.2018.03.011.

Wilde, W.J., Waalkes, S., Harrison, R., River, R., 1999. Life Cycle Cost Analysis of Portland Cement Concrete Pavements, 7. Washington D.C.

Wong, S.L., Ngadi, N., Abdullah, T.A.T., Inuwa, I.M., 2015. Current state and future prospects of plastic waste as source of fuel: a review. Renew. Sustain. Energy Rev. 50, 1167-1180. https://doi.org/10.1016/j.rser.2015.04.063.

Worldsteel Association, 2018. Fact sheet; steel industry co-products. Retrieved from. https://www.worldsteel.org/en/dam/jcr:1b916a6d-06fd-4e84-b35dc1d911d18df4/Fact_By-products_2018.pdf.

$\mathrm{Wu}, \mathrm{P} ., \mathrm{Xu}, \mathrm{Y} ., 2010$. Economic analysis in repairing road using the recycled aggregate concrete with fly ash. In: 2010 International Conference on E-Product EService and E-Entertainment, ICEEE2010. https://doi.org/10.1109/ ICEEE.2010.5660610.

Xiao, F., Yao, S., Wang, J., Li, X., Amirkhanian, S., 2018, August 20. A literature review on cold recycling technology of asphalt pavement. Construct. Build. Mater. 180, 579-604. https://doi.org/10.1016/j.conbuildmat.2018.06.006.

Yang, X., You, Z., Dai, Q., Mills-Beale, J., 2014. Mechanical performance of asphalt mixtures modified by bio-oils derived from waste wood resources. Construct. Build. Mater. 51, 424-431.

Yang, R., Kang, S., Ozer, H., Al-Qadi, I.L., 2015. Environmental and economic analyses of recycled asphalt concrete mixtures based on material production and potential performance. Resour. Conserv. Recycl. 104, 141-151. https://doi.org/ 10.1016/j.resconrec.2015.08.014.

Yang, X., Mills-Beale, J., You, Z., 2017. Chemical characterization and oxidative aging of bio-asphalt and its compatibility with petroleum asphalt. J. Clean. Prod. 142, 1837-1847. https://doi.org/10.1016/j.jclepro.2016.11.100.

Ye, M., Yan, P., Sun, S., Han, D., Xiao, X., Zheng, L., et al., 2017. Bioleaching combined brine leaching of heavy metals from lead-zinc mine tailings: transformations during the leaching process. Chemosphere 168, 1115-1125. https://doi.org/ 10.1016/j.chemosphere.2016.10.095.

Yi, H., Xu, G., Cheng, H., Wang, J., Wan, Y., Chen, H., 2012. An overview of utilization of steel slag. Procedia Environmental Sciences 16, 791-801. https://doi.org/ 10.1016/j.proenv.2012.10.108.

Ziari, H., Divandari, H., Hajiloo, M., Amini, A., 2019. Investigating the effect of amorphous carbon powder on the moisture sensitivity, fatigue performance and rutting resistance of rubberized asphalt concrete mixtures. Construct. Build. Mater. 217, 62-72.

Zeng, M., Pan, H., Zhao, Y., Tian, W., 2016. Evaluation of asphalt binder containing castor oil-based bioasphalt using conventional tests. Construct. Build. Mater. 126, 537-543. https://doi.org/10.1016/j.conbuildmat.2016.09.072.

Zhang, D., Chen, M., Wu, S., Liu, J., Amirkhanian, S., 2017. Analysis of the relationships between waste cooking oil qualities and rejuvenated asphalt properties. Materials 10 (5), 508. https://doi.org/10.3390/ma10050508.

Zhang, J., Gu, F., Zhang, Y., 2019. Use of building-related construction and demolition wastes in highway embankment: laboratory and field evaluations. J. Clean. Prod. 230, 1051-1060. https://doi.org/10.1016/j.jclepro.2019.05.182.

Zhang, W., Yang, J., Fan, X., Yang, R., Yu, B., 2011. Life-cycle cost analysis of base course using cold in-place recycling: case study. Adv. Geotech. Eng. 4428-4437.

Zhu, J., Alavi, M.Z., Harvey, J., Sun, L., He, Y., 2017. Evaluating fatigue performance of fine aggregate matrix of asphalt mix containing recycled asphalt shingles.

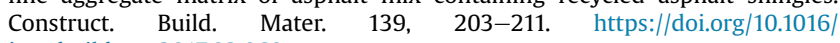
j.conbuildmat.2017.02.060. 